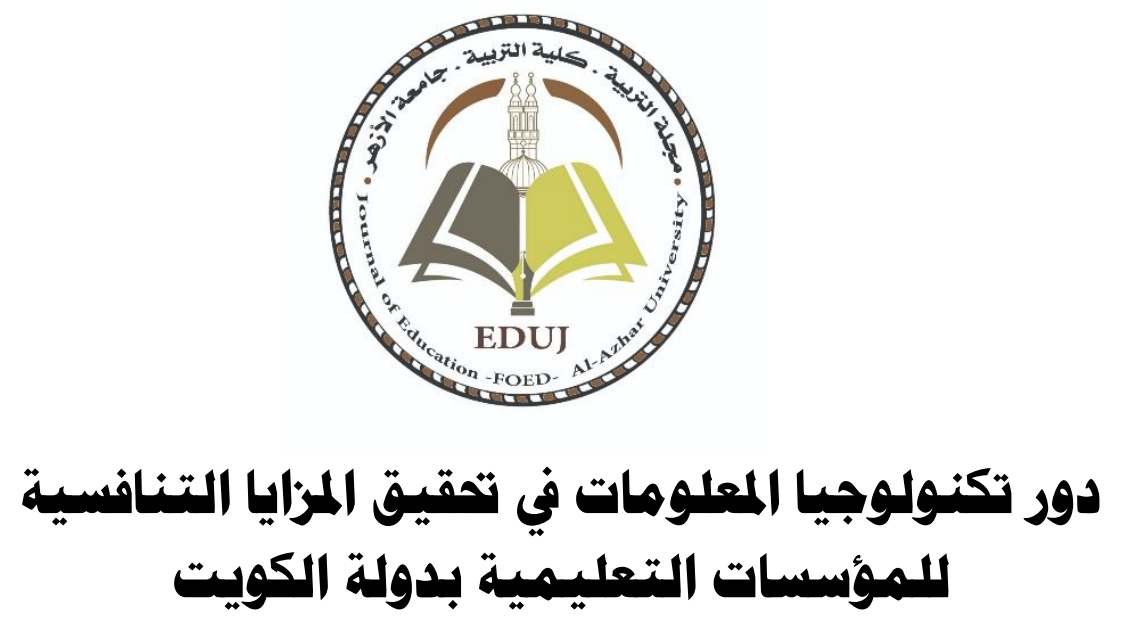

$$
\text { د/ ناصر همهد سهويري الهبمي }
$$

دكتوراه الفلسفه في التربيه، قسم الادارة التزبويه، كلية التزبيه،

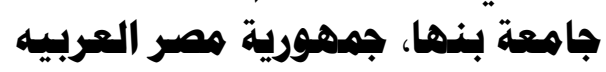


دور تكنولوجيا المعلومات في تحقيق المزايا التنافسية للمؤسسات التعليمية بدولة الكويت

\section{ناصر محممد سويري العجمي} قسم الادارة التربويه، كلية التربيه، جامعة بنها، جمهورية مصر العربيه. البريد الالكتروني: Naser_Alajmi@yahoo.com الملتخص:

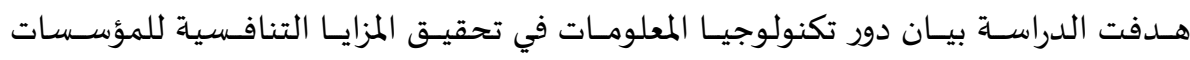

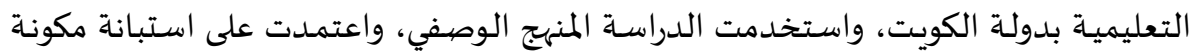

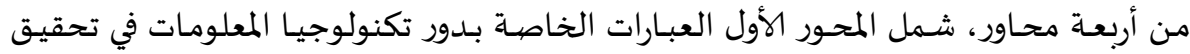

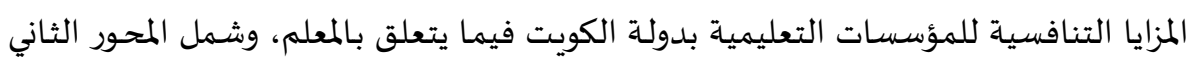

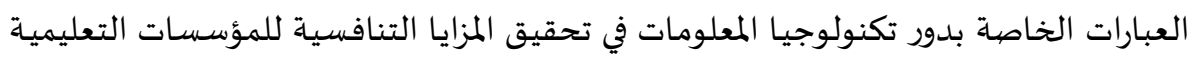

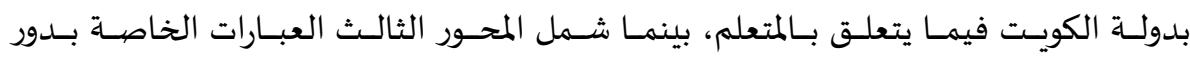

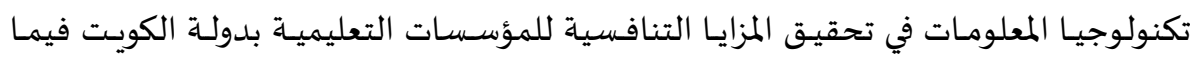

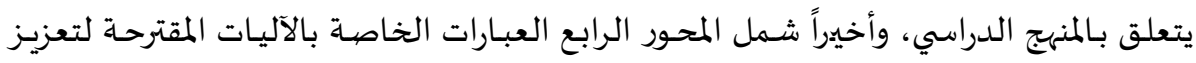

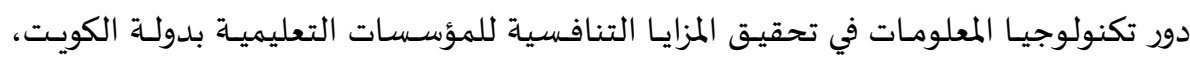

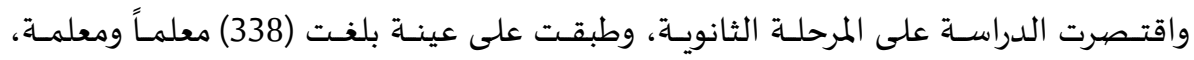

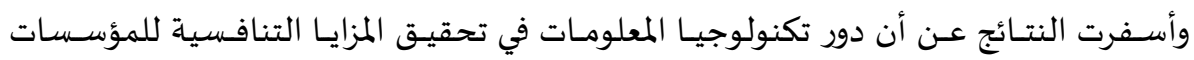

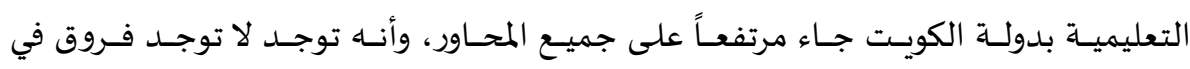

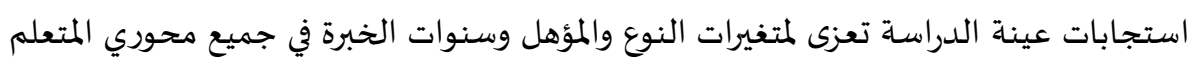
والمناهج الدراسية بينما وجدت فروق في محور المعلم. الكلمـات المفتاحيـة: تقنيـات التعلـيم، التعلـيم الإلكترونـي، المزايـا التنافسية، المؤسـسـات التعليمية. 
The Role of Information Technology in Achieving Competitive Advantages for Educational Institutions in the State of Kuwait

\author{
Nasser Mohammed Sweiri Al-Ajmi \\ Department of Educational Administration, Faculty of Education, \\ Benha University, Egypt.
}

\title{
E-mail: Naser_Alajmi@yahoo.com
}

\begin{abstract}
:
The current study aimed to demonstrate the role of information technology in achieving the competitive advantages of the educational institutions in the State of Kuwait. The study used the descriptive approach, and made use of a questionnaire consisting of four dimensions. The first dimension included items addressing the role of information technology in achieving the competitive advantages of educational institutions in the State of Kuwait with regard to the teacher. The second dimension included items related to the role of information technology in achieving the competitive advantages of the educational institutions in the State of Kuwait with regard to the learner, while the third dimension included items related to the role of information technology in achieving competitive advantages for educational institutions in the State of Kuwait with regard to the curriculum. Finally, the fourth dimension included the items related to the proposed mechanisms to enhance the role of information technology in achieving the competitive advantages of the educational institutions in the State of Kuwait. The study was delimited to the secondary stage, and it was administered to a sample consisting of (338) male and female teachers. The results of the study revealed that the role of information technology in achieving the competitive advantages of the educational institutions in the State of Kuwait was high on all dimensions, and that there were no differences in responses. The study results were not attributed to the variables of gender, qualification and years of experience in all dimensions of the learner and the curriculum, but the differences were found in the teacher dimension.
\end{abstract}

Keywords: educational technologies, e-learning, competitive advantages, educational institutions. 


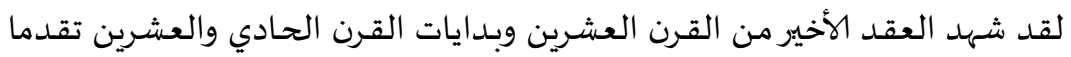

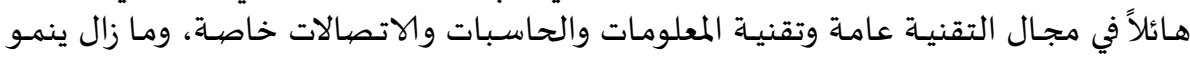

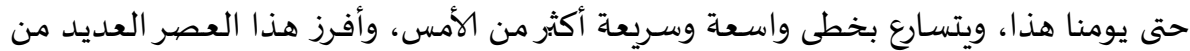

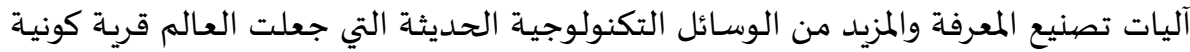

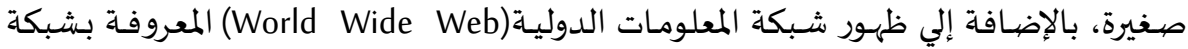
الإنترنت، وتوظيفها في كافة مناحي الحياة.

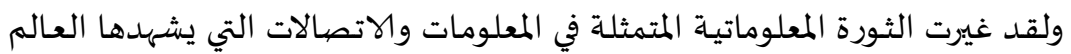

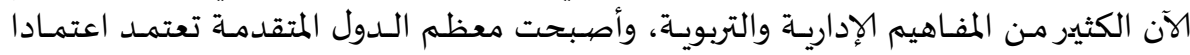

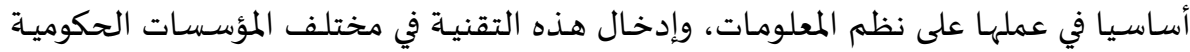

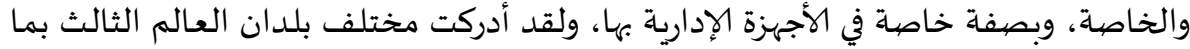

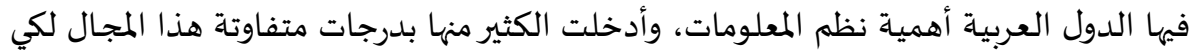
تشارك في مجال الاستفادة العلمية والاقتصادية المعلة وادخلت الماتية

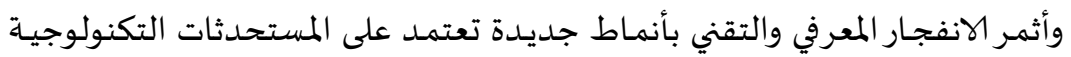

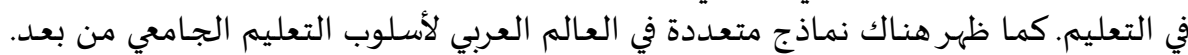

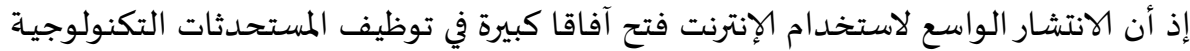

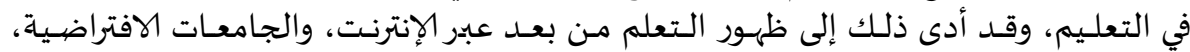

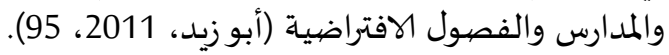

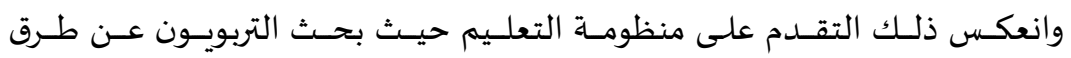

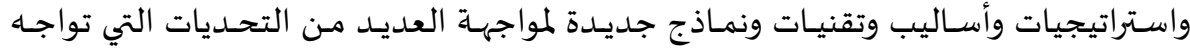

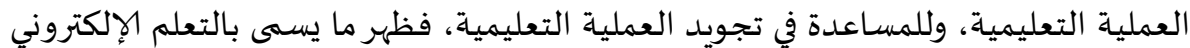

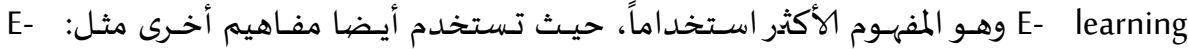

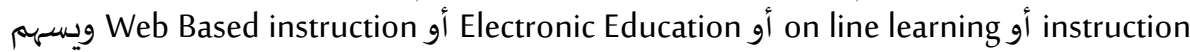

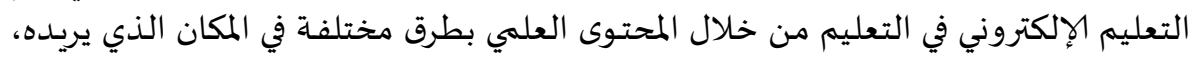

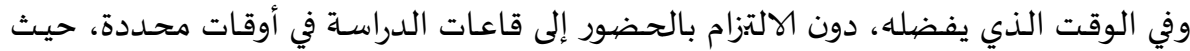

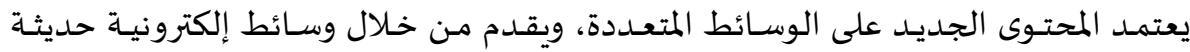
مثل الحاسوب الإنترنت، الأقمار الاصطناعية (عيسى، 2010، 10).

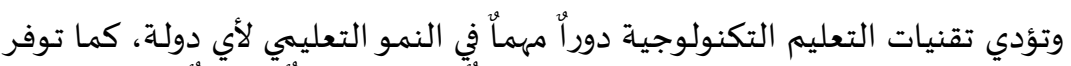

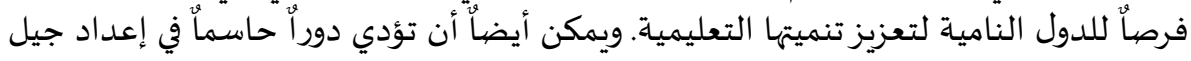

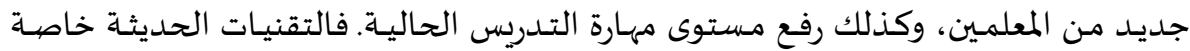

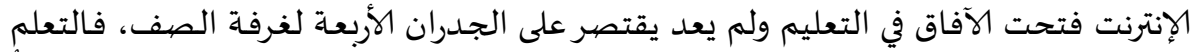

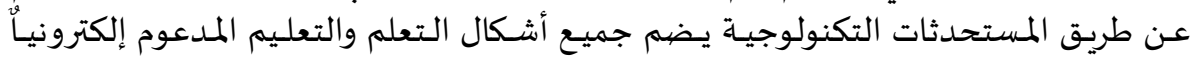

.(Behera, 2013)

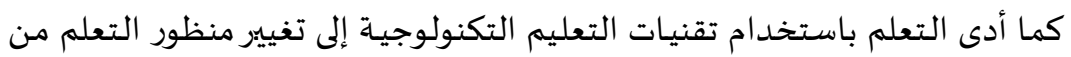

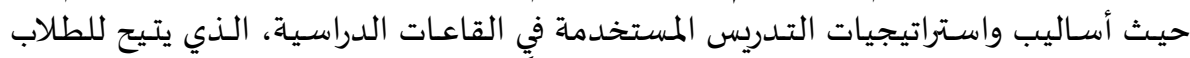

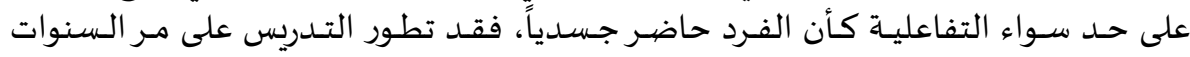




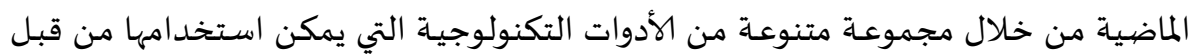

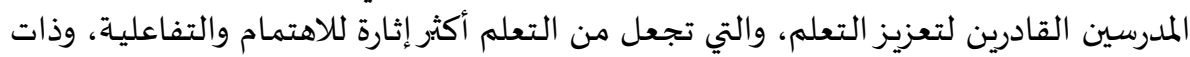

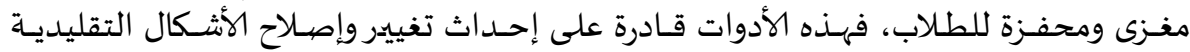

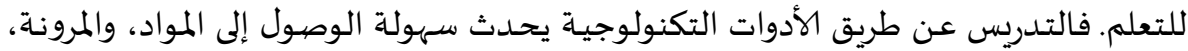
والوقت وسرعة الدراسـة، وردود الفعل الفورية التي تجعل من التعلم متعة للطلاب (

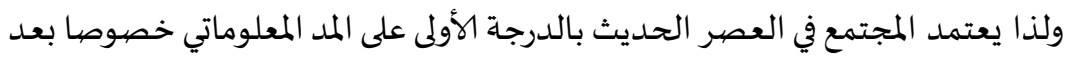

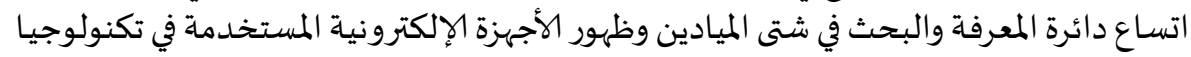

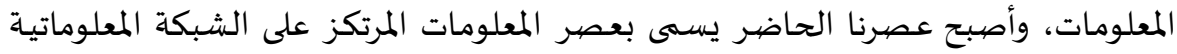

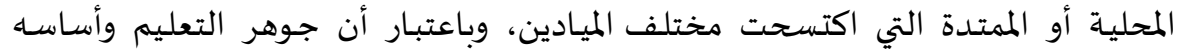

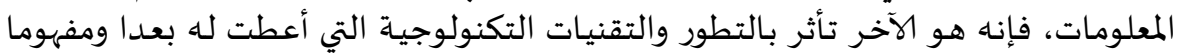

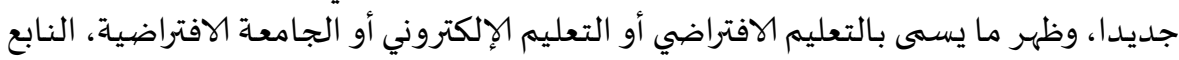

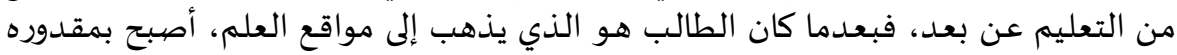

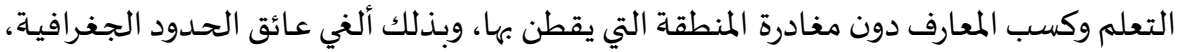

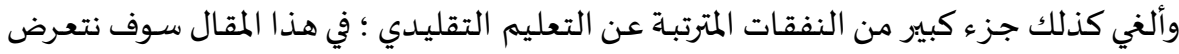

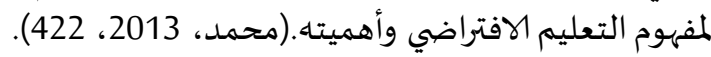

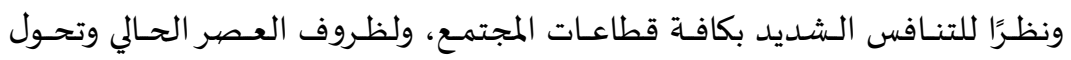

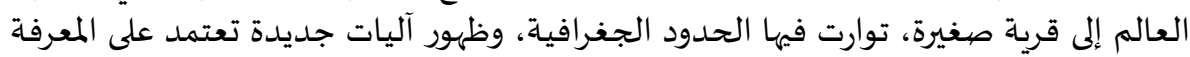

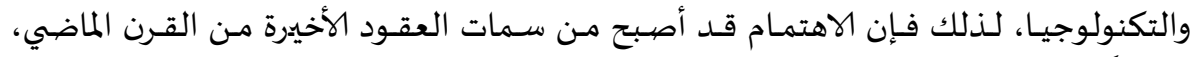

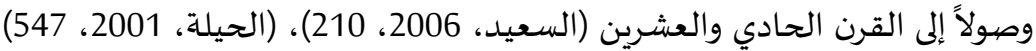

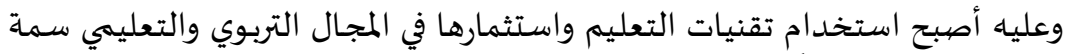

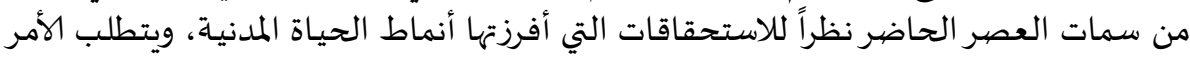

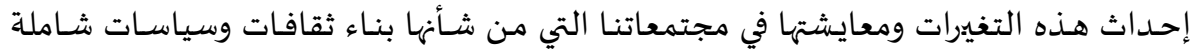

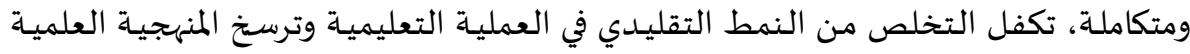

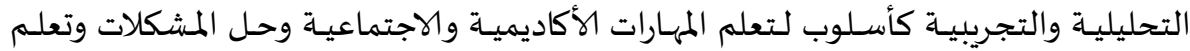

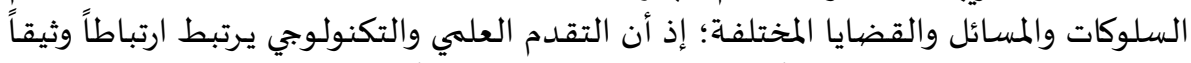

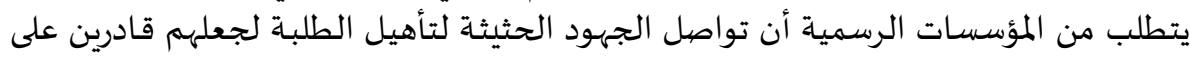

التعايش والعطاء والمنافسة (Dinder, 2008).

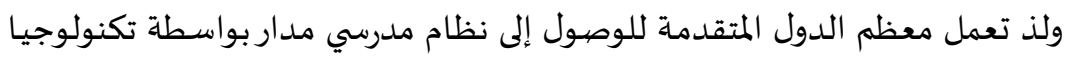

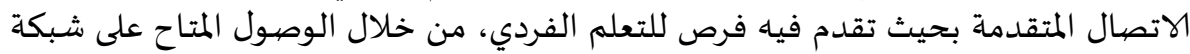

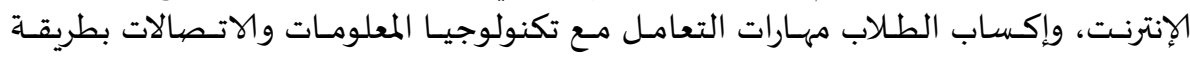

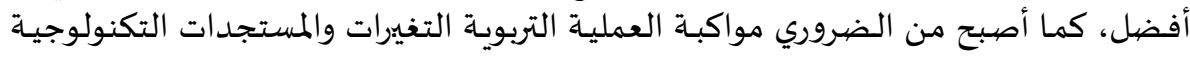

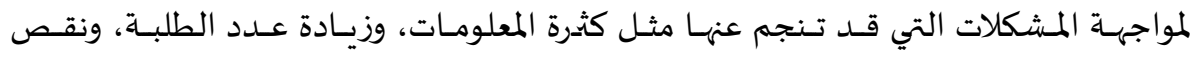
المعلمين، وبعد المسافات وتراجع نوعية التعليم (القاسم، 2013). 
ومع ذلك تختلف تلك الدول في قدرتها على الاستفادة من المعلومات كمورد أساسي

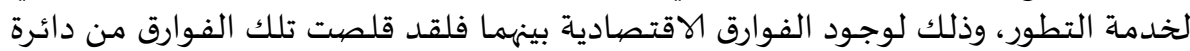

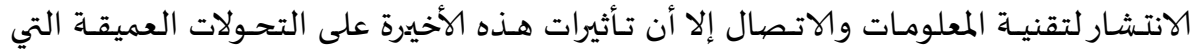

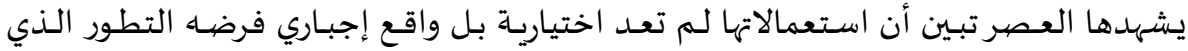

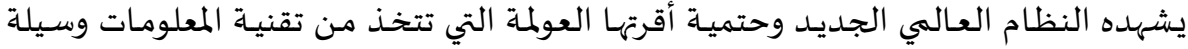

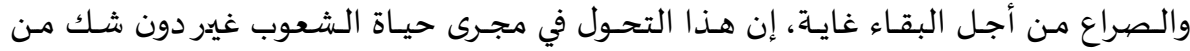

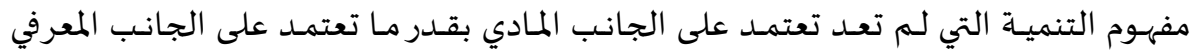
والمعلوماتي.

وتأتي منصات التعليم القائمة على التقنيات التكنولوجياة في مقدمة تقنيات التيات الجيل

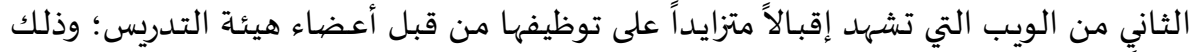

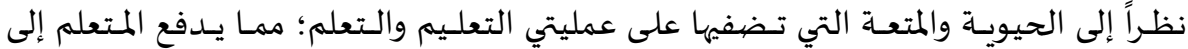

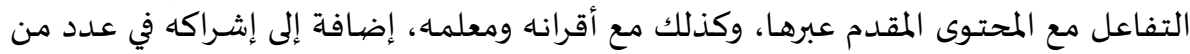

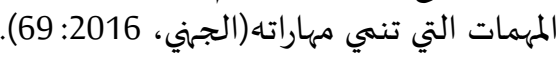

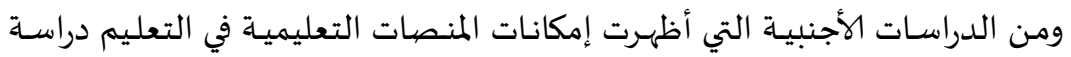

كل من سايزلوبيز (Saez Lopez, 2014)، ودراسة باتسيلا وآخرين(الماتيات (Batsila, et.al, 2014).

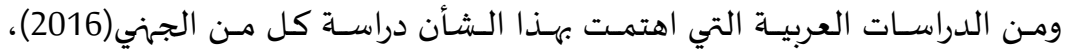

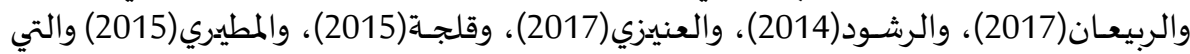
أظهرت نتائجها فعالية المنصات التعليمية الإلكترونية في العملية التعليمية.

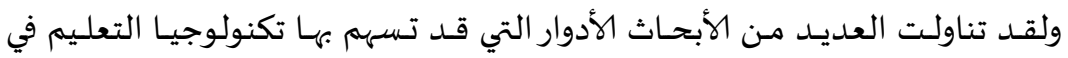

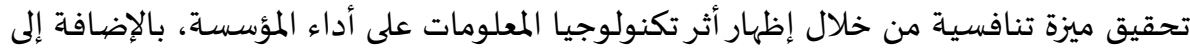

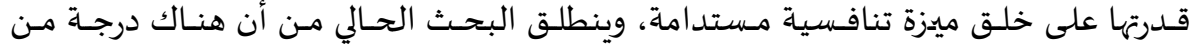

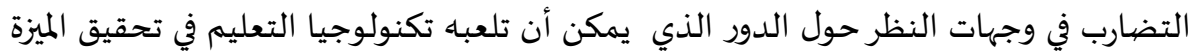

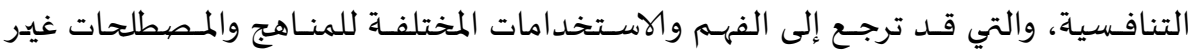

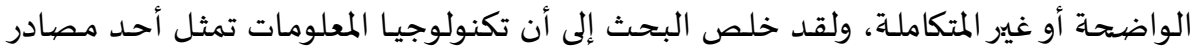

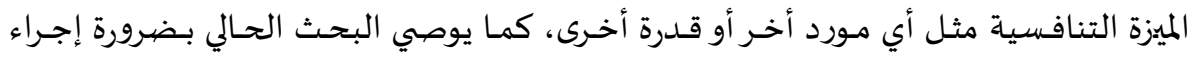

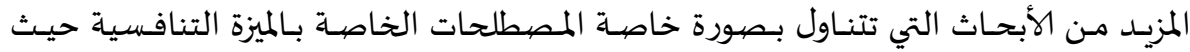

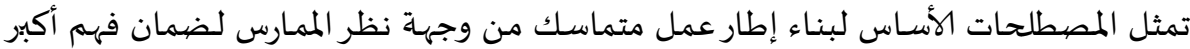

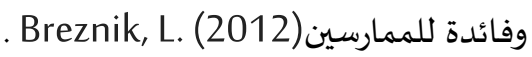

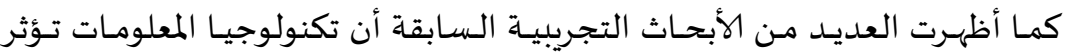

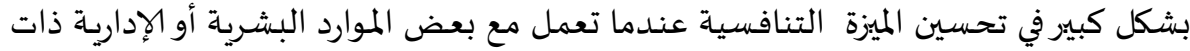

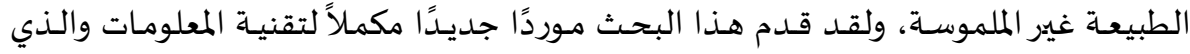

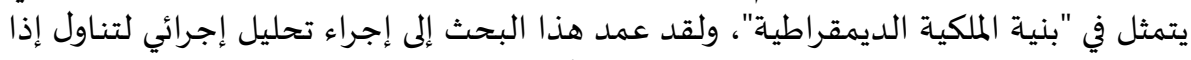

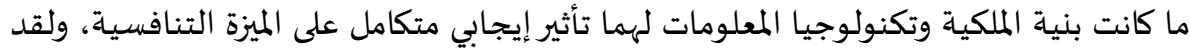

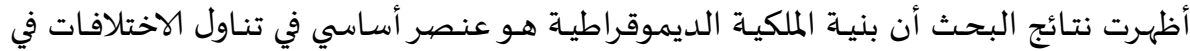

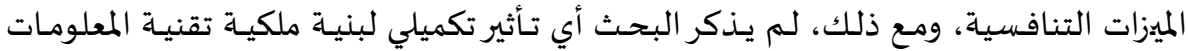

.(Bruque-Cámara, Fuentes, Hernández-Ortiz, \& Vargas-Sánchez, 2003) 


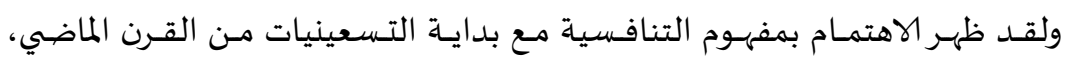

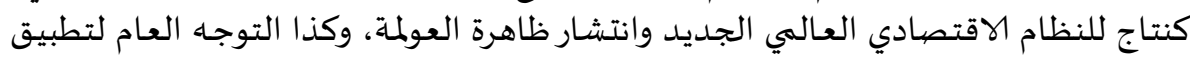

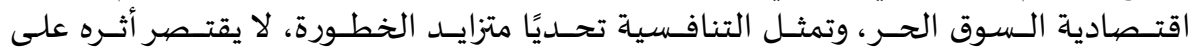

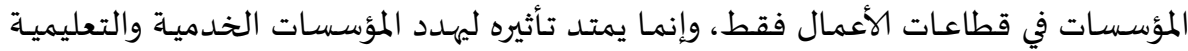

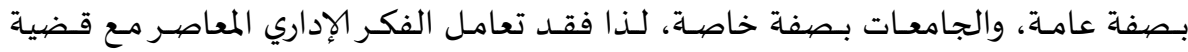

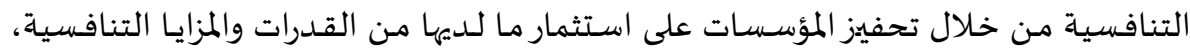

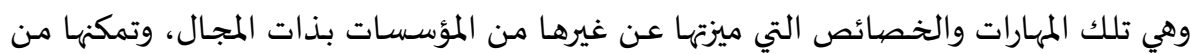

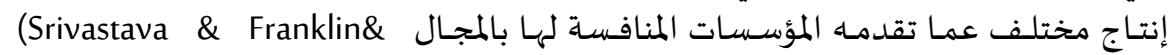
Martinette, 2013, p.48)

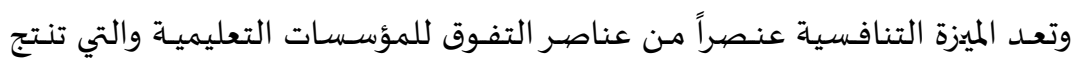

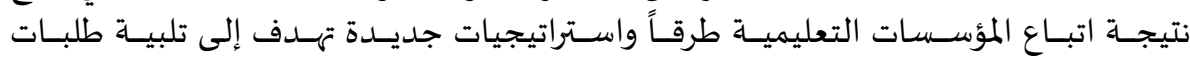

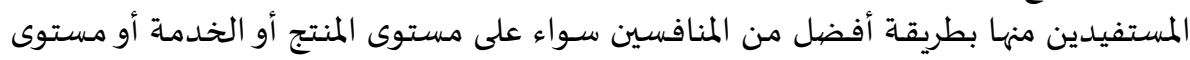

التكلفة والسعر (بلوانس، 2013، 18).

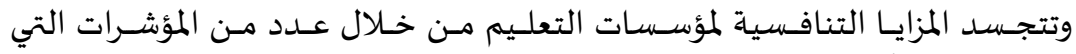

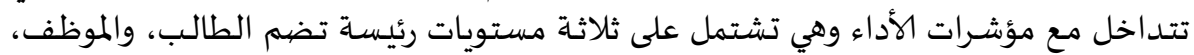

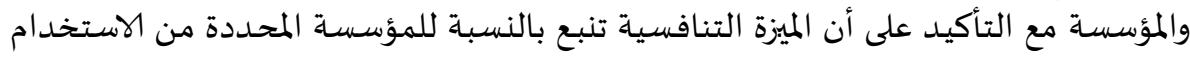

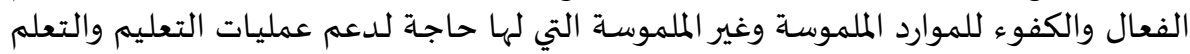

(Huang, Hsun, 2010)

وتجمع معظم الأدبيات على أن أية مؤسسة حققت ميزة تنافسية، عند ذلك الكت تتمكن

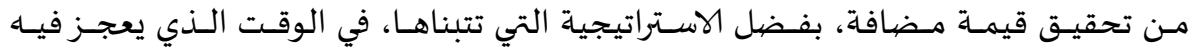

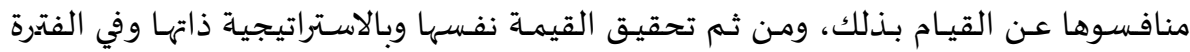

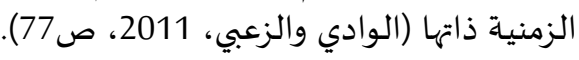

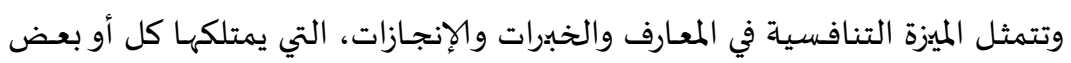

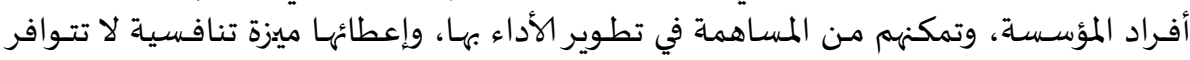

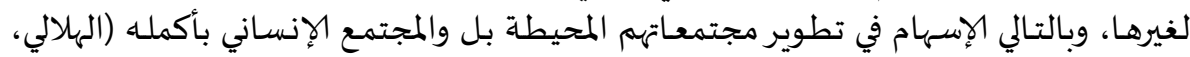

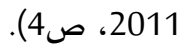

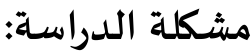

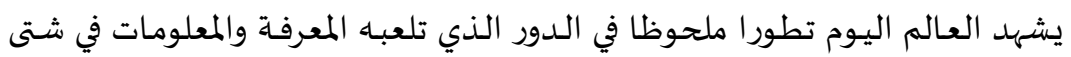

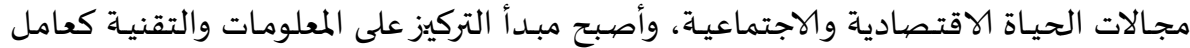

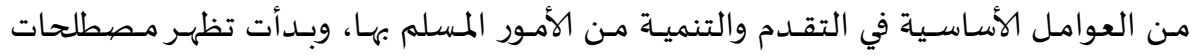

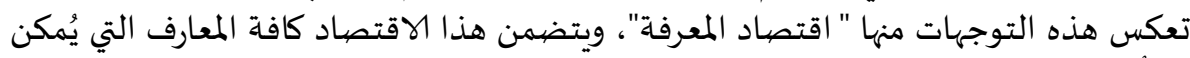

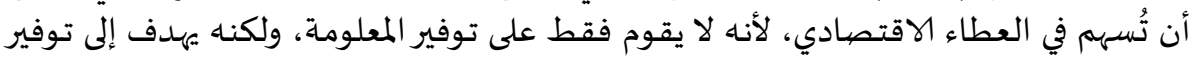

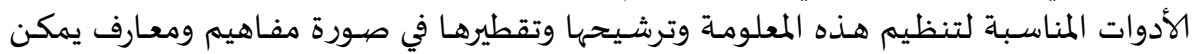
تطبيقها عمليا في حل المشكلات، ففي اقتصاد المعرفة تتقدم المعرفة المعاس على العلم. 


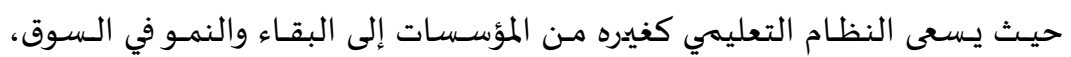

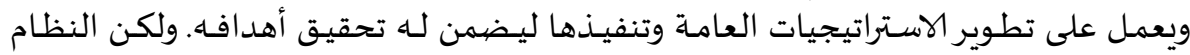

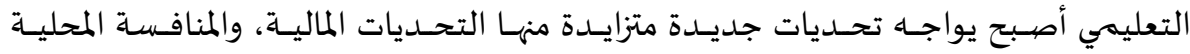

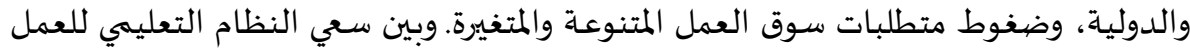

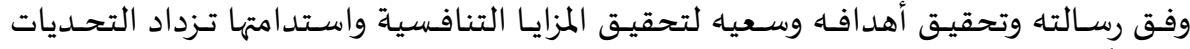

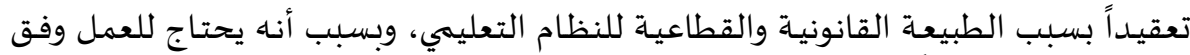

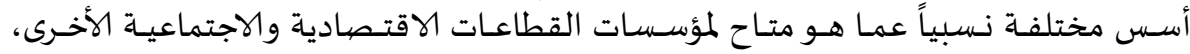

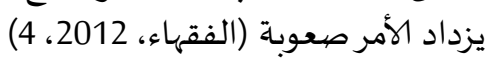

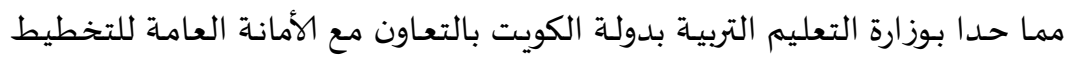
والتنميـة بإعـداد خطة إسـتراتيجية لمشاريع الإنمائيسة للسنوات (2016/2015 - 2017/2016)

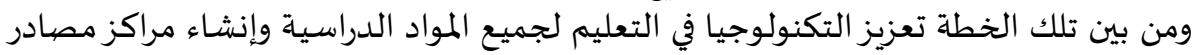

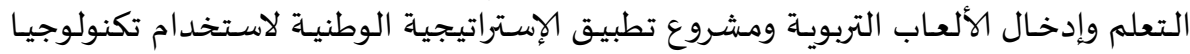

المعلومات في العملية التعليمية وتطوير مشروعات التحرية الحكومة الالكترونية في الأعمال الإدارية.

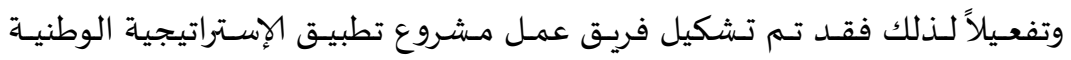

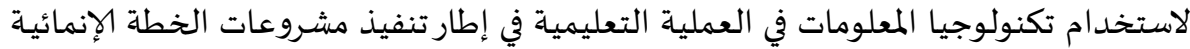
2016/2015

وقد أشارت بعض الدراسـات إلى أن التعليم في معظم الدول العبية يعاني من أوجها

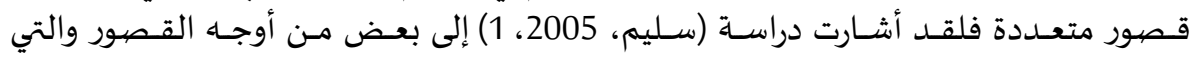

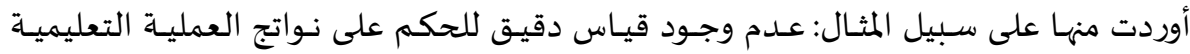

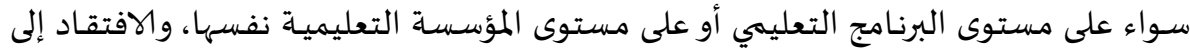

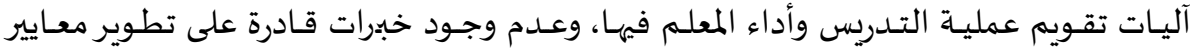

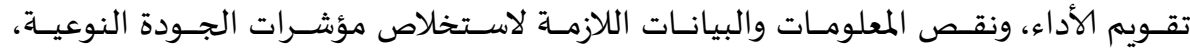

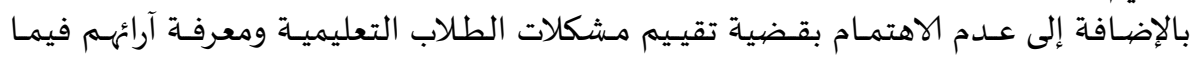

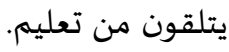

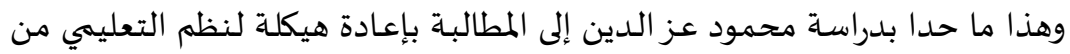

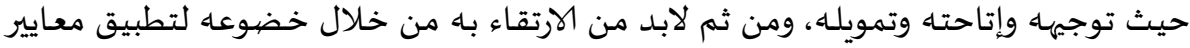

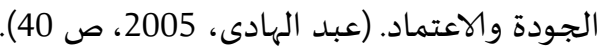

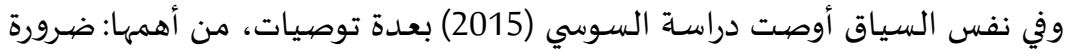

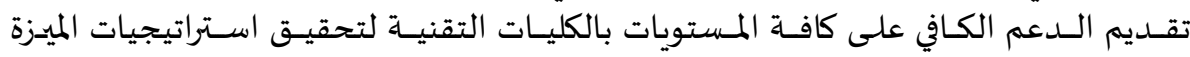

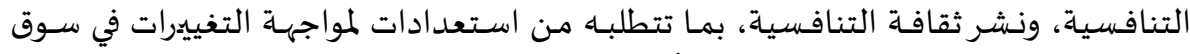

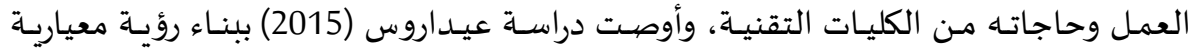

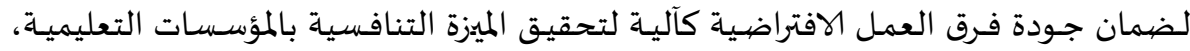

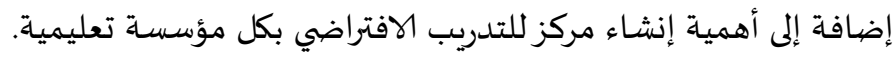




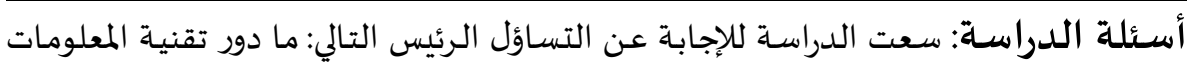

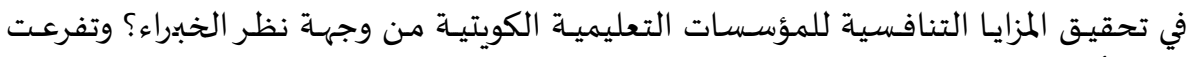

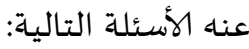

1. ما دور تقنية المعلومات في تحقيق المزايا التنافسية للمؤسسـات التعليمية الكويتية فيما

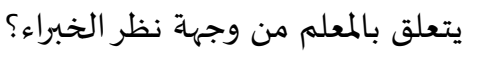

2. ما دور تقنية المعلومات في تحقيق المزايا التنافسية للمؤسسات التعليمية الكويتية فيما

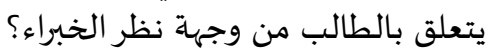

3. ما دور تقنية المعلومات في تحقيق المزايا التنافسية للمؤسسات التعليمية الكويتية فيما

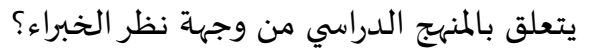

4. ما السبل المقترحة لتعزيز ما دور تقنية المعلومات في تحقيق المزايا التنافسية للمؤسسات التعليمية الكويتية من وجهة نظر المترجة الخبراء؟

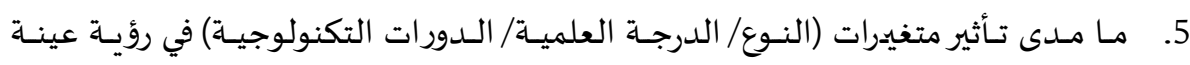

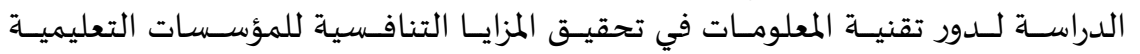

أهـداف الدراسـة: هـدفت الدراسـة الكشف عملـا يلي: دور تقنيـة المعلومات في تحقيق المزايـا

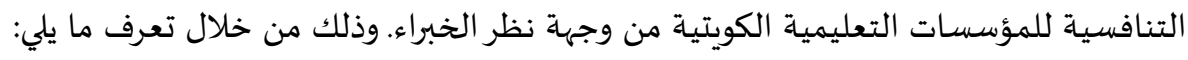

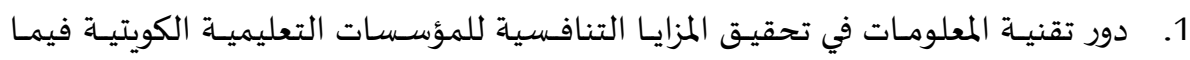

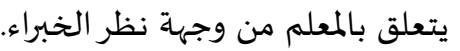

2. دور تقنيـة المعلومـات في تحقيق المزايـا التنافسية للمؤسـسـات التعليميـة الكويتيـة فيمـا يتعلق بالطالب من وجهة نظر الخبوراء.

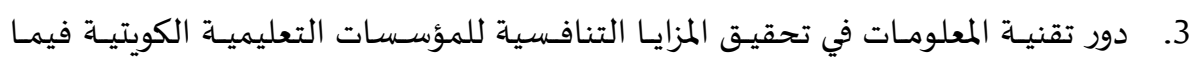
يتعلق بالمنهج الدراسي من وجهة نظمية نظر الخبراء.

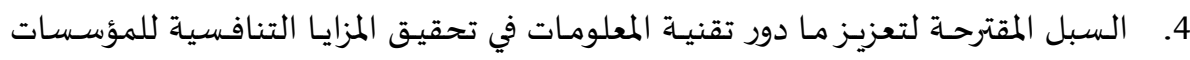
التعليمية الكويتية من وجهاة نظر الخبراء.

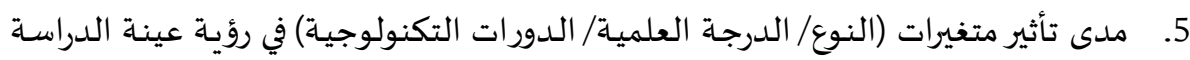
لدور تقنية المعلومات في تحقيق المزايا التنافسية للمؤسسات المسات التعليمية الكويتية.

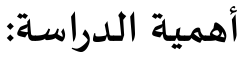

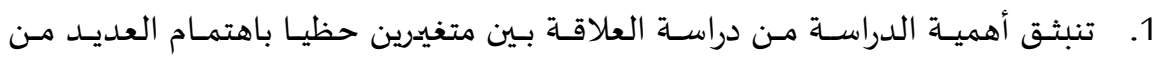

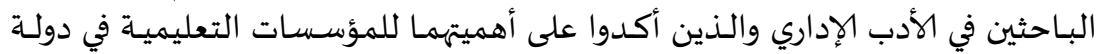

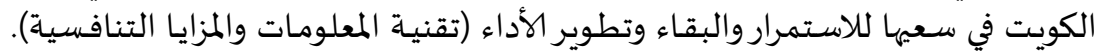

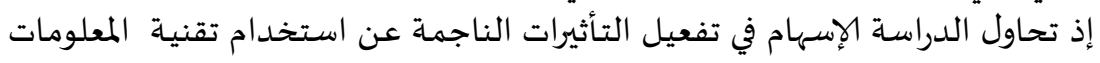




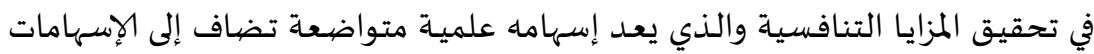

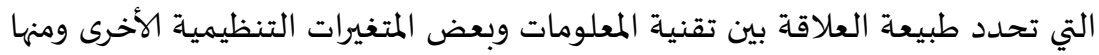
المزايا التنافسية في العملية التعليمية.

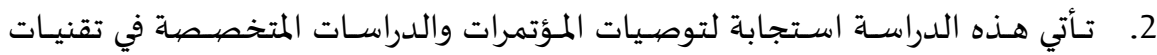

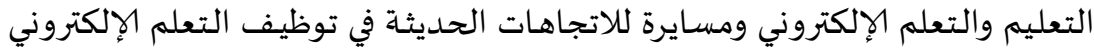

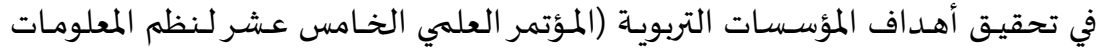

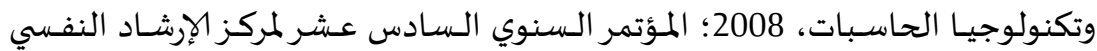

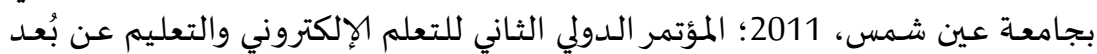

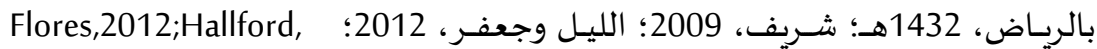
.2011; Dietrich,2011.

3. أهميـة تقنيـات التعليم التكنولوجيـة والأثار الإيجابيـة المترتبـة على توظيفها في العمليـة التعليمية. مصطلحات الدراسـة: (1)

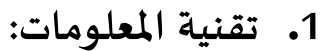

يتكون لفظ التقنية (التكنولوجيا) Technology من مقطعين، الأول Techno ويعني:

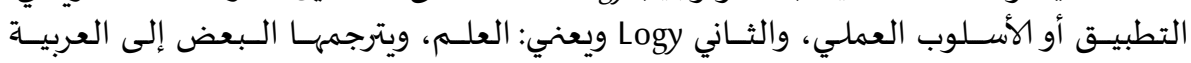

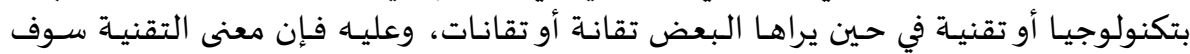

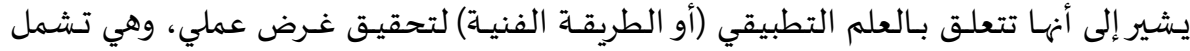

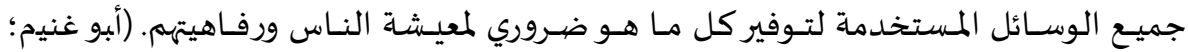
. (89؛2007

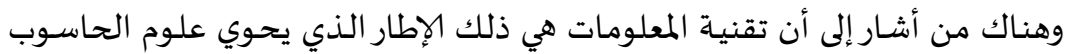

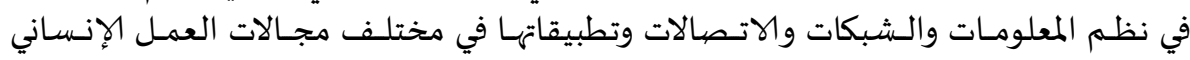
للمنظمة. (O'Brien, 2004,: 433)

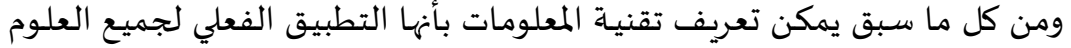

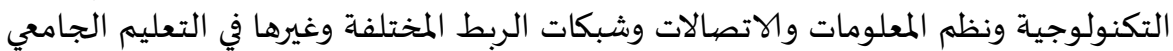

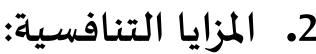

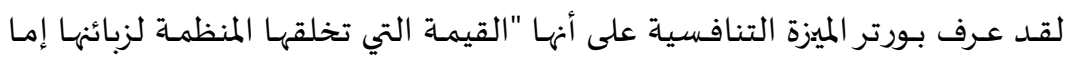

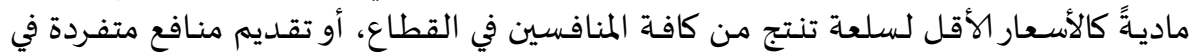

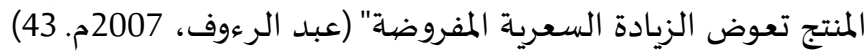

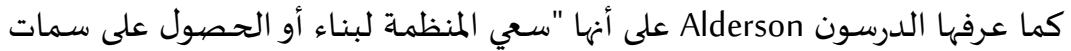

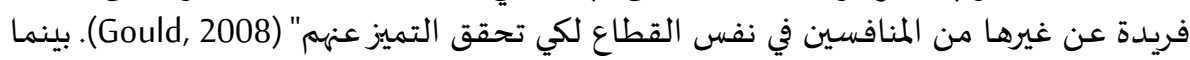

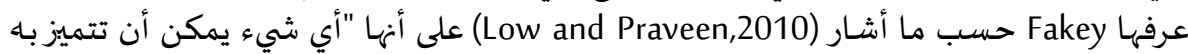

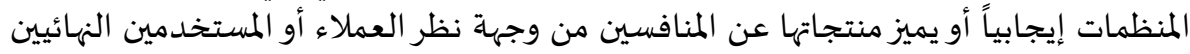

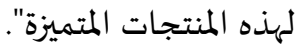




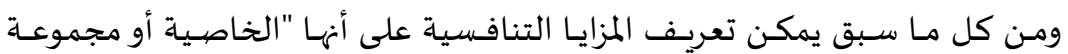

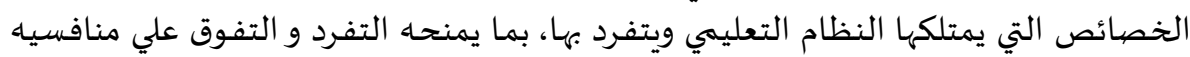

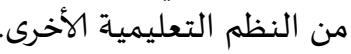

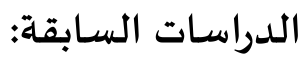

1. دراسة (سـالم الكندي، 2011): هدفت الدراسـة التعرف إلى واقع توظيف المستحدثدات

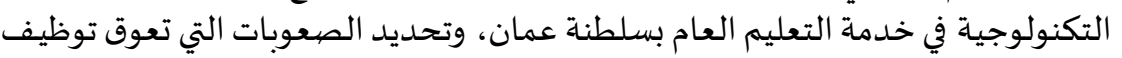

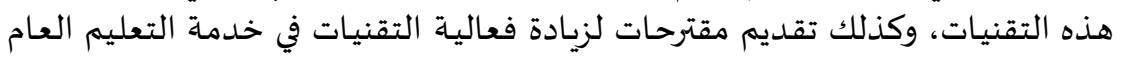

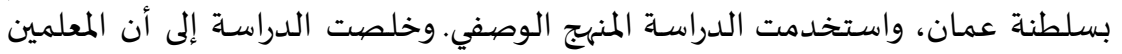

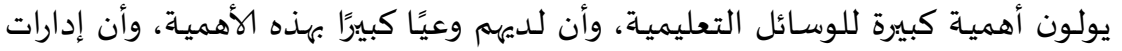

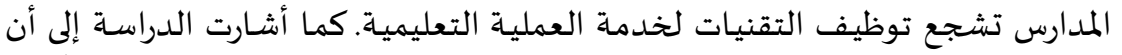

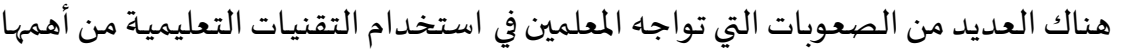

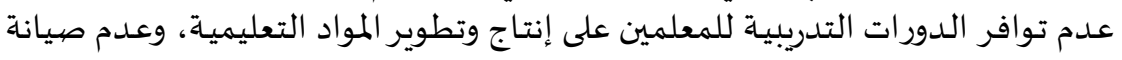

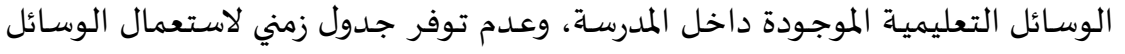

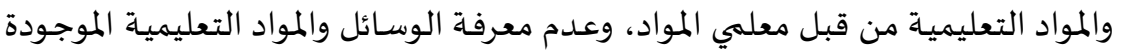

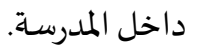

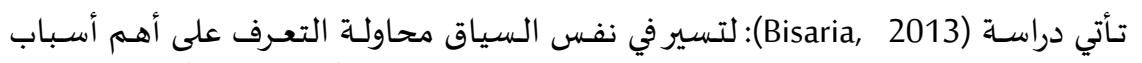

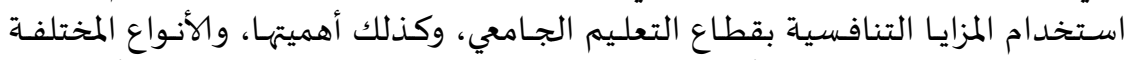

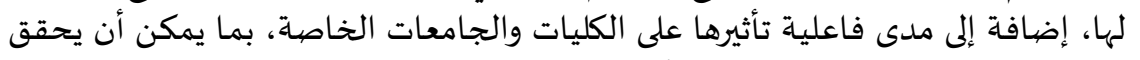

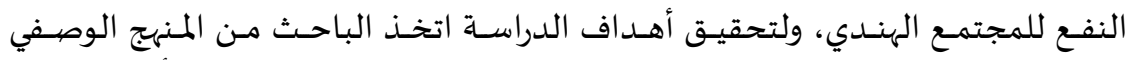

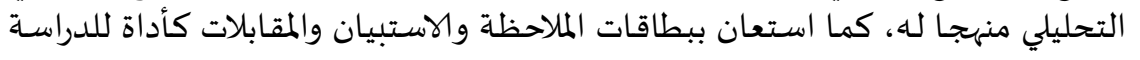

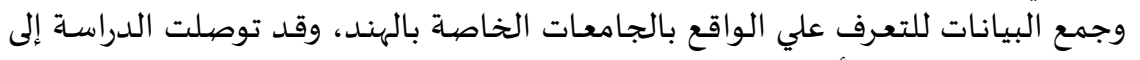

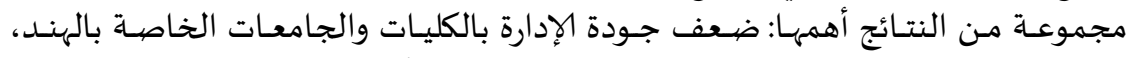

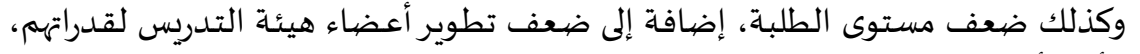

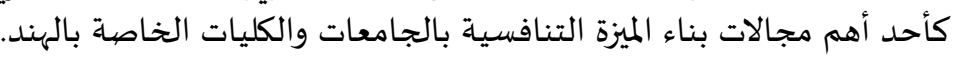

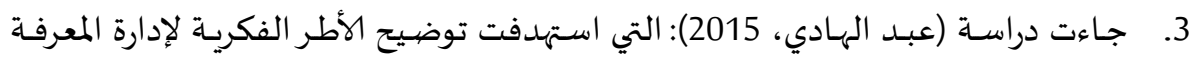

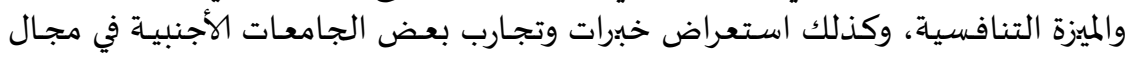

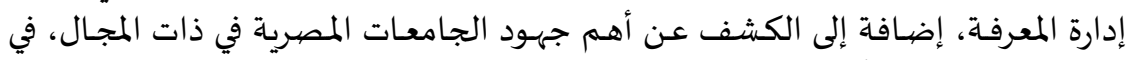

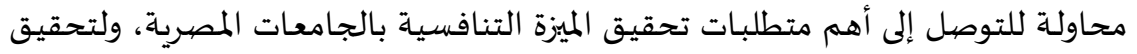

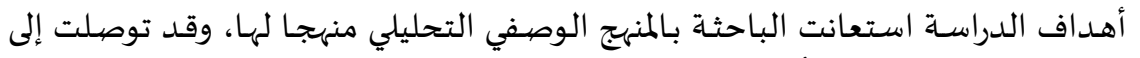

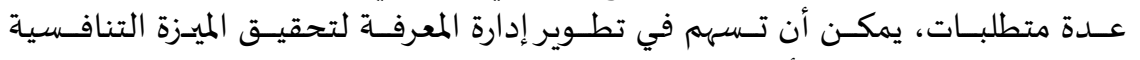

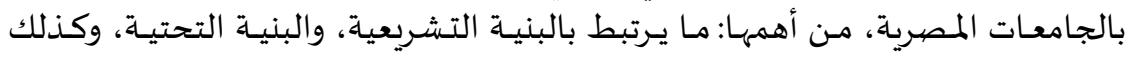

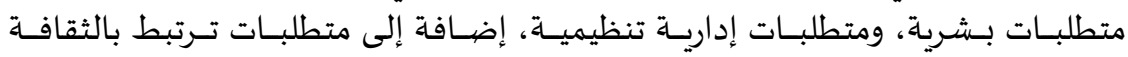
المجتمعية. 


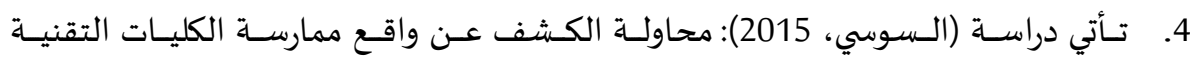

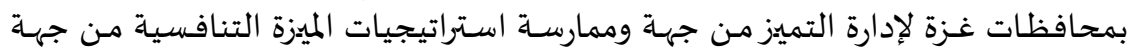

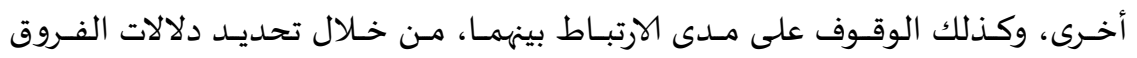

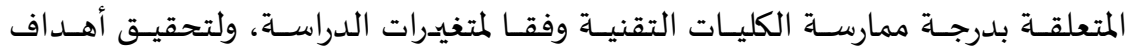

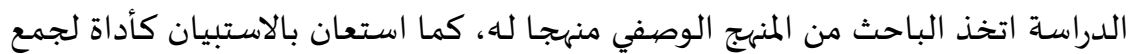

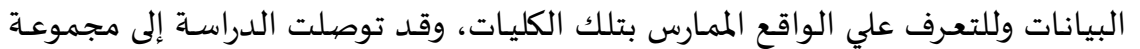

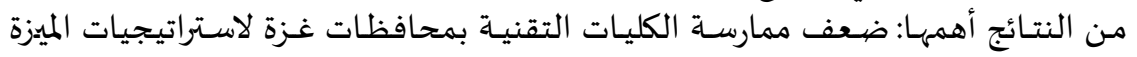
التنافسية من وجهة نظر العاملين والهيئات التدريسية بها.

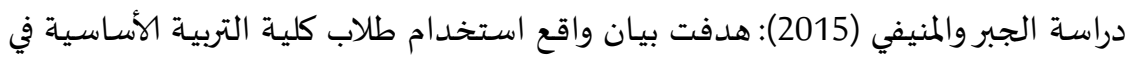

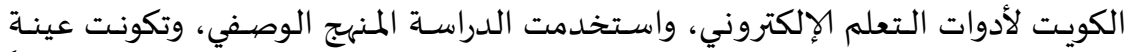

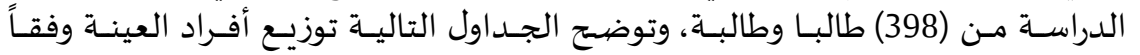

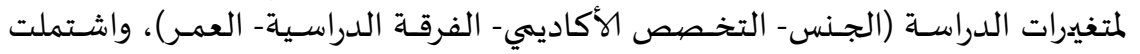

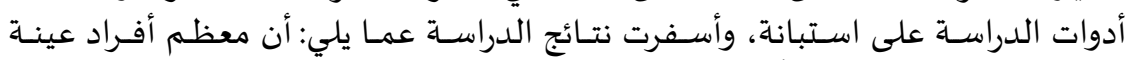

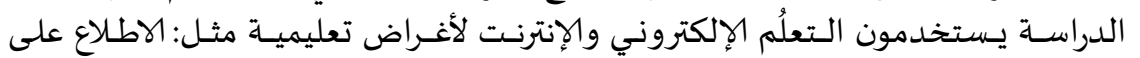

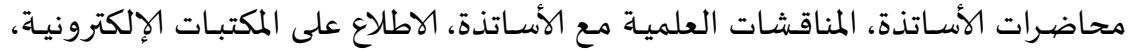

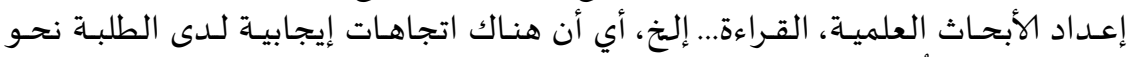

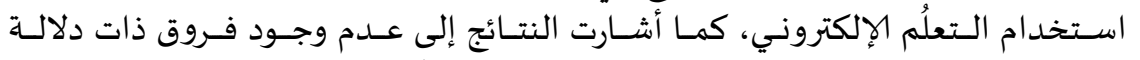

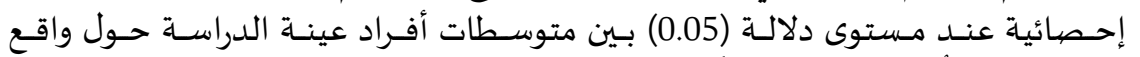

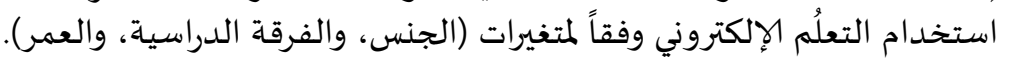

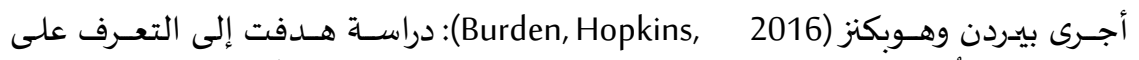

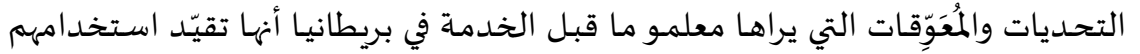

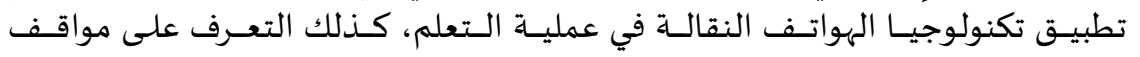

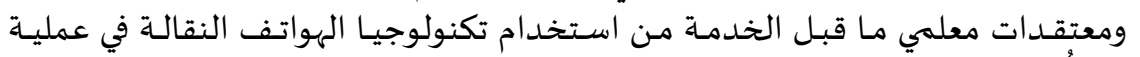

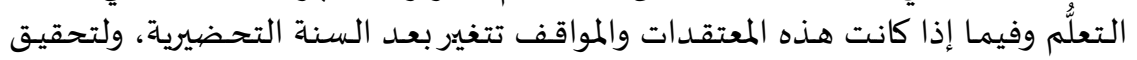

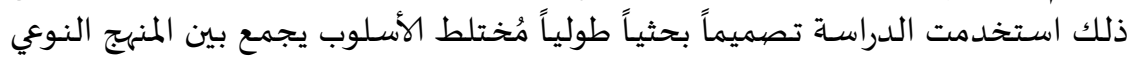

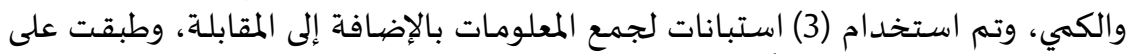

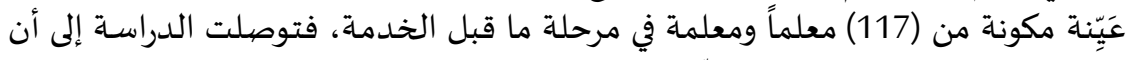

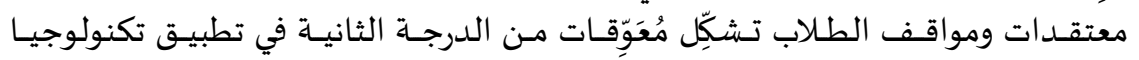

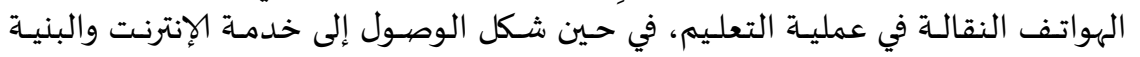

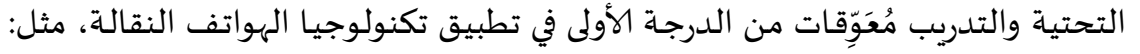
الأيباد (ipad) في التعليم.

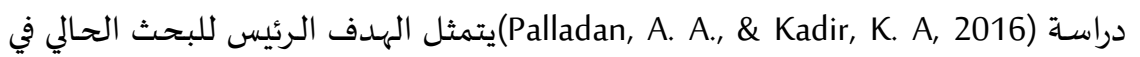

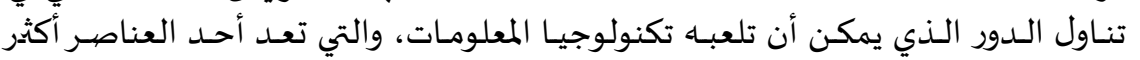

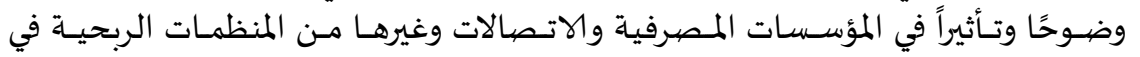

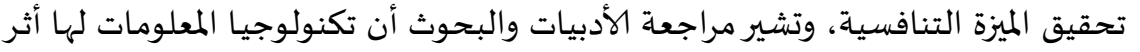

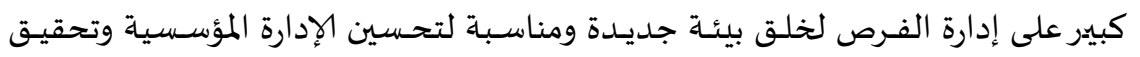

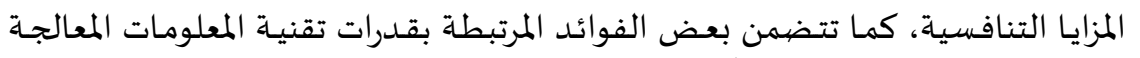

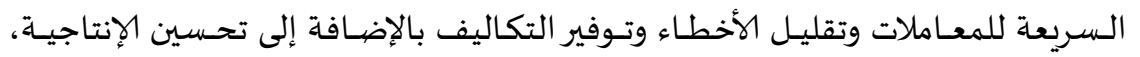




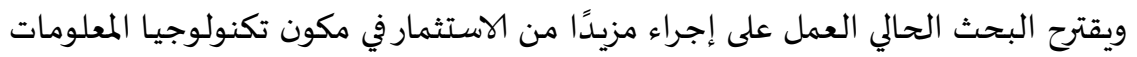

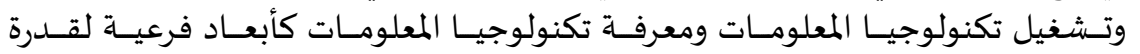

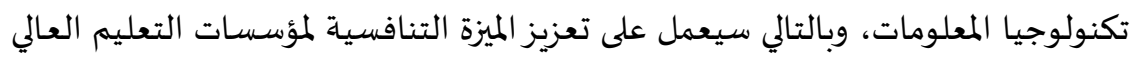
العامة بدولة نيجيريا.

8. دراسة عابد (2019): هدف تناول إدارة الجودة الشاملة كمدخل لتحقيق الميزة التنافسية

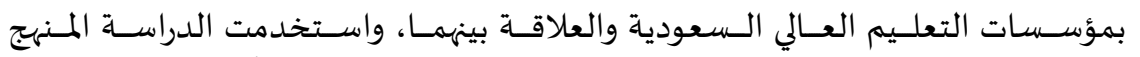

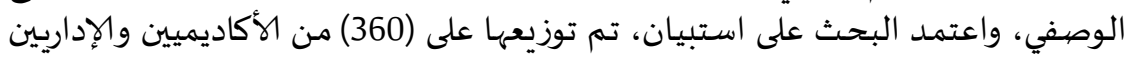

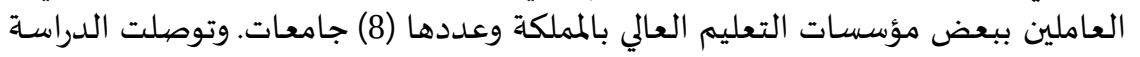

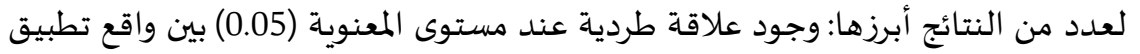

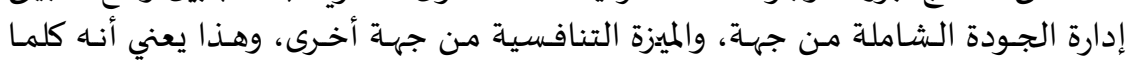

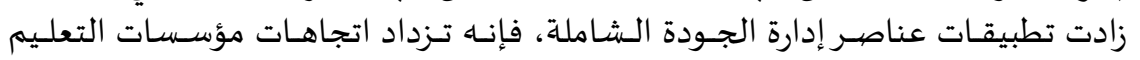
العالي بالمملكة نحو تحقيق الميزة التنافسية.

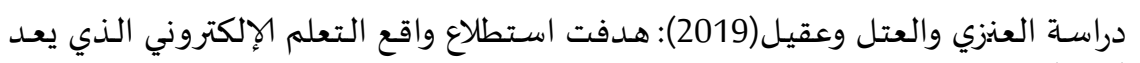

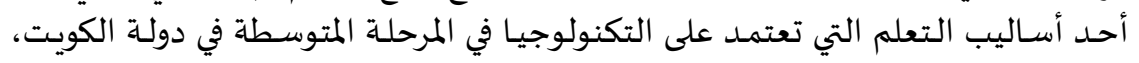

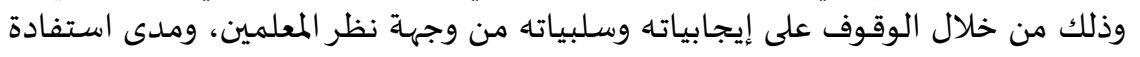

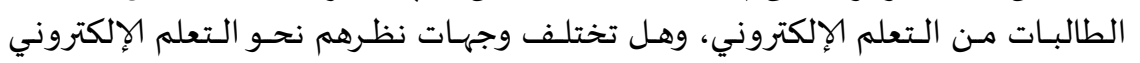

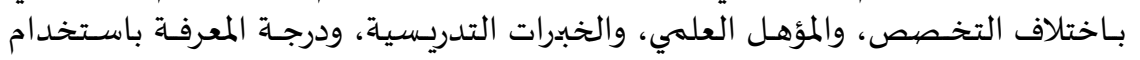

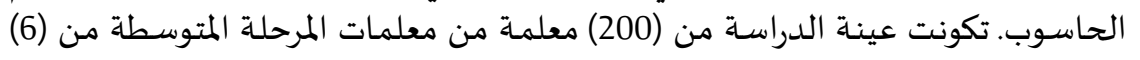

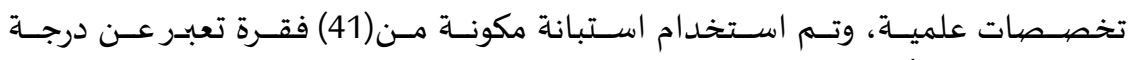

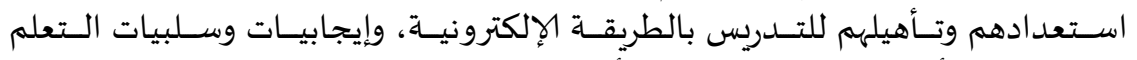

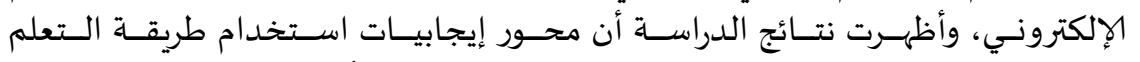

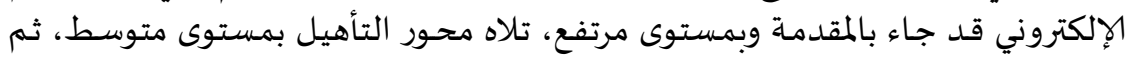

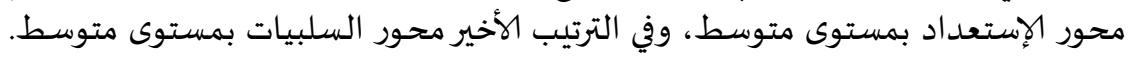

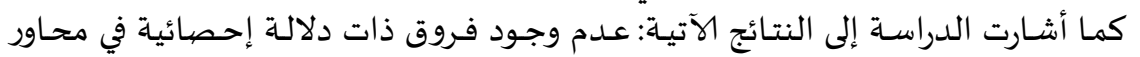

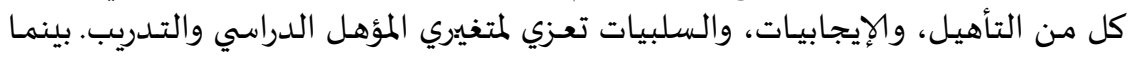

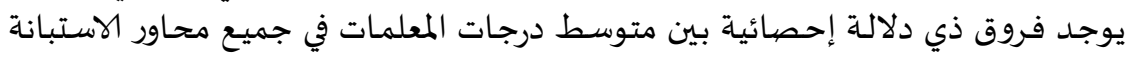

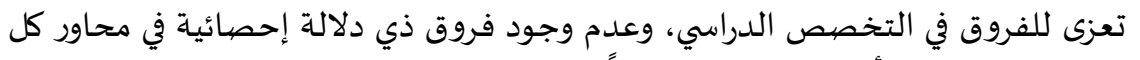

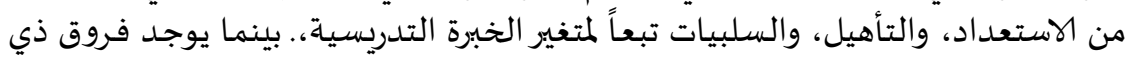

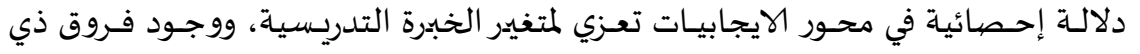

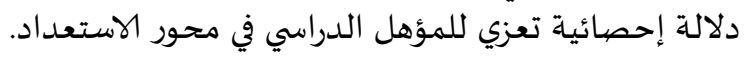

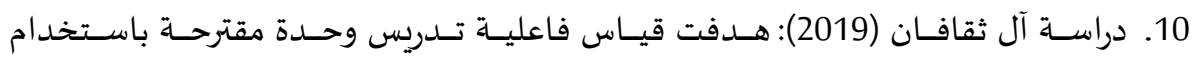

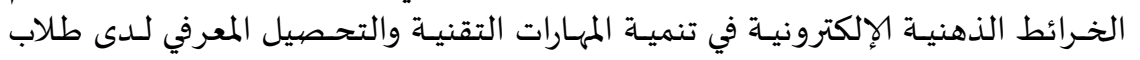

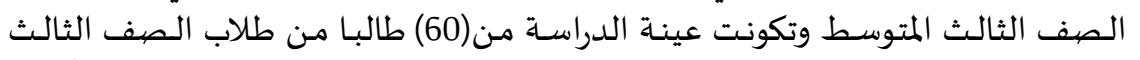

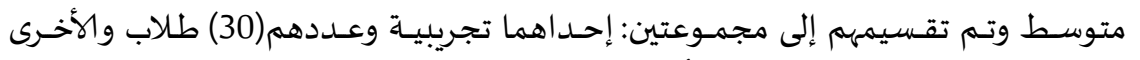

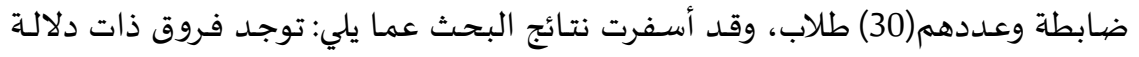




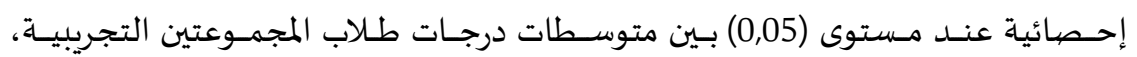

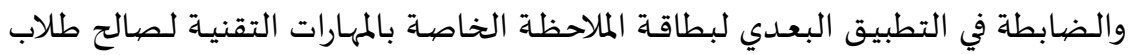

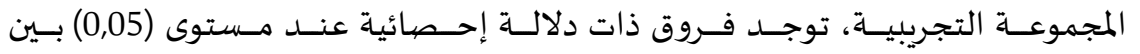

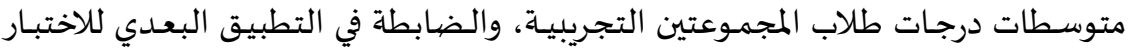
التحصيل المعرفي لصالح طلاب المجموعة التجريبية.

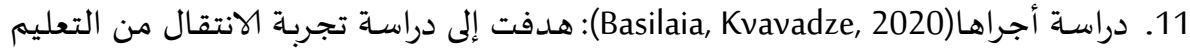

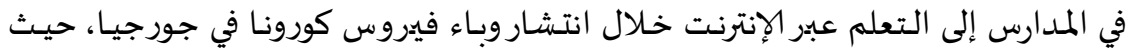

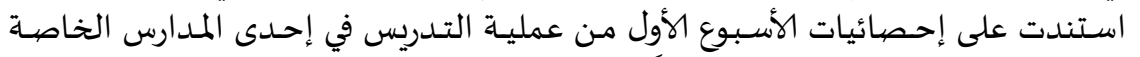

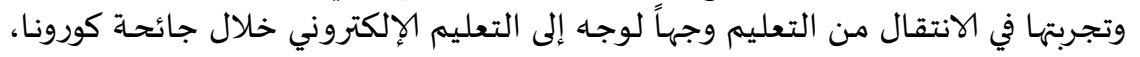

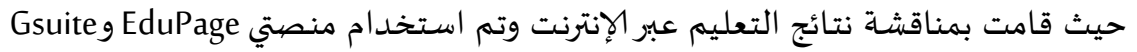

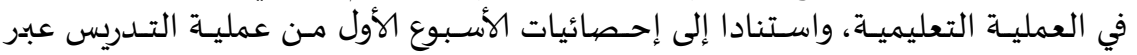

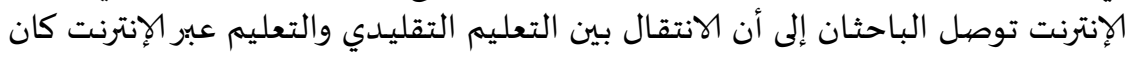

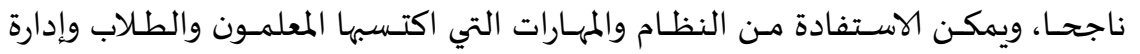

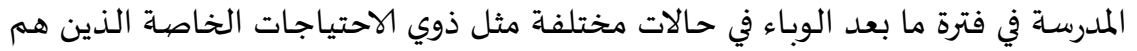

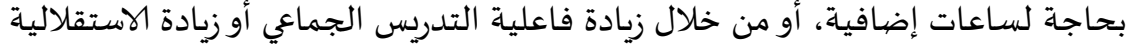
لدى الطالب والحصول على مهارات جديدة.

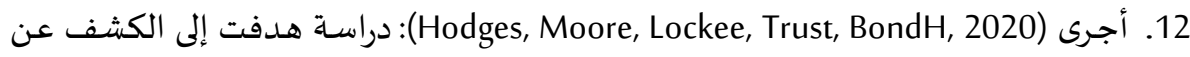

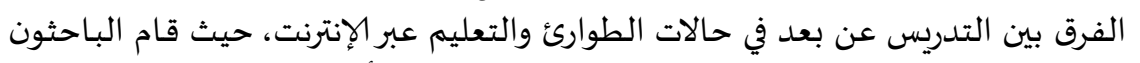

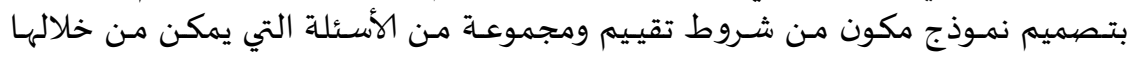

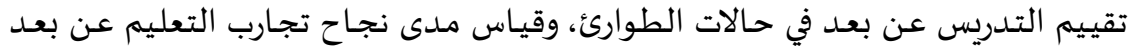

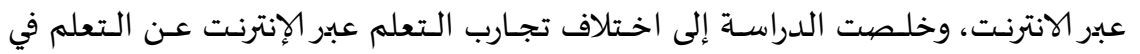

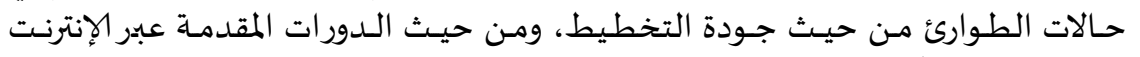

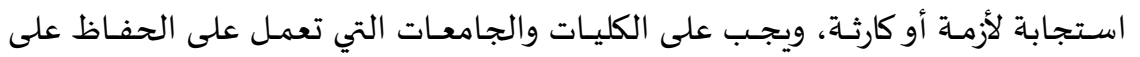

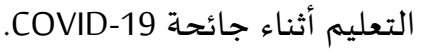

\section{التعليق على الدراسات السابقة:}

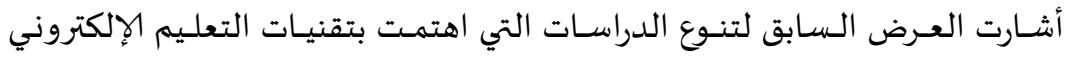

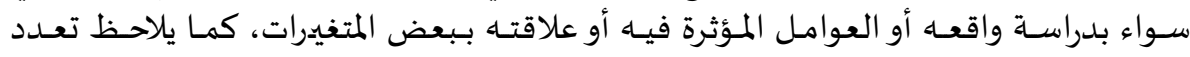

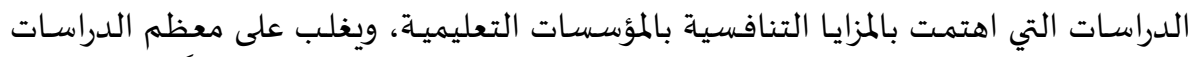

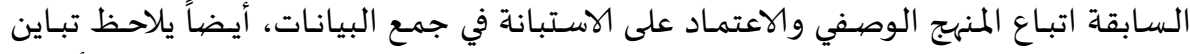

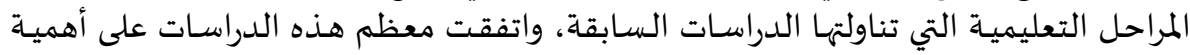

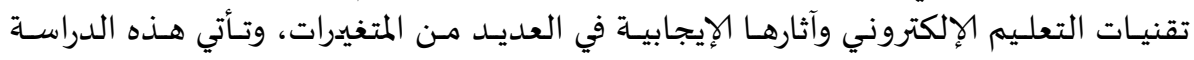

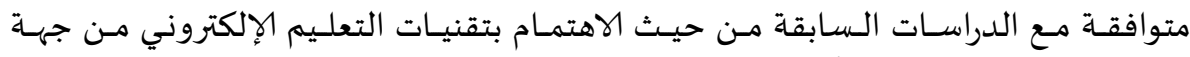

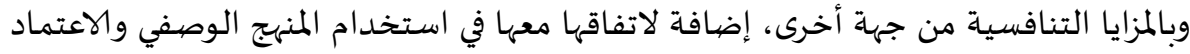

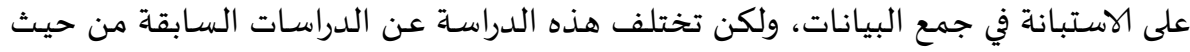

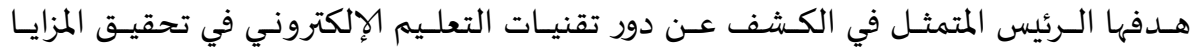

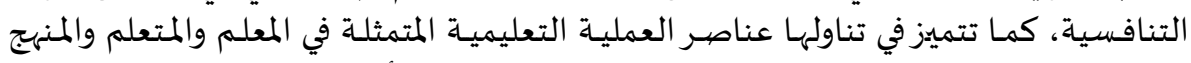

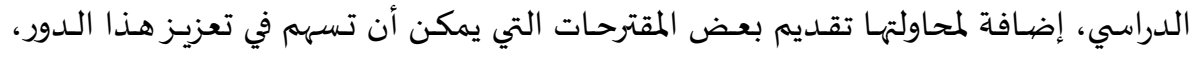




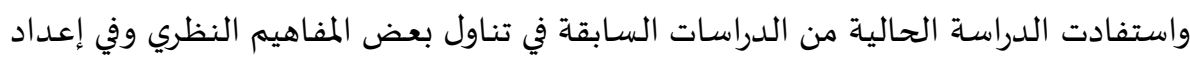

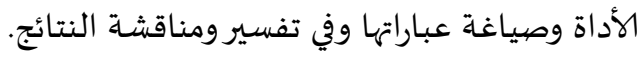

الإطار النظري: (- إن

المحور الأول: المزايا التنافسية

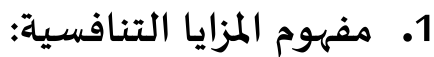

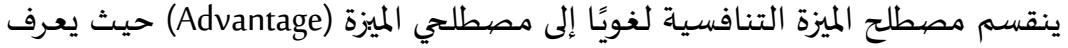
بأنه: التفوق في حالة ما لتحقيق بعض المإجراءاءت، أما الما التنافسية (Competitive) فتعرف بأنها:

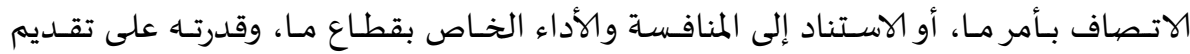

الخدمات في نفس النطاق (Webster, 2016, p.1).

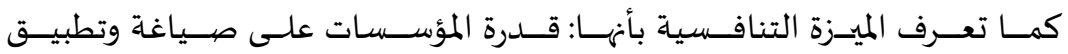

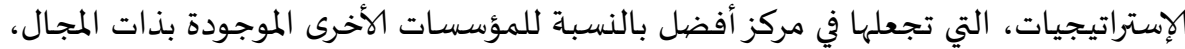

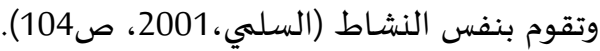

وعرفها (Sigalas\& Economou \& Georgopoulos, 2013, p.7) بأها: الأداة التي يمكن

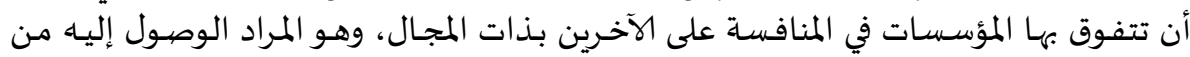

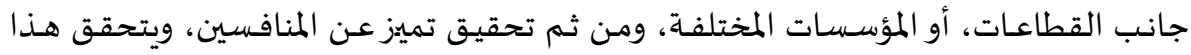

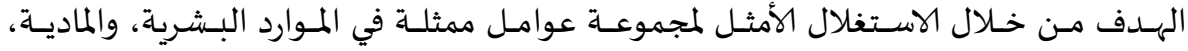

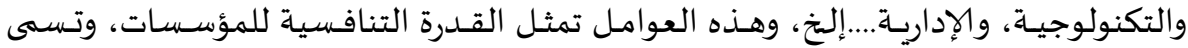

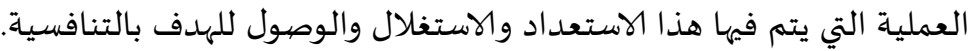

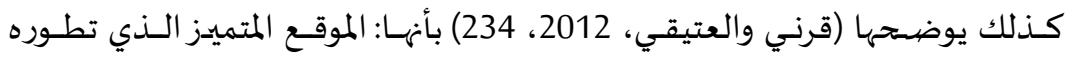

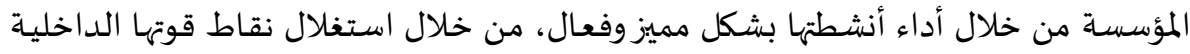

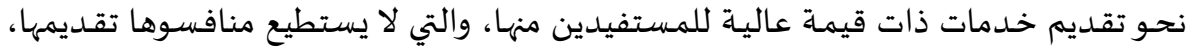

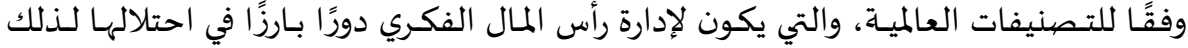
الموقع، والحفاظ على استمراريته.

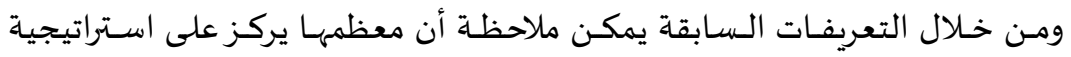

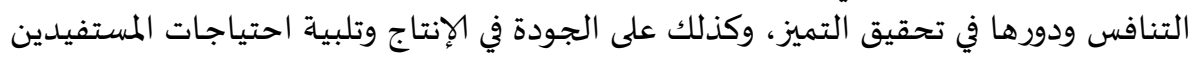

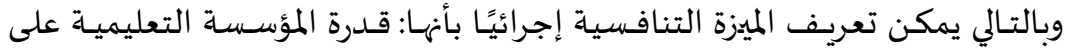

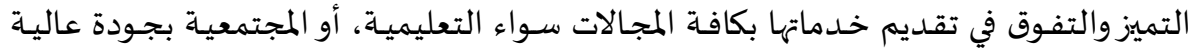

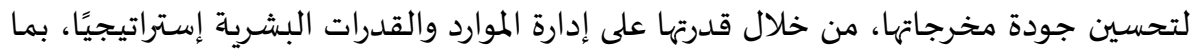

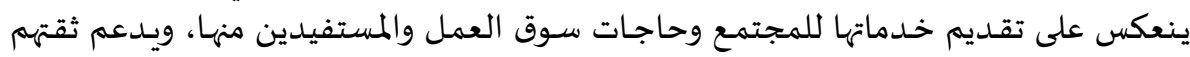

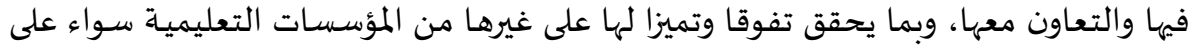

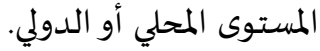


2. خصبائص الميزة التنافسية

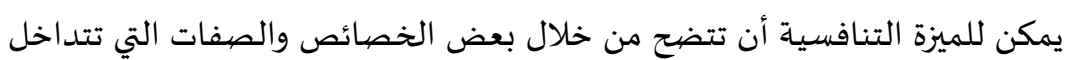
فيما بينها والتي وصفها (الزعبي، 2005) في النقاط الآتية:

بأهها نسبية و تتحقق بالمقارنة وهي ليست مطلقة. تمكن من تحقيق التفوق و الأفضلية للمنظمة التي تتسم بها قياسا للمنافسين

تصدر عادة من داخل المنظمة و تخلق قيمة لها.

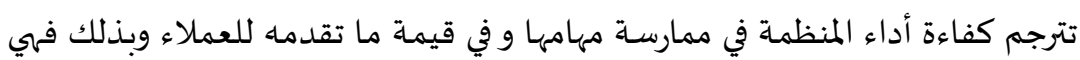

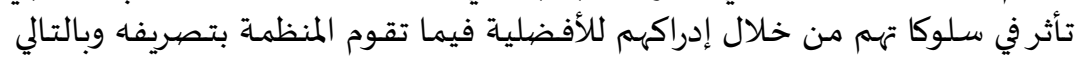
تحفزهم على الاقتناء.

وعليه فالميزة التنافسية تتمتع بفن إيجاد أو استغلال تلك الميليزة التي هي أكثر ديمومة

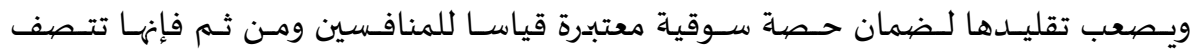
بالخصائص الآتية(بن نذير، 2009): تبنى على اختلاف وليس على تشابه؛ يتم تأسيسها على المدى الطويل، باعتبارها تختص بالفرص المستى لمستقبلية؛ عادة ما تكون مركزة جغرافيا.

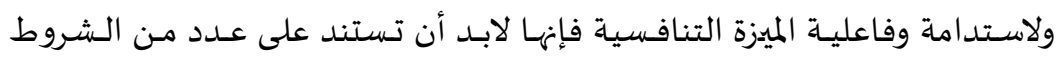
حصرها بن نذير فيما يلي (بن نذير، 2009م): حاسمة، أي تعطي الأسبقية والتفوق على المنافس. الاستمرارية، بمعنى يمكن أن تدوم خلال الزمن. إمكانية الدفاع عنها، أي يصعب على المنافس محاكاتها أو إلغاءها.

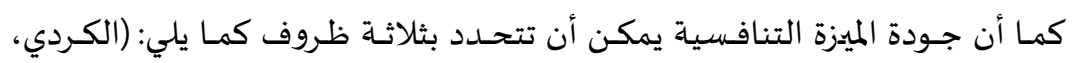

مصدر الميزة: يمكن ترتيب الميزة التنافسية وفق درجتين:

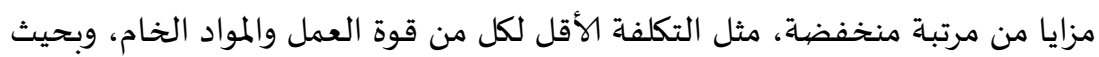

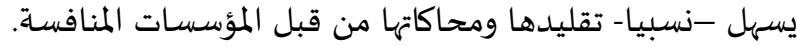

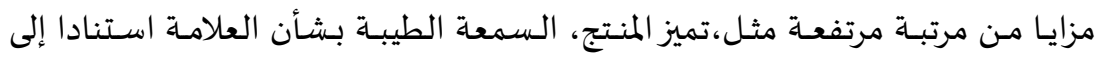

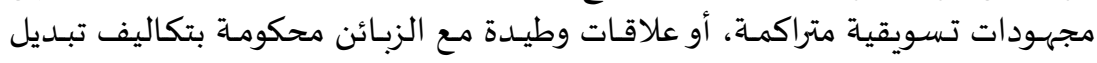
مرتفعة.

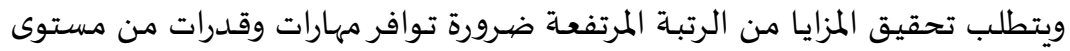

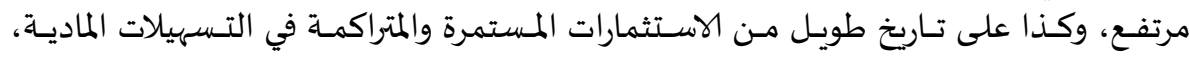




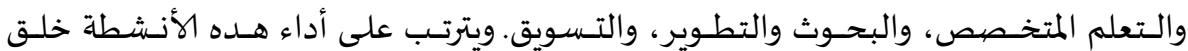

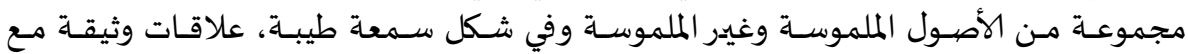
الزبائن، وحصيلة من المعرفة المتخصصية.

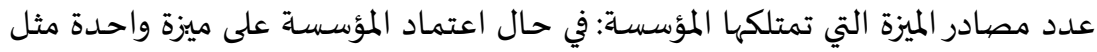

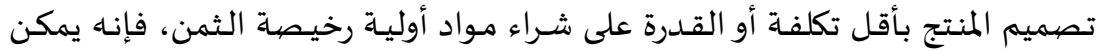

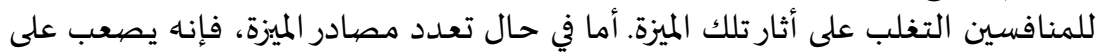

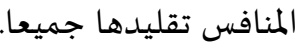

درجة التحسين والتطوير والتجديد المستمر في الميزة:تتحرك المؤسسات نحو خلق مزايا

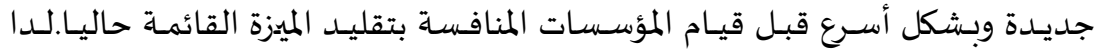

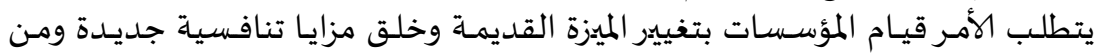

مرتبة مرتفعة.

\section{3. أبعاد تحقيق الميزة التنافسية:}

يرتبط تحقيق الميزة التنافسية ببعدين أساسيين هما (أبو بكر، 15:2006):

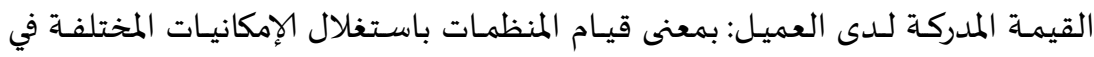

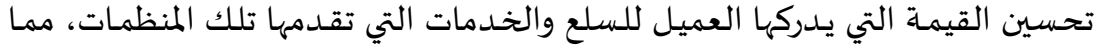

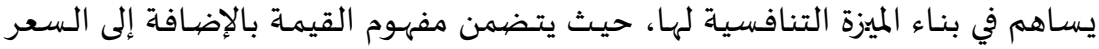
والجودة، مدى الاقتناع بالمنتج أو الخدمة وخدمات المات ما بعد البيع.

وتؤدي إدارة رأس المال الفكري دورا هاما في تدعيم مفهوم القيمة لدى العمئ العيل الذي الذي

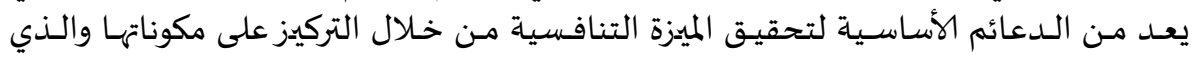

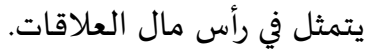

التميز: يمكن تحقيق الميزة التنافسية أيضا من خلال عرض سلعة أو خدمة لا يستطيح

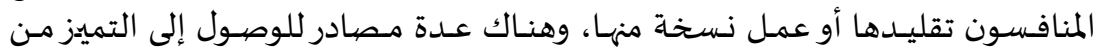
أهمها الموارد المالية، رأس المال الفكري والإمكانيات التنظيمية.

4. استراتيجيات الميزة التنافسية:

لكي تحقق المؤسسات التعليمية التميز يمكها إتباع إحدى هاتين الاستراتيجيتين:

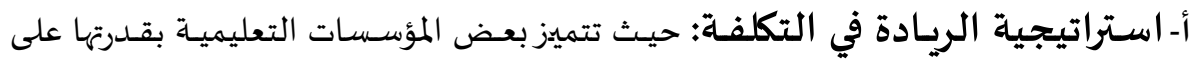

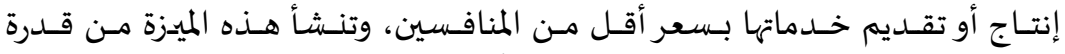

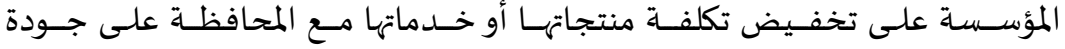

المنتجات/المخرجات. 
ب - استر اتيجية التمايز: وتعني تميز المؤسسة بقدرتها على إنتاج منتجات أو تقديم خدمات

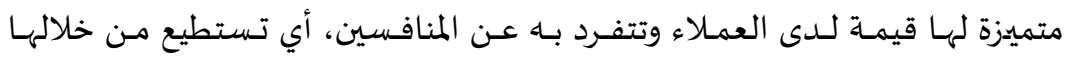
العمل على جذب واستقطاب أكبر عدد من العملاء.

وفي هذا الصدد فإنها حتى يكون للميزة التنافسية فعالية فلابد أن تتاح للمؤسسة فئسة

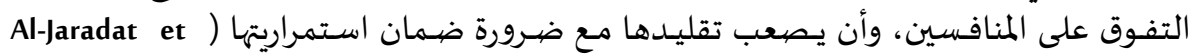

(al, (2012, 400

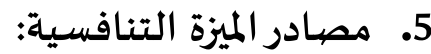

هناك عدة مصادر يمكن أن تتفوق المؤسسة من خلالها ومنها (نجم، 1999، 9):

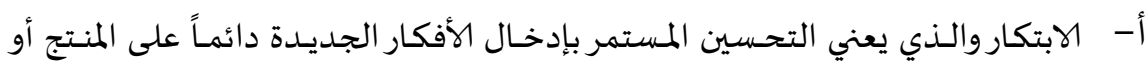

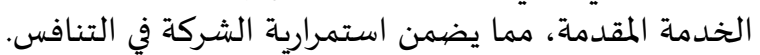

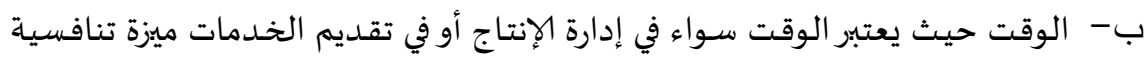

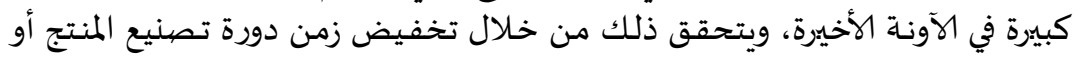

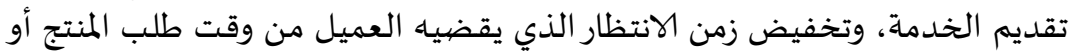

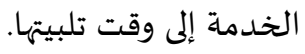

ج- المعرفة والتي يقصد بها الخبرة والتجارب المتراكمة لدى الأفراد العاملين في المؤسسة.

المحور الثاني: تقنيات التعليم التكنولوجية

1 1 مفهوم التِقْنيات التعليمية:

تعددت التعريفات التي تناولت مفهوم التِقنْيات التعليميـة، ومن هذه التعريفات ما

"المواد والأدوات والأجهزة التعليمية المختلفة التي يستخدمها المعلم، بخبرة ومهارة في

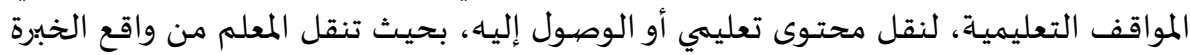

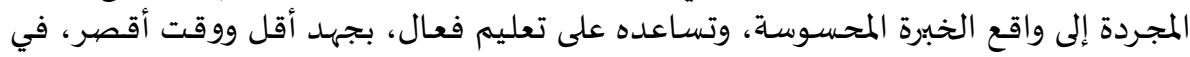
جو مشوّقِ ورغبة في تعليم أفضل" (الحارثي، 2013، 12 12).

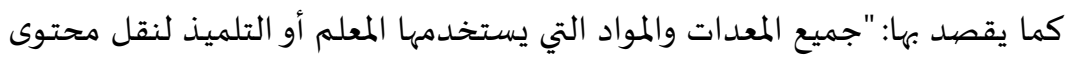

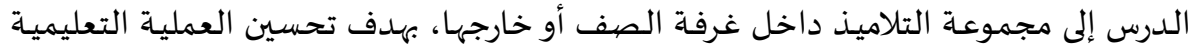
وزيادة فاعليتها دون الاستناد إلى الألفاظ وحدهال غرفة الحهيلة الحخارج، 2008، 459).

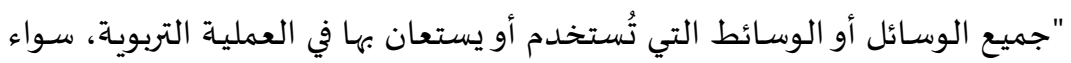

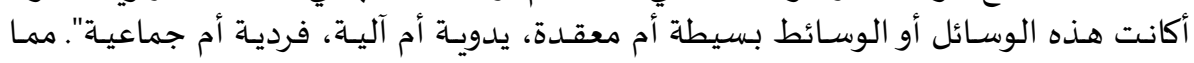

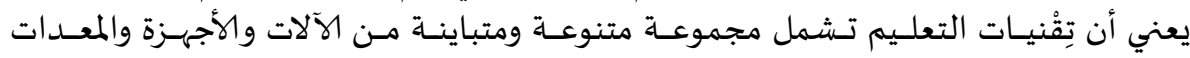

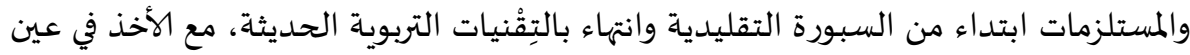

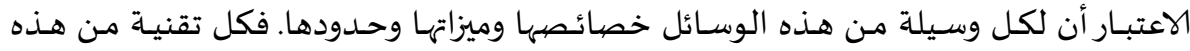

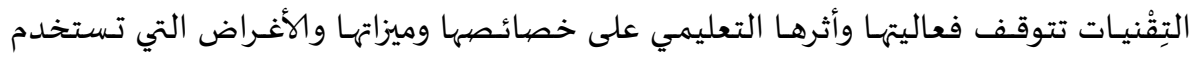




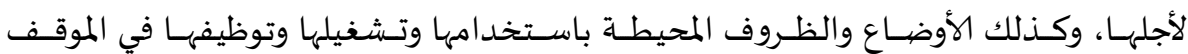

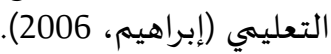

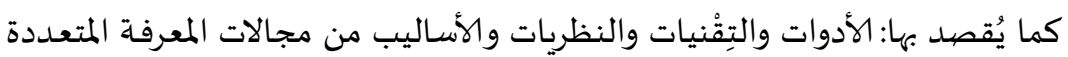

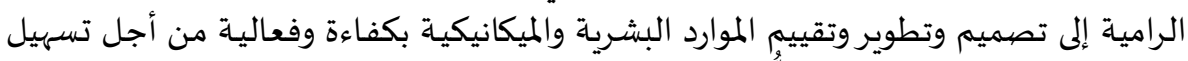

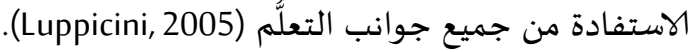

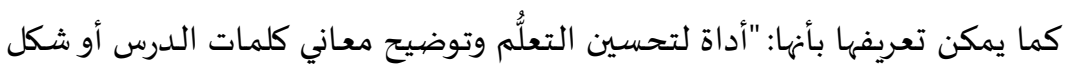

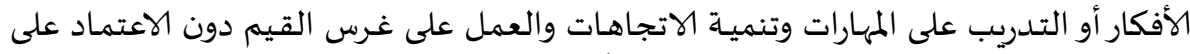

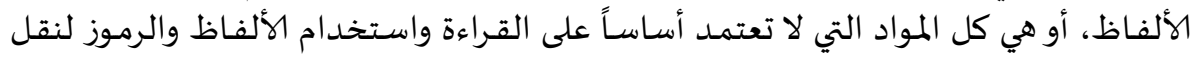

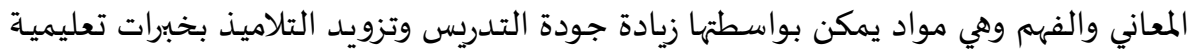
باقية الأثر" (الببلاوي، وأحمد، 2010، 16 16).

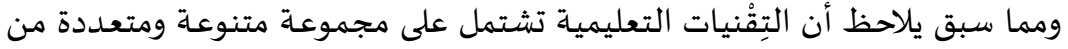

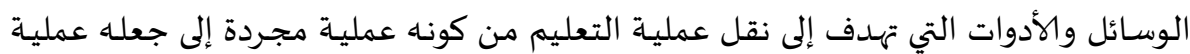

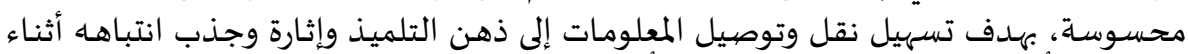
عملية التعلُّم مما يساعد على بقلى بقاء أثر التعلُّم لفترة أطول.

\section{2. تصنيف التِقْنيات التعليمية:}

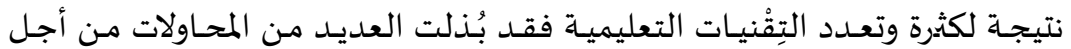

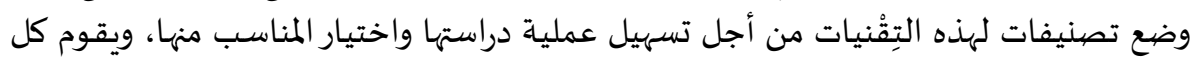
تصنيف على أساس معين، ومن أشهر هذه التصنيفيفات مات ما يلي:

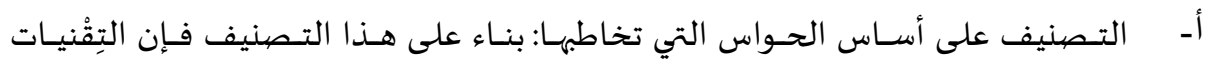

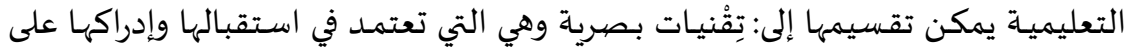

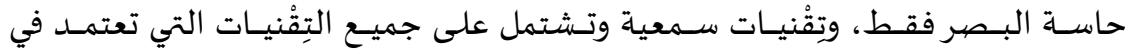

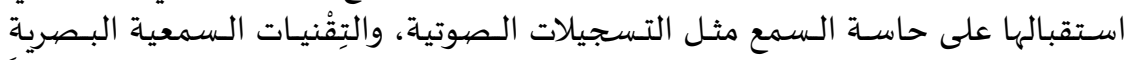

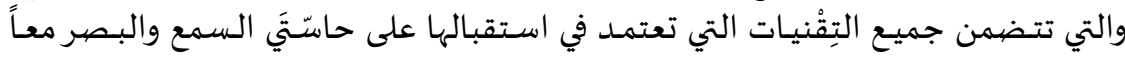
مثل الأفلام المتحركة (إسماعيلي، ويامنه، 2011)

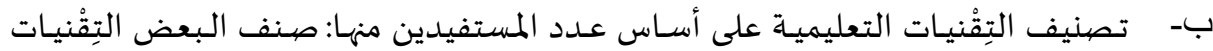

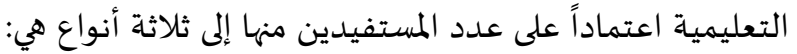

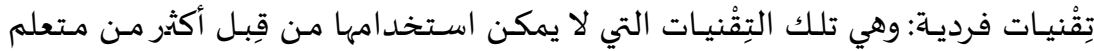

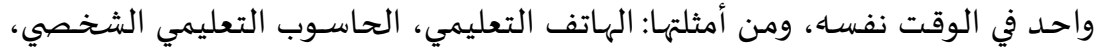

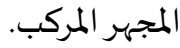

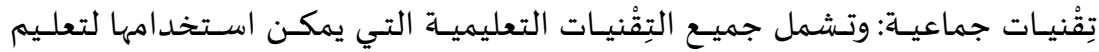

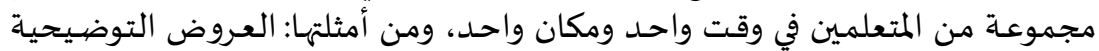


والعلميـة، التلفـاز التعليمي، التسجيلات الصهوتية، والعـرض الضوئي للصهور المعلقـة، الشرائح المصهورة، والشفافيات. التعليعي، الت

تِقْنيات جماهرية: وهي تلك التِقْنيات التي تستخدم لتعليم جمهور كبير من المتعلمين في وقت واحد وفي أماكن متفرقة (سالم، 2010).

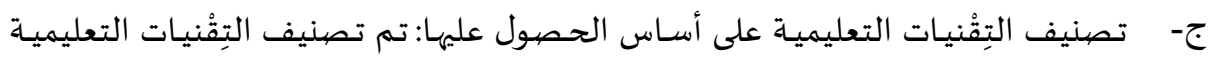
على أساس الحصول علهيا إلى قسمين، هما:

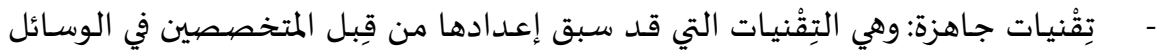
التعليمية أو من قِبل الشركات التجارية التية مثل الخرائط والأفلام المتحركة والثابتابتة.

- تِقْنيـات منتجـة يـدوياً: وهي المـواد التعليميـة التي يقـوم المعلم أو المتعلم أو الاثنـان معـاً

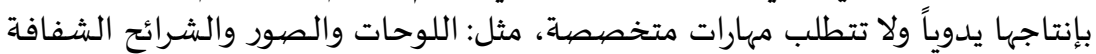

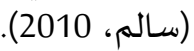

دـ- تصنيف التِقْنيات التعليمية على أساس طريقة عرضها: صنفت بناء وفق ذلك إلى:

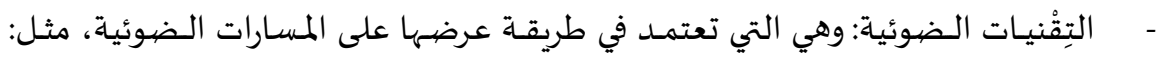

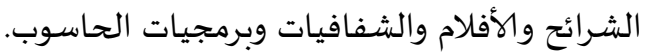

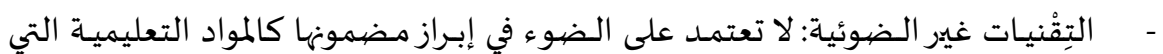

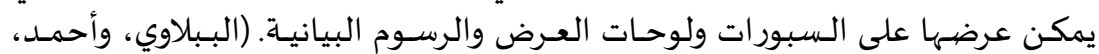

هـ تصنيف التِقنْيـات التعليميـة على أسـاس الخبِرات التي تهيؤهـا: (الحيلـة، 2008، 100)،

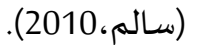

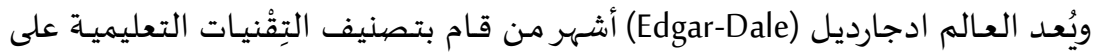

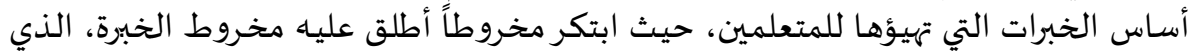

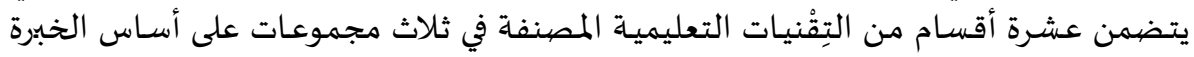

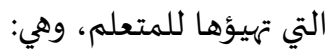

\section{المجموعة الأولى: التِقنْيات المحسوسة}

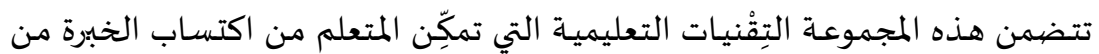

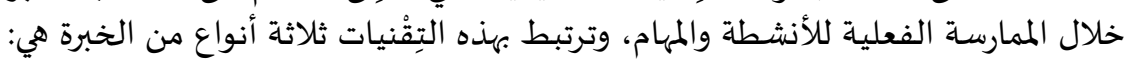

الخبرات المباشـرة: هي الخبرات التي يتم فيها الاتصال المباشـر بين المتعلم والبيئة، ويكون

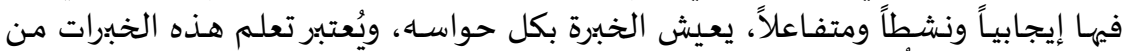
أفضل أنواع التعلُّم وأكثرها بقاء فيلاء في الذاكرة.

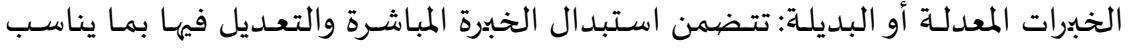

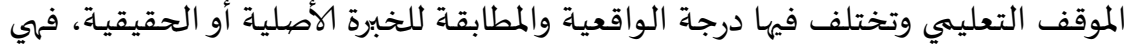


ليست الحقيقية ذاتها وإنما بديلة مختصهرة للحقيقيـة، وعادة ما يتم اللجـوء لهذه الخبرة لتجنب صُعوبات معينة في الحصيول على الخبرة المباشرة.

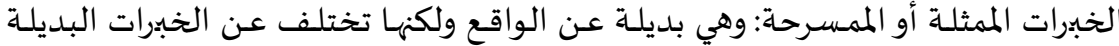
بعدم احتفاظها بقدر كبير من الشكل الظاهر للواقع الأصلي.

المججموعة الثانية: التِقْنيات شبـه المحسـوسـة

وتتطلـب هـذه المجموعـة المـشـاهدة والملاحظــة مـن قبـل المـتعلم، وتتـضمن خمسسة مستويات للوسائل التعليميـة، وهي:

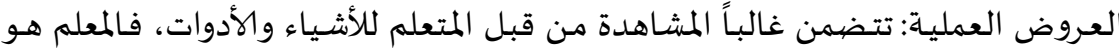
الذي يقوم بتنفيذ العرض دون مشاركة المتعلم، مثل مهارة السباحة أو قيادة السيارة.

الرحلات العلميـة: الهدف منها الحصول على الخبرات التعليمية التي يصعب الوصيول إليها

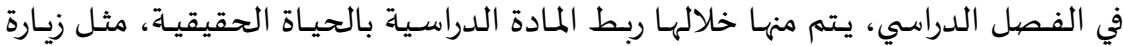

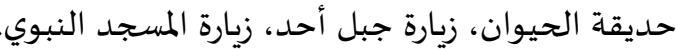

المعـارض والمتـاحف: تـضم مجموعـة متنوعـة مـن الوسـائل كالنمـاذج بأنواعهـا المختلفــة، والعينات، والصيور والخرائط.

الـصهور المتحركـة:وتـشتمل على الأفـلام التعليميـة بمـا فيهـا الأفـلام المتحركـة والنـاطقــة

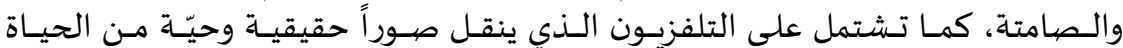
الخارجياة.

$$
\text { الصور الثابتة، الإذاعة والتسجيلات الصوتية. }
$$

\section{المججموعة الثالثة: التِقْنيات المجردة}

تتطلب هذه المجموعة استخدام الرموز البصرية أو اللفظية وتقل درجـة واقعية الخبرة

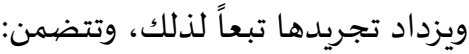

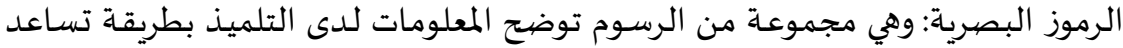

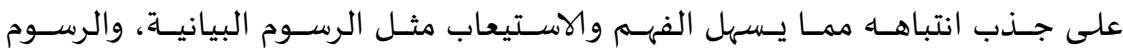
التوضيحية والخرائط.

الرموز اللفظية: تعتبر أكثر مستويات الخبرة تجريداً حيث تأتي في المستوى العاشر والأخير

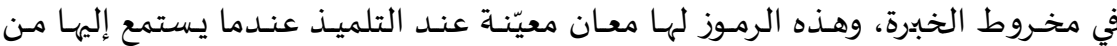

المعلم.

من خلال ما سبق نرى أن "ديل" قـد صنـف التِقنْيـات التعليميـة بربطها بنوعيـة الخبرة

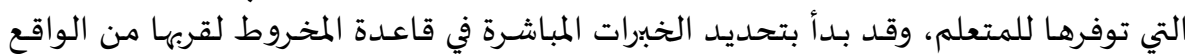

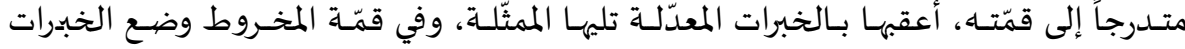




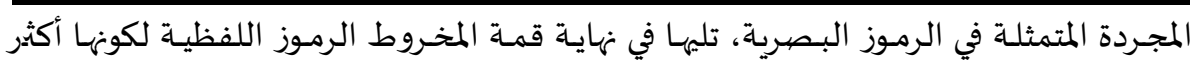

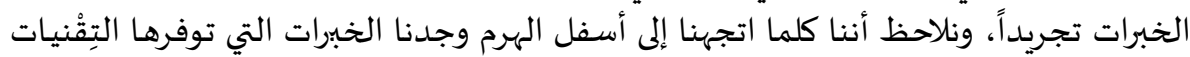

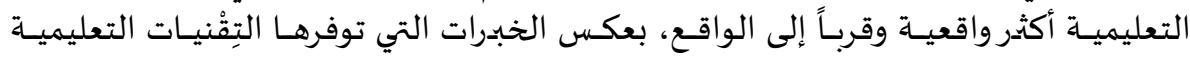
الموجودة على أعلى المخروط.

3. مبررات توظيف التقنيات التعليمية التكنولوجية في التعليم:

توجد مجموعة من المبررات تقف وراء ضرورة استخدام المستحدثات التكنولوجية

بالمنظومة التعليمية بعناصرها كافة، ومن تلك المبررات تورات ما يلي (وهبة، 2006، 8-9) (الحيلة،

:377، 2000

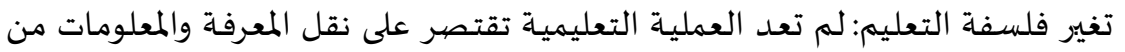

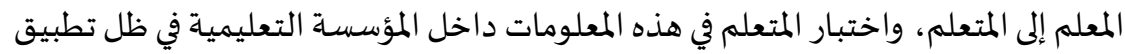

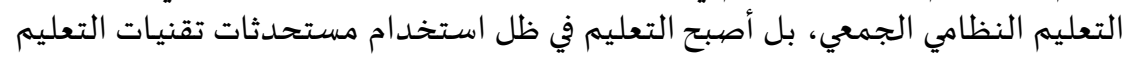

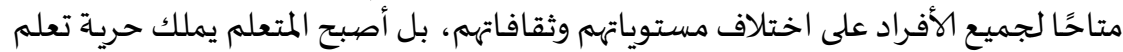
ما يشاء ومتى شاء وفق قدراته الأكاديمية واستعداداداته النفسية.

تغير دور المعلم: كان المعلم هو المصددر الرئيس للمعرفة ومحور العملية التعليمية، يقوم

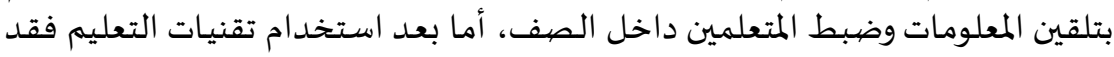

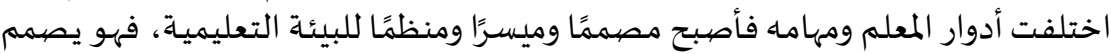

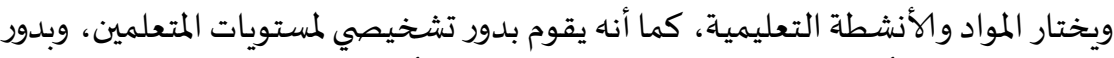

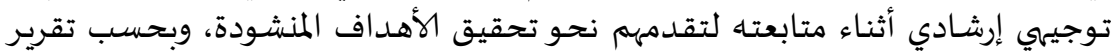

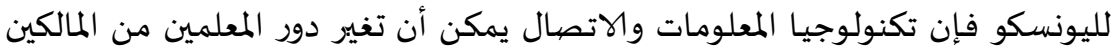
للمعرفة والمرسلين لها إلى دور أكثر تيسيرًا ودعمًا واستمرارًا لمكار للتعلم.

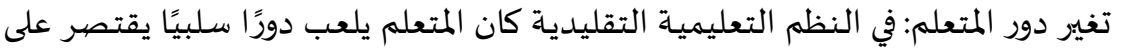

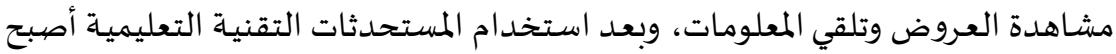

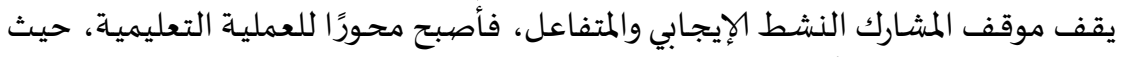

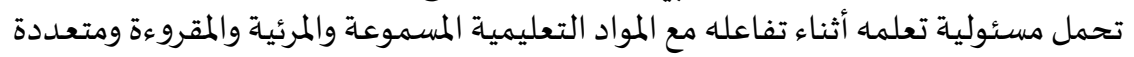

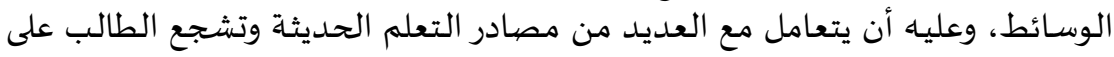
تحمل مسؤولية تعلمه والنجاح في التعلم الذاتي وتحقيق الثقاة بالنفس.

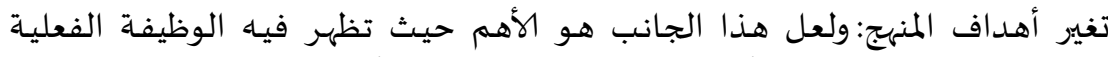

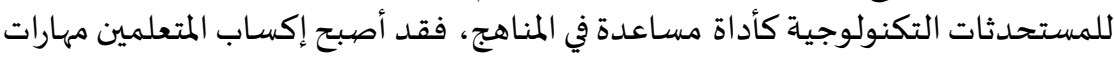

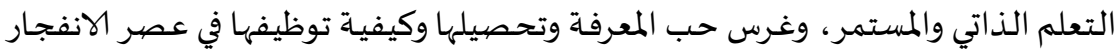
المعرفي والمعلوماتى من أبرز الأهداف العامة للمناهيت المعرفة وتجعراسياسية.

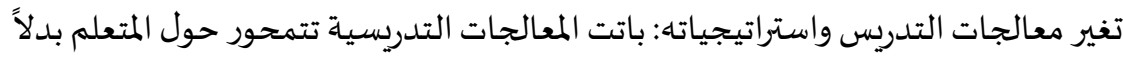

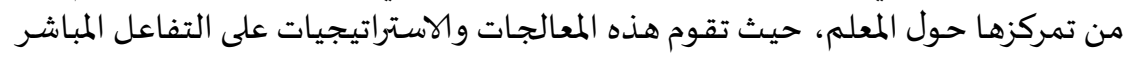
الإيجابي بين المتعلم والمستحدئ المعات التقنية التعليمية.

تطور مفهوم الوسائل التعليمياة: لم يعد ينظر للوسائل التعليمية على أنها أدوات ثانوية أو أو

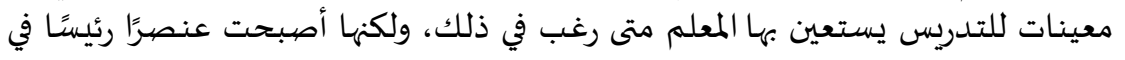


استراتيجية التدريس ومنظومة فرعية للمنظومة التعليمية الكبرى، تدور حولها الأنشطة

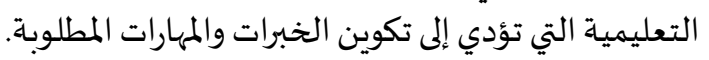
4. التقنيات المستخدمة في التعلم الإكتروني:

يرتكـز اسـتخدام الـتعلم الإلكتروني على مجموعــة مـن التقنيـات الحديثـة يحـددها

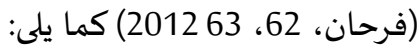

$$
\text { الحاسب الآلي. }
$$

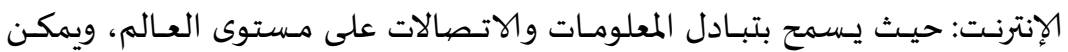

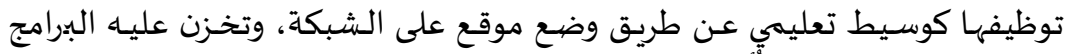

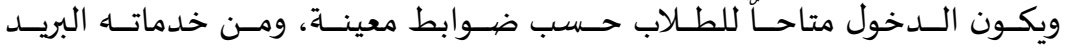

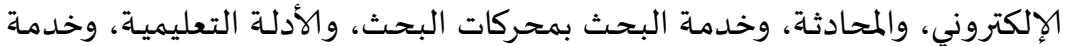

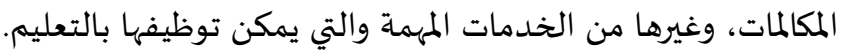

الإنترانت: وهى الشبكة الداخلية وتتمثل في ربط أجهزة الحاسب في المدرسة ببعضها إلمانها

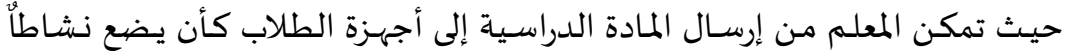

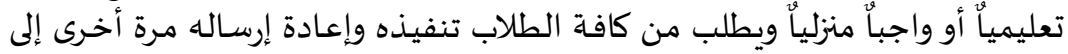

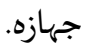

المقرر الإلكتروني E-Course: وهو مقرر يستخدم في تصهيمها أنشطة ومواد تعليميـة

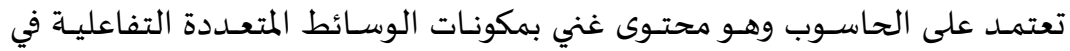

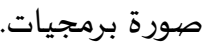

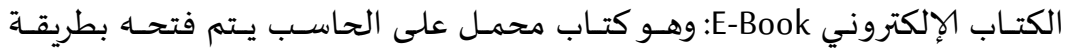

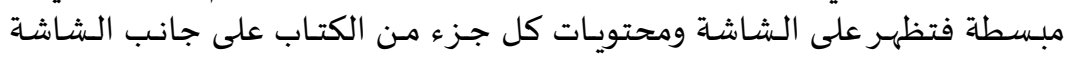

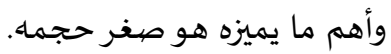

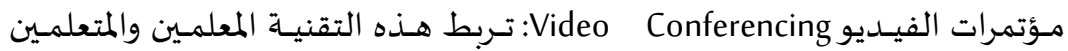

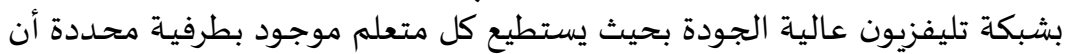
يرى ويسمع المختص ومادته العلمية. برامج القمر الصناعي Satellite Program:وفي هذه التقنية يتوحد محتوى التعليم

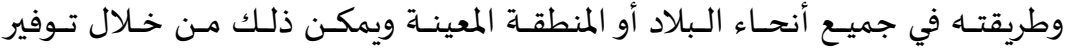
محطات أرضية لاستقبال هذه القنوات التعليمية. الفيديو التفاعلي Interactive Video: وهي عبارة عن دمج الحاسب والفيديو في تقنية واحدة. 


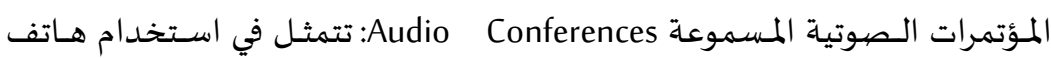
عادي يتصل بعدة خطوط تعمل على توصيل المعلم بالمتعلمين.

الفـصـول الافتراضـيـة Classroom: وهي مجموعـة بـرامج على هيئسة أنشطة

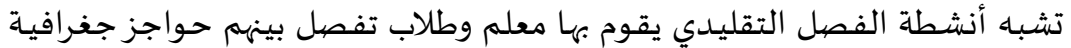

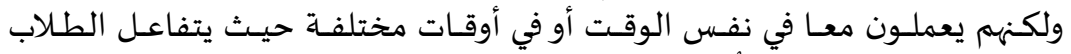

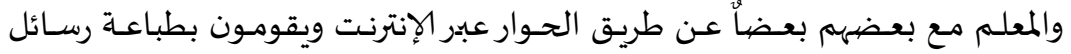
يستطيع جميع الأفراد المتصلين بالشبكة وعنئ رؤيتها.

5. المتطلبات والمهارات اللازمة للتِقْنيات التعليمية:

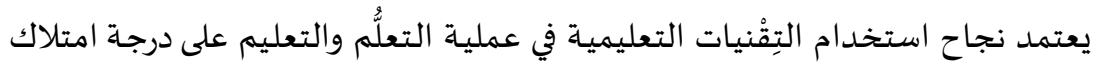

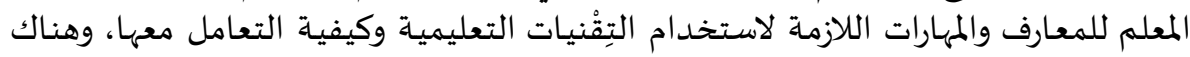

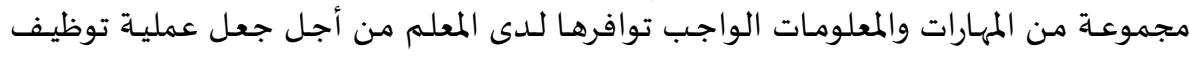

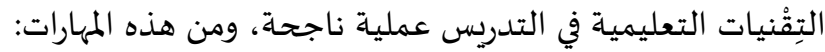

قدرته على استخدام التقنيـة التعليميـة بـصورة صسحيحة، حيـث لا يخفى على الجميع ما

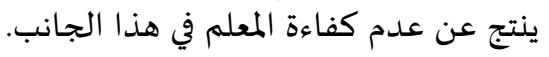

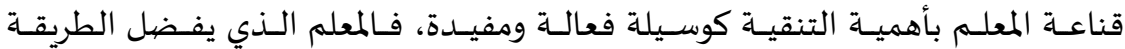

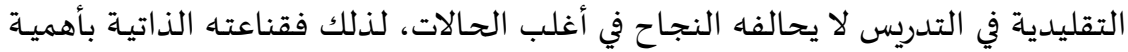

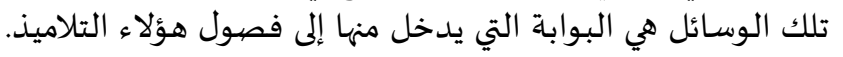

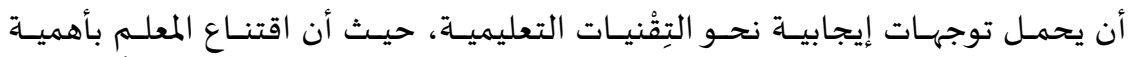

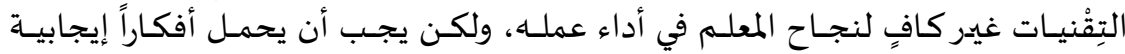
وتوجهات غير سلبية نحو تلك الأجهزة.

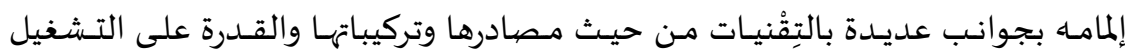
والصيانة البسيطة (هوساوي، 2007).

وقـد قسم بعض البـاحثين هـذه المهارات ضـمن أربعـة محساور رئيسية، وهي: اسـتخدام

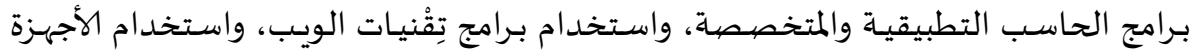
التعليمية، والإلمام بالمعارف التقنية، وفيما يلي عرض لهذه والمتخدة المهارات (فلمبان، 2014، 36-47):

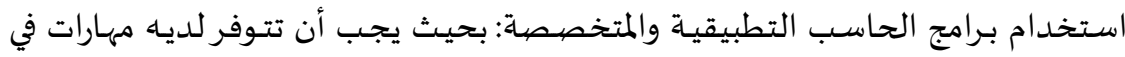

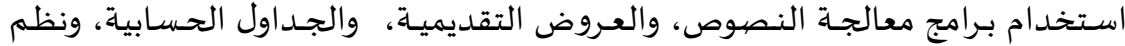

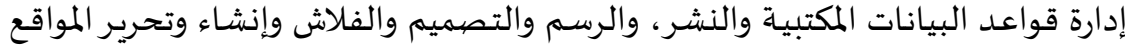

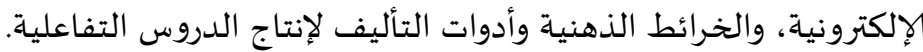

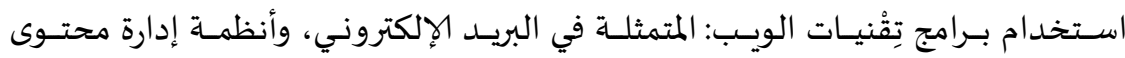

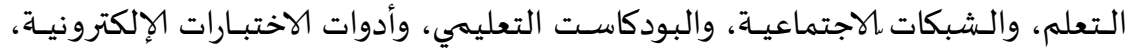

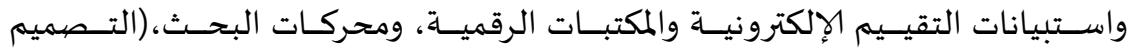

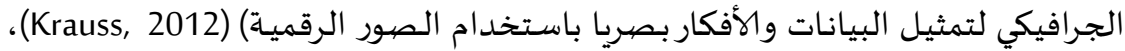

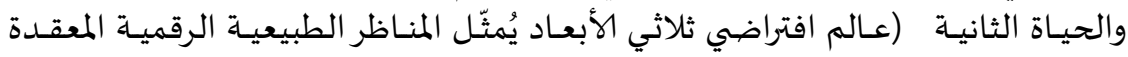




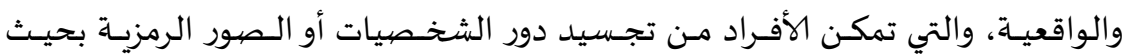

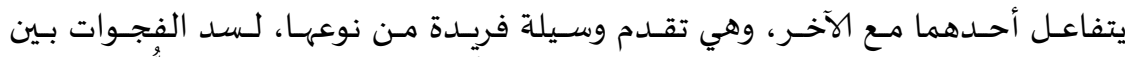

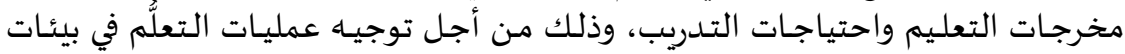
جديدة ومختلفة وفي ضوء الأهداف المنشودة (Anstadt, Bradley, \& Burnette, 2013).

استخدام الأجهزة التعليمية: بحيث تتوفر لدى المعلم مهارات استخدام الأجهزة المحمولة

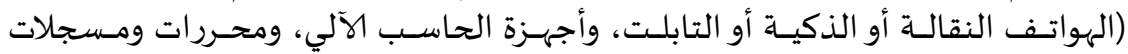

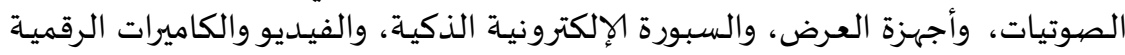

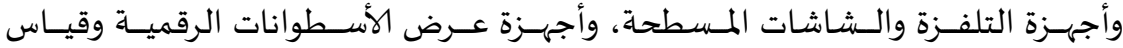

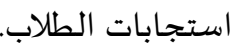

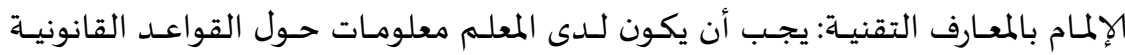

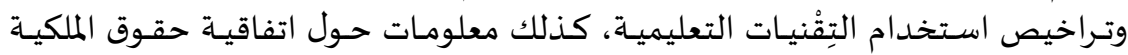

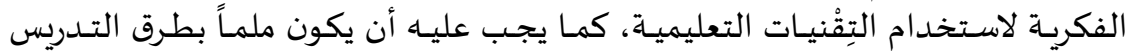

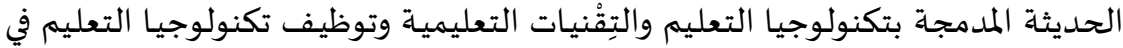

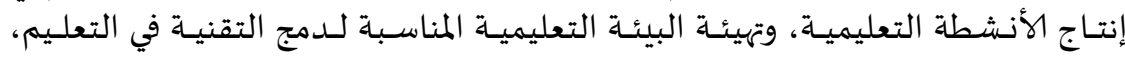

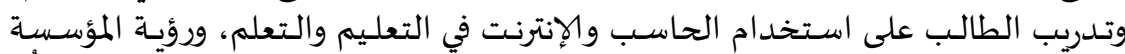

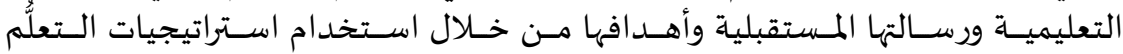
والتكنولوجيا التعليمية الحديثة.

\section{6. دور المعلم في التعلم الإلكتروني وفق تقنيات التعليم:}

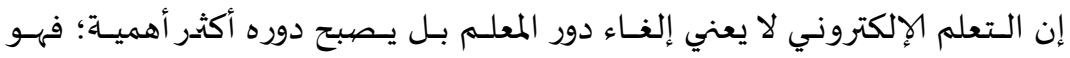

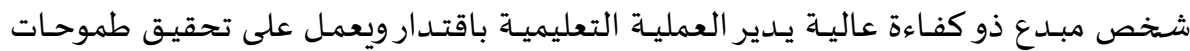

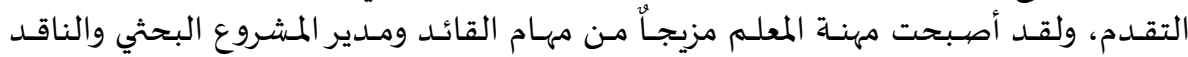

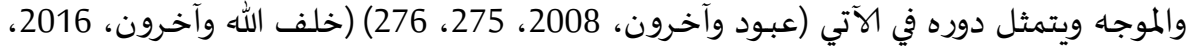

العمل على تحويل غرفة الصف من مكان يتم فيهاه تلقي المعلومات بشكل ثابت بابت وفي

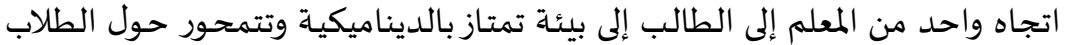
حيث يقوم الطلاب بالعمل في شكل مجموعات عبر شبكة الإنترنت. إتباع مهارات تدريسية تأخذ بعين الاعتبار الاحتياجات والتوقعات المتنوعة والمتباينة للمتعلمين. أن يطور فهمـا عمليـاُ لتكنولوجيـا التعليم مـع اسـتمرار تركيزه على الـدور التعليمي

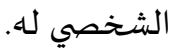
العمل بكفاءة كمرشد وموجه للمحتوى التعليمي. 
تصميم التعليم، وتوظيف التكنولوجيـا، وتشجيع تفاعل الطلاب، وتطوير التعلم

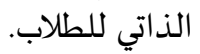

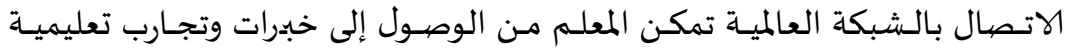

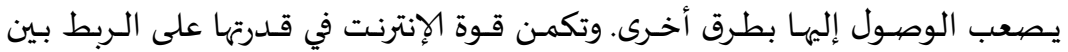

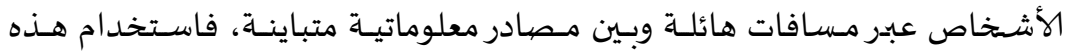

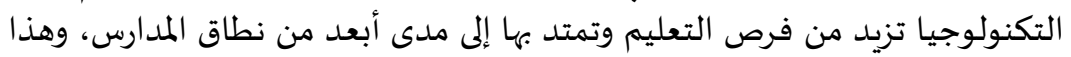

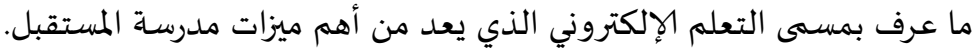

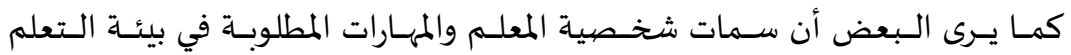

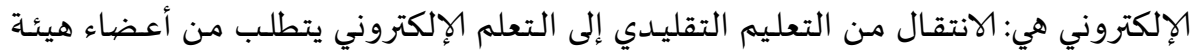

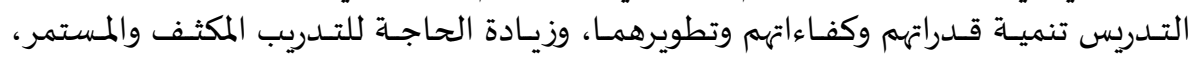

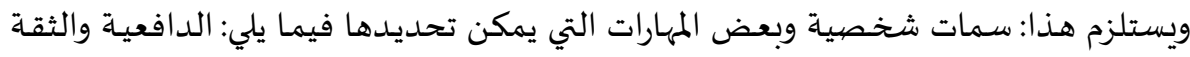

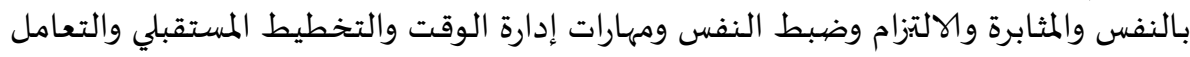

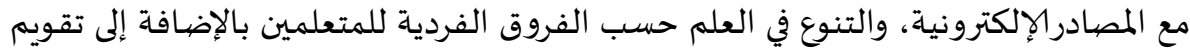

أداء الطلاب (خلف الله وآخرون، 2016، 168).

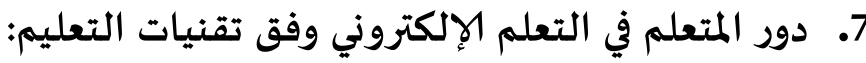

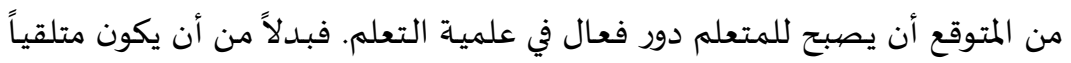

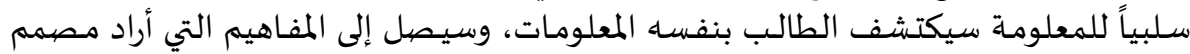

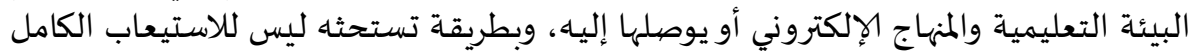

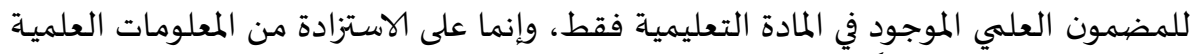

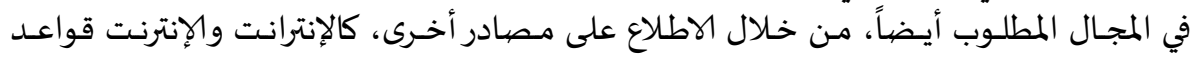

المعلومات والبيانات أينما توفرت (السلطي، 2004، 284)

ويمكن للمتعلم أن يقوم بالأدوار الآتية في التعلم الإلكتروني:

$$
\text { التعلم الذاتي بالسرعة التي تتناسب قدراته. }
$$$$
\text { تبادل الخبرات مع طلاب آخرين. }
$$

متابعة واجباته وحلها.

تنفيـذ مشروعات وأبحـاث تخـدم مـواد الدراسـة والاسـتفادة مـن المواقع الإلكترونيـة

المتعددة باعتباره مراجع علمية.

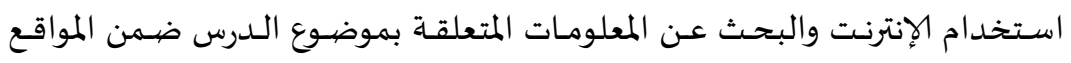

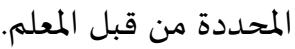

المشاركة في الحواروالنقاش عند عرض المعلم للمادة.

المشاركة في الحواروالنقاش من خلال غرف المحادثة والبريد الإلكتروني ومؤتمرات 


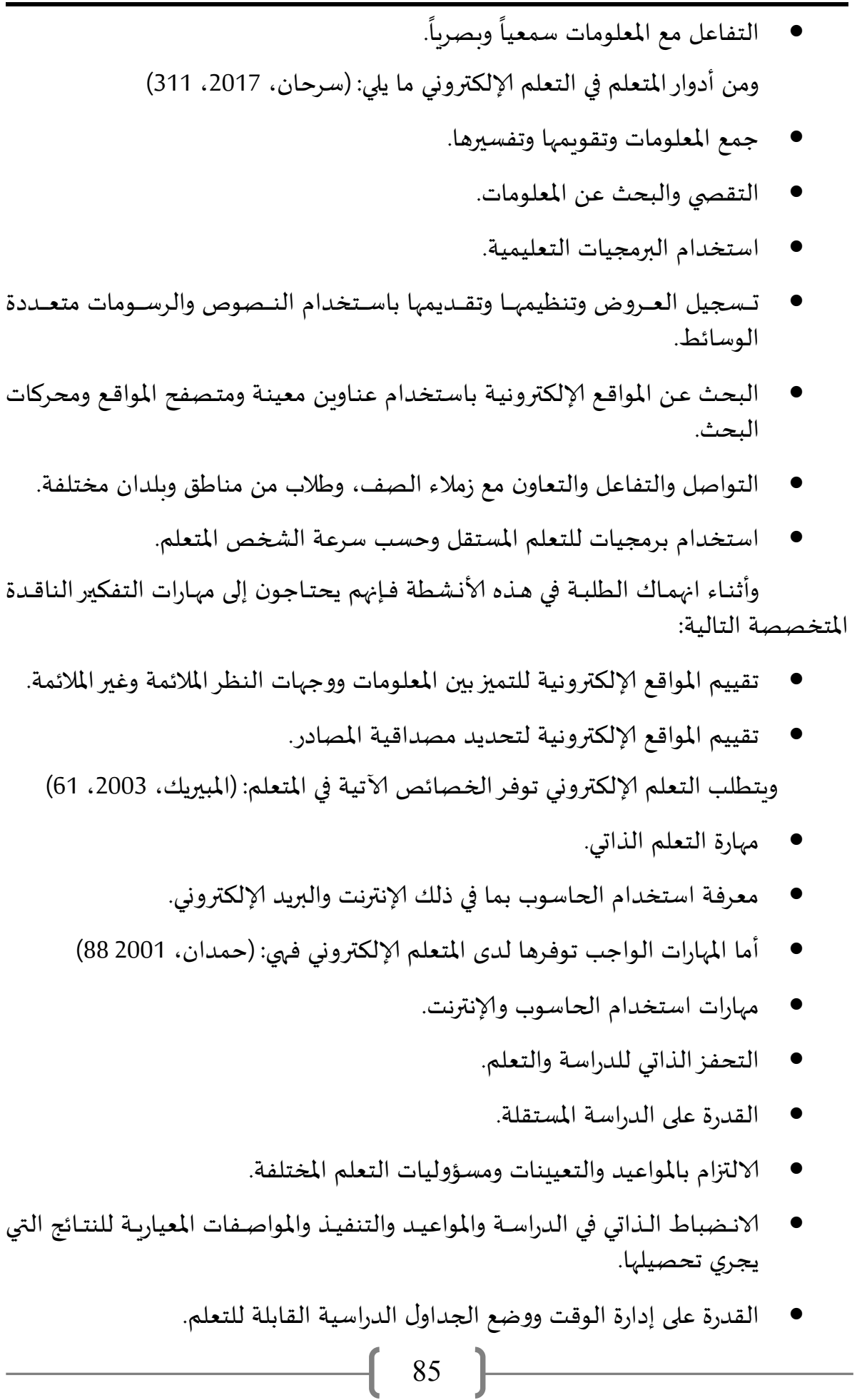




\section{• القدرة على العمل وبذل الجهد المطلوب للتعلم الإلكتروني.}

8. تقنية المعلومات والمزايا التنافسية للنظم التعليمية

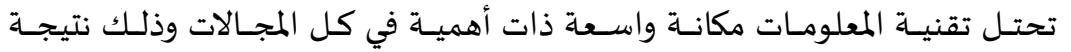

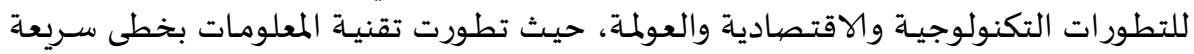

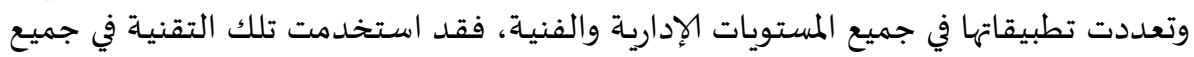

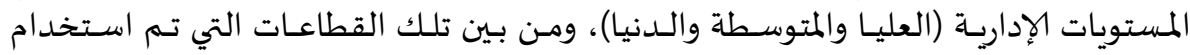

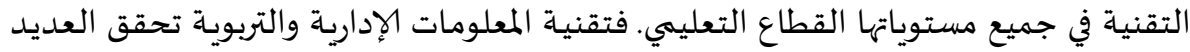

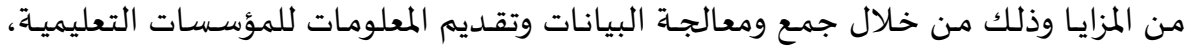

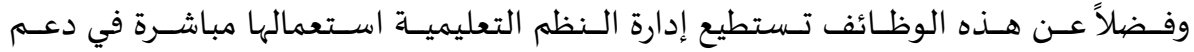

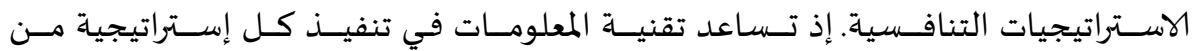
الاستراتيجيات التنافسية التي تحقق المزايا التنافسية.

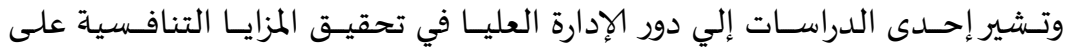

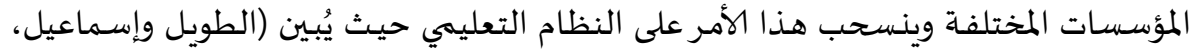

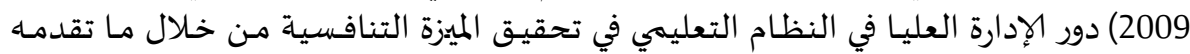

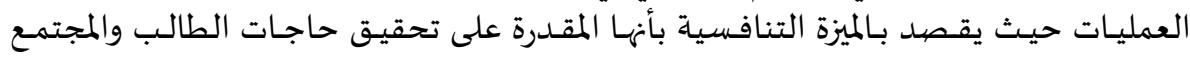

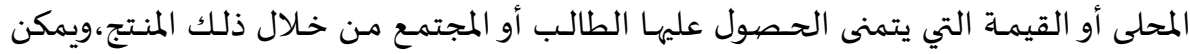

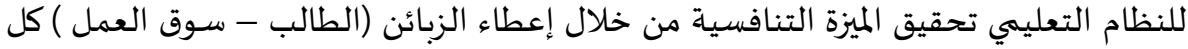
ما يرغبون باه بصورة أفضل من أيه نظام آخر.

فظهور تقنيـة المعلومات أوجـد فرصيا جديدة أمام إدارة النظام التعليمي ومسئوليه

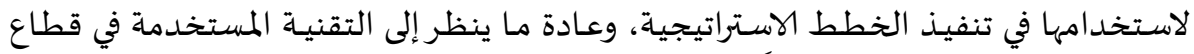

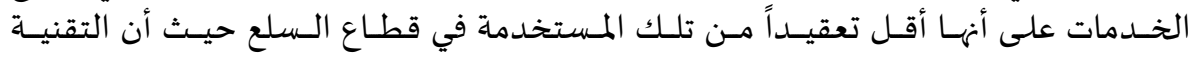

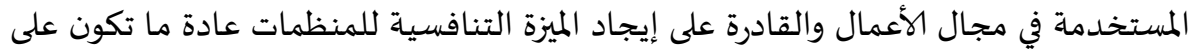
ثلاثة أنواع ويمكن أن ينسحب ذلك على قطاع التعليم وهي كالتالي( (DANLI,2014)، تقنية المنتج وتتعلق بتحديد صفات وخصائص مخرجات التعليم واستخداماته. تقنيـة العمليـات وتتعلق باستخدام المعرفـة في عمليـات التعليم والتعلم وذلك لتنظيم المدخلات والعمليات التصنيفية.

تقنية الإدارة وتتعلق باستخدام المعرفة في إدارة المؤسسات التعليمية

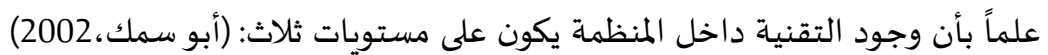
المستوى الفردي حيث يقصد بالتقنية هنا المهارات الشخصية والمعرفة التي يمتلكها الفرد

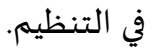

المستوى الوظيفي حيث يقصد بالتقنية الإجراءات والأساليب التي تستخدمها (الوحدات والأقسام) في أداهيا لأعمالها. المستوى التنظيمي وتتمثل في الطريقة التي يحول التنظيم بها المدخلات إلى مخرجات. 
وتعد تقنيـة المعلومات بكل أبعادها وقـدراتها من الأمور المهمـة الإستراتيجية في نقل

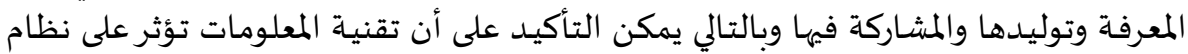

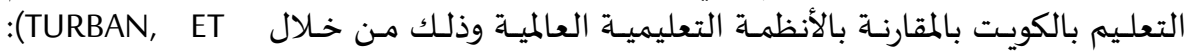

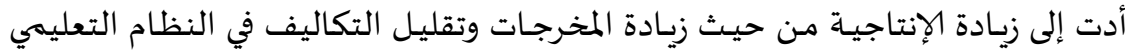

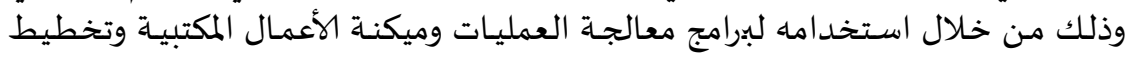
ومراقبة العمليات التعليمية والإدارية وتقليل المدة الزمنية اللازمة لإنجاز المهام والعمليات الماتيات وتخطية

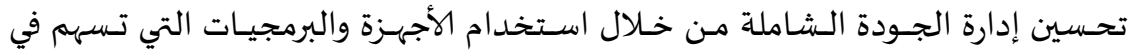
تحسين عملية جمع البيانات وتلخيصها وتحليلها وإصدار التهار التقارير اللازمة في ضونئها. تحسين عملية اتخاذ القرارات باستخدام برامج دعم واتخاذ القرارات.

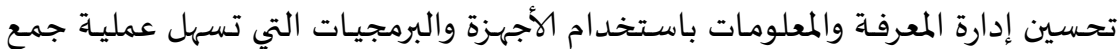

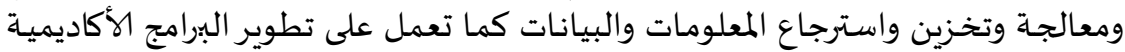
والفنية التي تستخدم في إيجاد الميزة التنافسية.

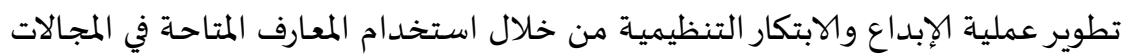

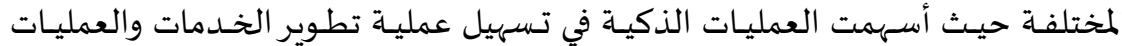
التعليمية والإدارية وطرق ووسائل التعليم والتعلم. تسهيل عملية إدارة التغيير في النظام التعليهي من خلال الأدوات التكنولوجية مما يؤدي إلى تحسين أداء الجامعات وزيادة كفاءتها وفعاليتها في تحقيقها لأهدافيات النها. العمل على تطوير الخدمات المميزة والجديدة من خلال بنـاء القواعد المعرفيـة والببرامج

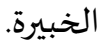

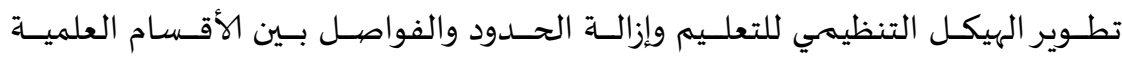

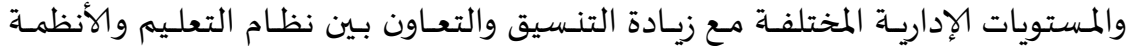
الاجتماعية والاقتصادية الأخرى في تنفيذ الأعمال.

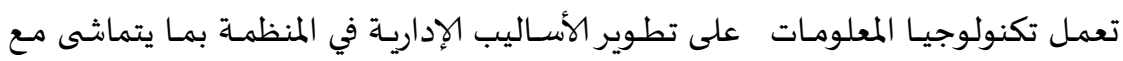
استراتيجيات الإدارة الحديثة في التغيير والقيادة. 


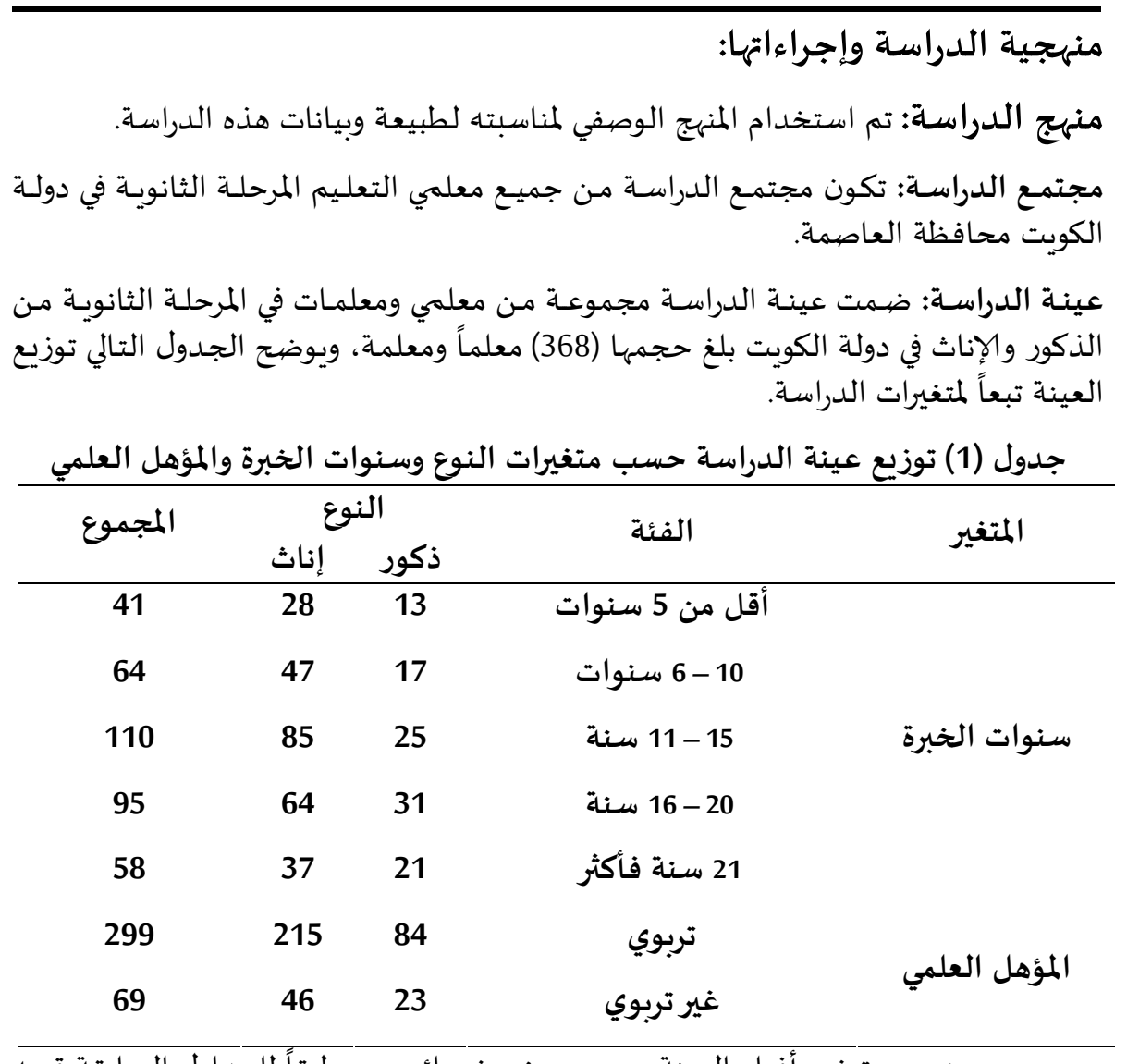

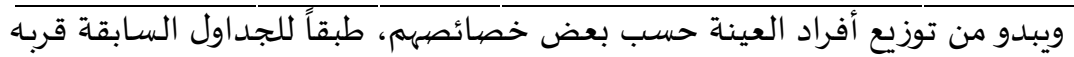

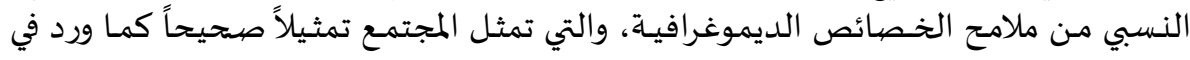

إحصائيات وزارة التربية في دولة الكويت.

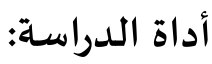

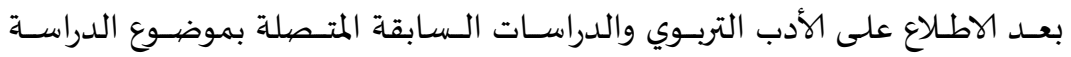

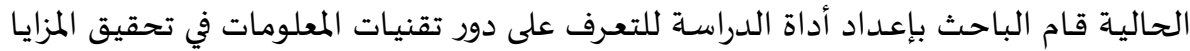

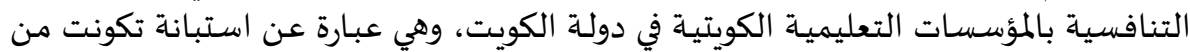

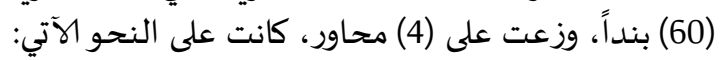

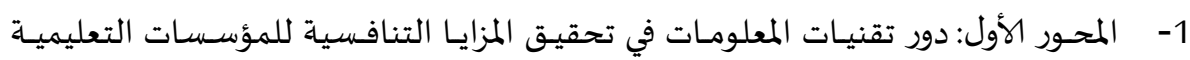
الكويتية فيما يتعلق بالمعلم ويتكون من (15) بندا.

2- المحـور الثـاني: دور تقنيـات المعلومات في تحقيق المزايـا التنافسية للمؤسسـات التعليميـة الكويتية فيما يتعلق بالطالب، ويتكون من (15) بندا..

3- المحور الثالث: دور تقنيـات المعلومـات في تحقيق المزايـا التنافسية للمؤسسـات التعليميـة

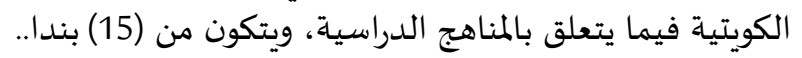




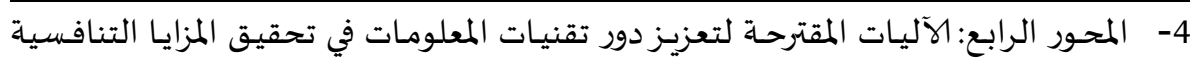

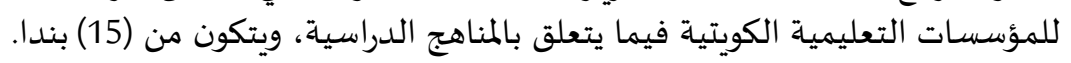

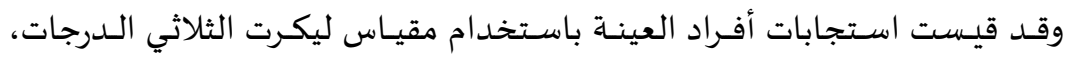

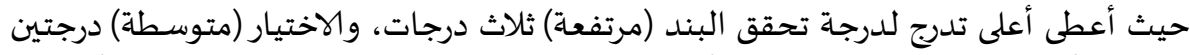

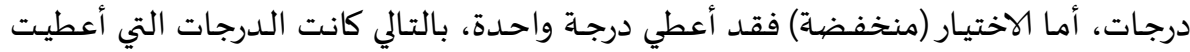

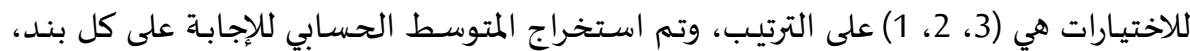
بحساب درجات المعلمين على هذا البند بالقسمة على على عدد أفراد الماد العينة.

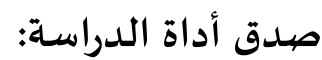

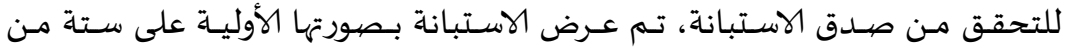

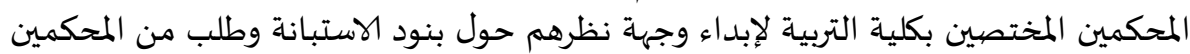

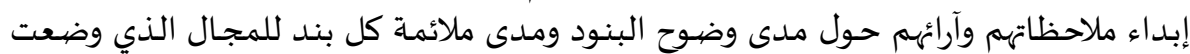

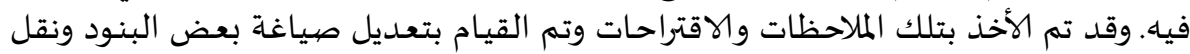

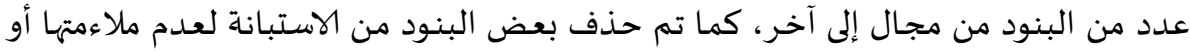
تكراراها بصيغة أخرى لتصل البنود الخداة في صورتها النهائية إلى (60) بندا.

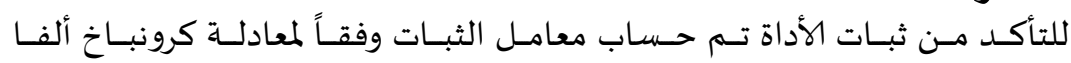

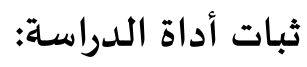
Cronbach (Alpha)

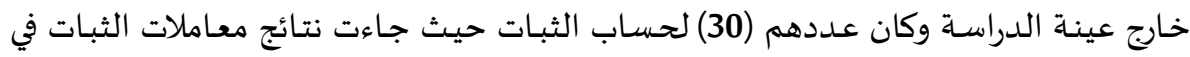

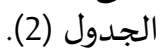

جدول (2) قيم معامل ثبات ألفا كرونباخ لمحاور الدراسة والأداة ككل

\begin{tabular}{|c|c|c|c|}
\hline ( ) معامل الثبات & 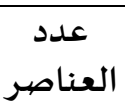 & المحور & \\
\hline 0.661 & 15 & 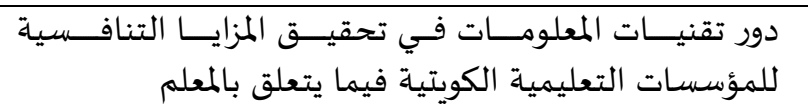 & 1 \\
\hline 0.828 & 15 & 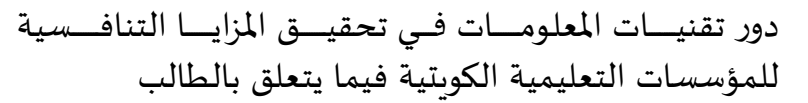 & 2 \\
\hline 0.807 & 15 & 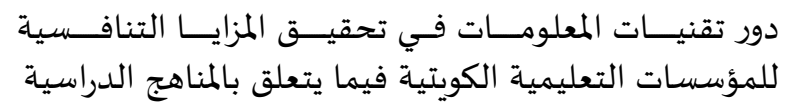 & 3 \\
\hline 0.965 & 15 & 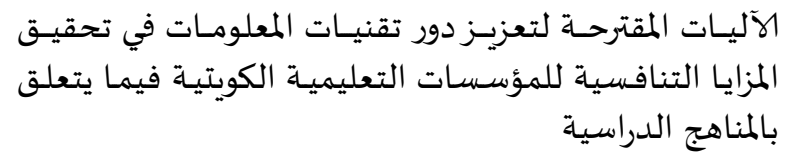 & 4 \\
\hline 0.848 & 60 & الثبات العام للدراسـة & \\
\hline
\end{tabular}




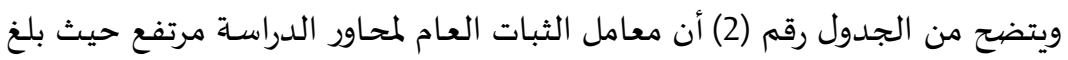

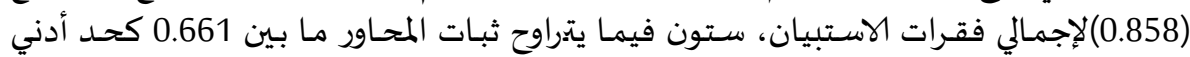

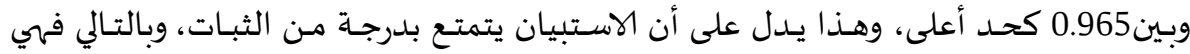

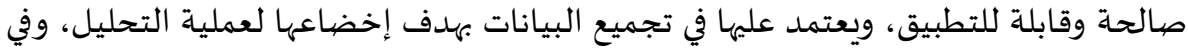

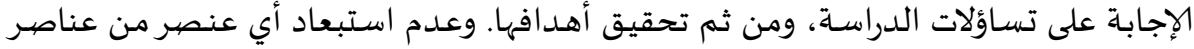

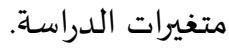

\section{تطبيق الأداة:}

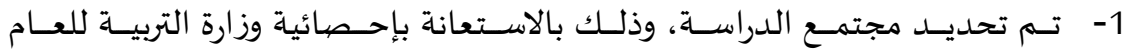

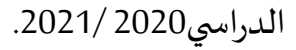

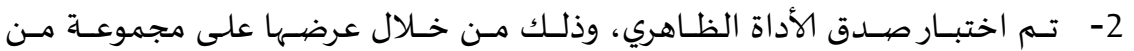

المحكمين.

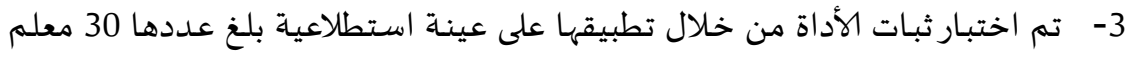

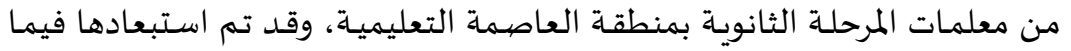

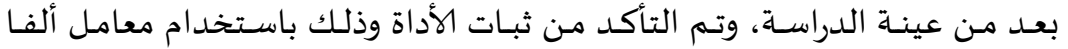

كرونباخ.

4- طبقت الدراسة على عينة الدراسـة والتي بلغ عددها (368) معلماً ومعلمة من معلمي

في المرحلة الثانوية في دولة الكويت، علئة الدراست

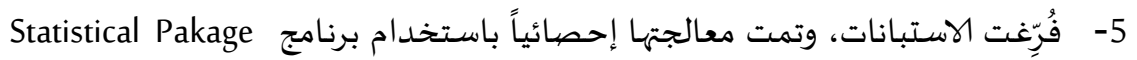

(SPSS) For Social Science

\section{الأساليب الإحصيائية:}

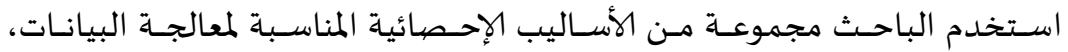

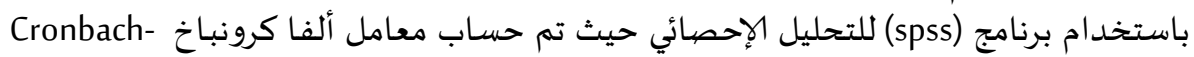

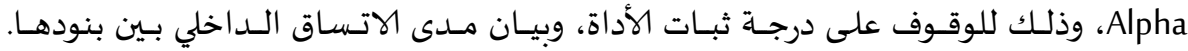

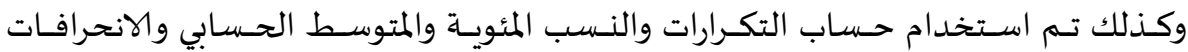

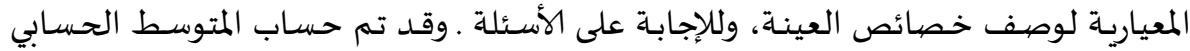

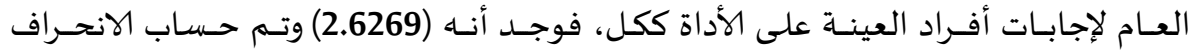

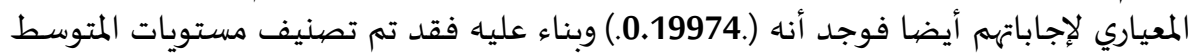

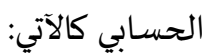

\section{توضيح مقياس ليكرت الثلاثي:}

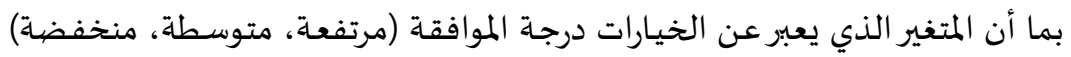

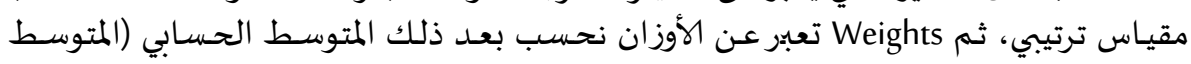

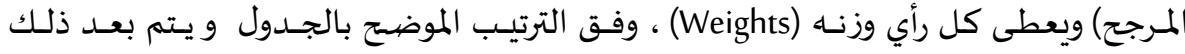

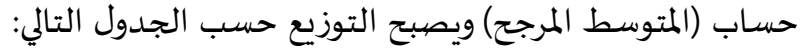




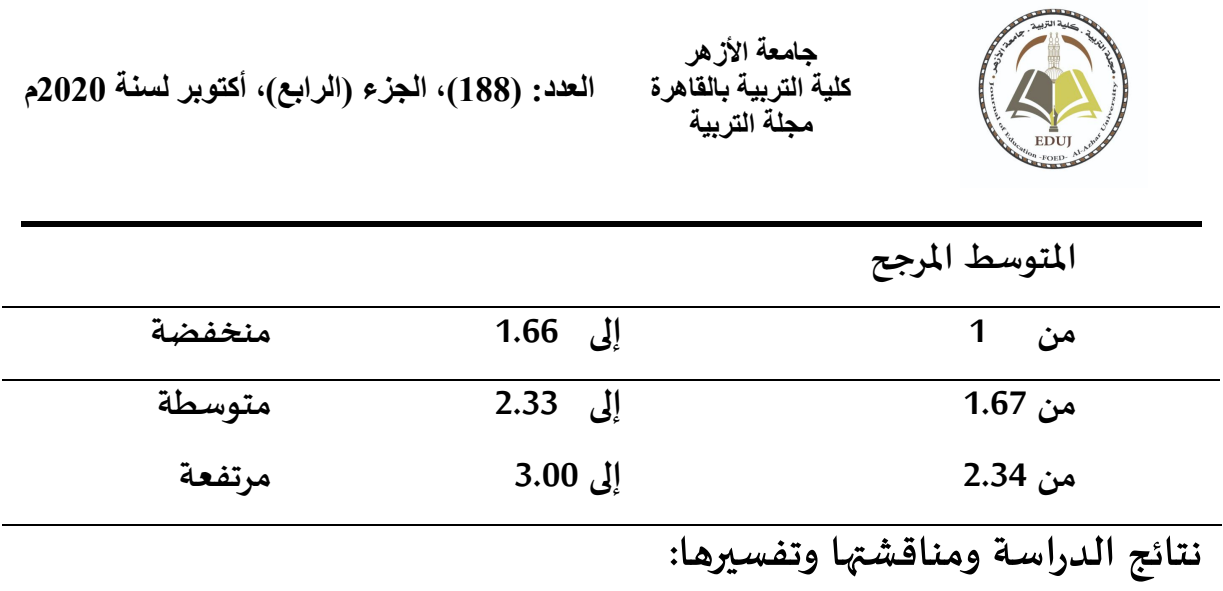

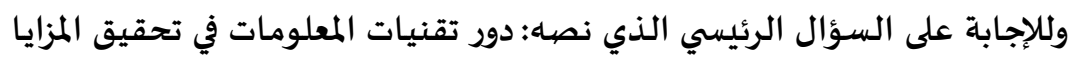

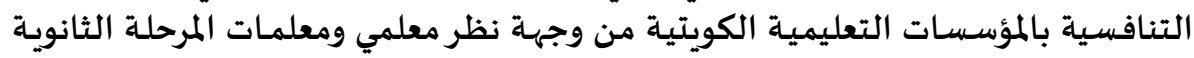

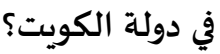

جدول (3) المتوسطات الحسابية والانحرافات المعيارية ومتوسطات الرتب ومربع كاي

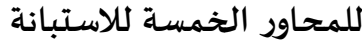

\begin{tabular}{|c|c|c|c|c|c|}
\hline الترتيب & المعياري & المستوسطي & 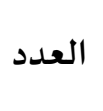 & اسم المحور & المحور \\
\hline 1 & .124560 & 2.9391 & 15 & 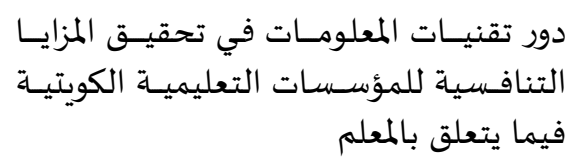 & الأول \\
\hline 4 & 0.45380 & 2.3743 & 15 & 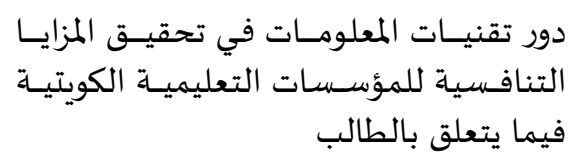 & الثاني \\
\hline 2 & 0.33782 & 2.6929 & 15 & 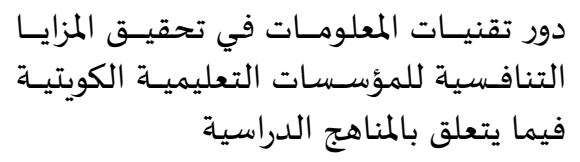 & الثالث \\
\hline 3 & .563190 & 2.4533 & 15 & 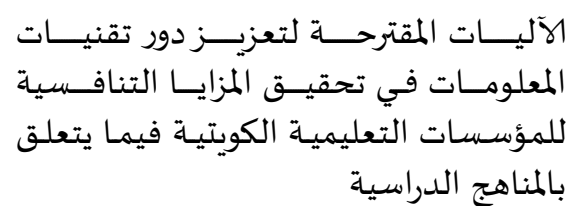 & الرابع \\
\hline & .206260 & 2.6149 & 60 & المتوسط العام لمستوي للإجمالي & \\
\hline
\end{tabular}




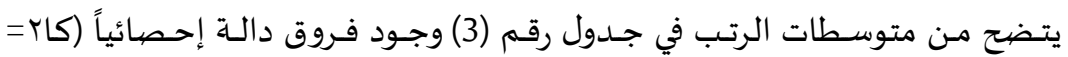

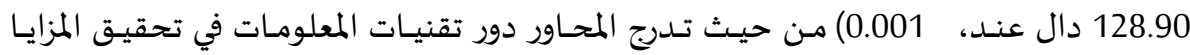

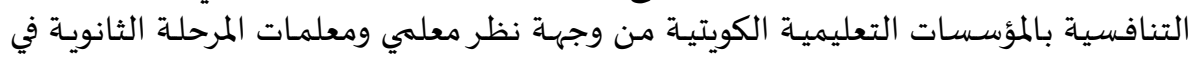

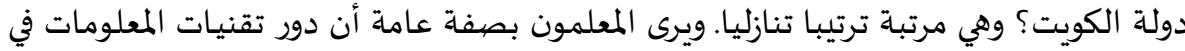

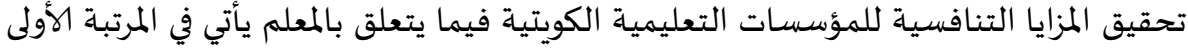

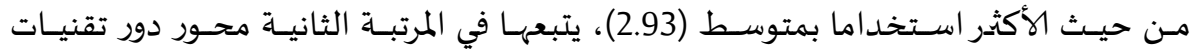

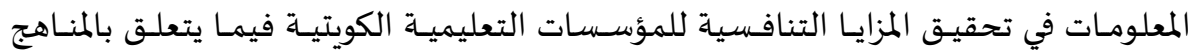

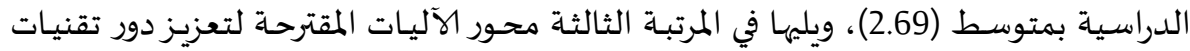

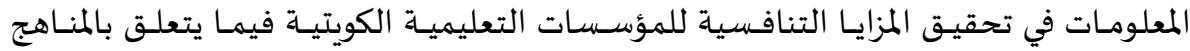

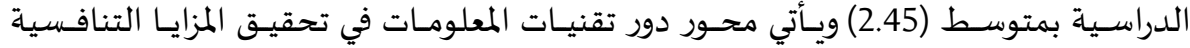
للمؤسسات التعليمية الكويتية فيما يتعلق بالطالب في المرتبة الرابعة بمتوسط (2.37)

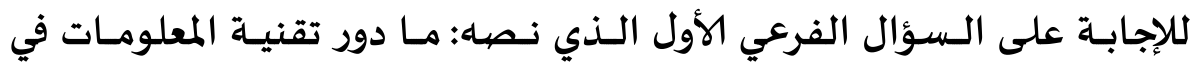
تحقيق المزايا التنافسية للمؤسسات التعليمية الكويتية فيما يتعلق بالمعلم من

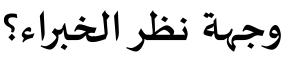

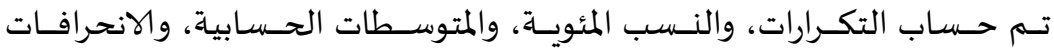

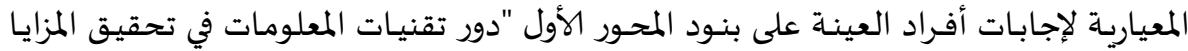

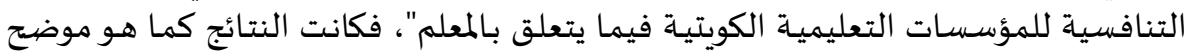
في الجدول (4) الآتي: جدول (4) التكرارات والنسب المئوية والمتوسطات الحسابية والانحرافات المعيارية لإجابات

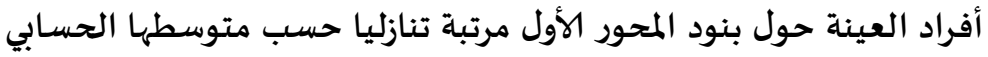

\begin{tabular}{|c|c|c|c|c|c|c|c|c|}
\hline \multirow[b]{2}{*}{ الأتجاه } & \multirow[b]{2}{*}{ الترتيب } & \multirow[b]{2}{*}{ المعياري } & \multirow[b]{2}{*}{ المرجح } & \multicolumn{3}{|c|}{ دراجة الموافقة أفراد العينة } & \multirow[b]{2}{*}{ مقياس } & \multirow{2}{*}{ 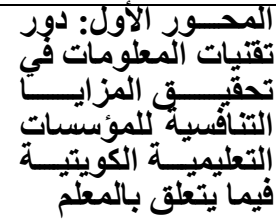 } \\
\hline & & & & منذفض & متوسطة & مرتفعة & & \\
\hline \multirow{2}{*}{ مرتفعة } & \multirow{2}{*}{1} & \multirow{2}{*}{0.074} & \multirow{2}{*}{2.99} & o & 2 & & 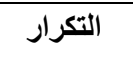 & المعلومــــاتِ \\
\hline & & & & $\% 0$ & $\% 0.5$ & $\% 99.5$ & النسبة \% & العلمية. \\
\hline \multirow{2}{*}{ مرتفعة } & \multirow[b]{2}{*}{11} & \multirow[b]{2}{*}{0.374} & \multirow{2}{*}{2.91} & 11 & 10 & 347 & التكرار & 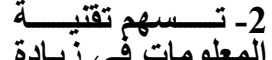 \\
\hline & & & & $\% 3.0$ & $\% 2.7$ & $\% 94.3$ & النسبة \% & للمعلم. المـزون \\
\hline \multirow[b]{2}{*}{ مرتفعة } & \multirow[b]{2}{*}{10} & \multirow[b]{2}{*}{0.338} & \multirow[b]{2}{*}{2.92} & 8 & 12 & 348 & الت التكرار & 3- تمكــن تقتيــــــة \\
\hline & & & & $\% 2.2$ & $\% 3.3$ & $\% 94.6$ & النسبة \% & 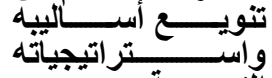 \\
\hline مرتفعة & 3 & 0.164 & 2.98 & 2 & 2 & 364 & الت التكرار & 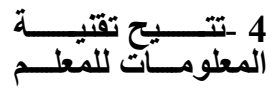 \\
\hline
\end{tabular}




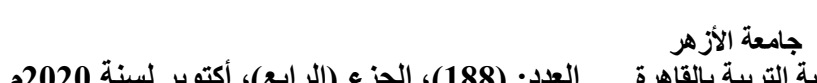

$$
\begin{aligned}
& \text { كلية التربية بالقاهرة العداد: (188)، الجزء (الرابع)، أكتوبر لسنة 2020م } \\
& \text { مجلة التربية }
\end{aligned}
$$

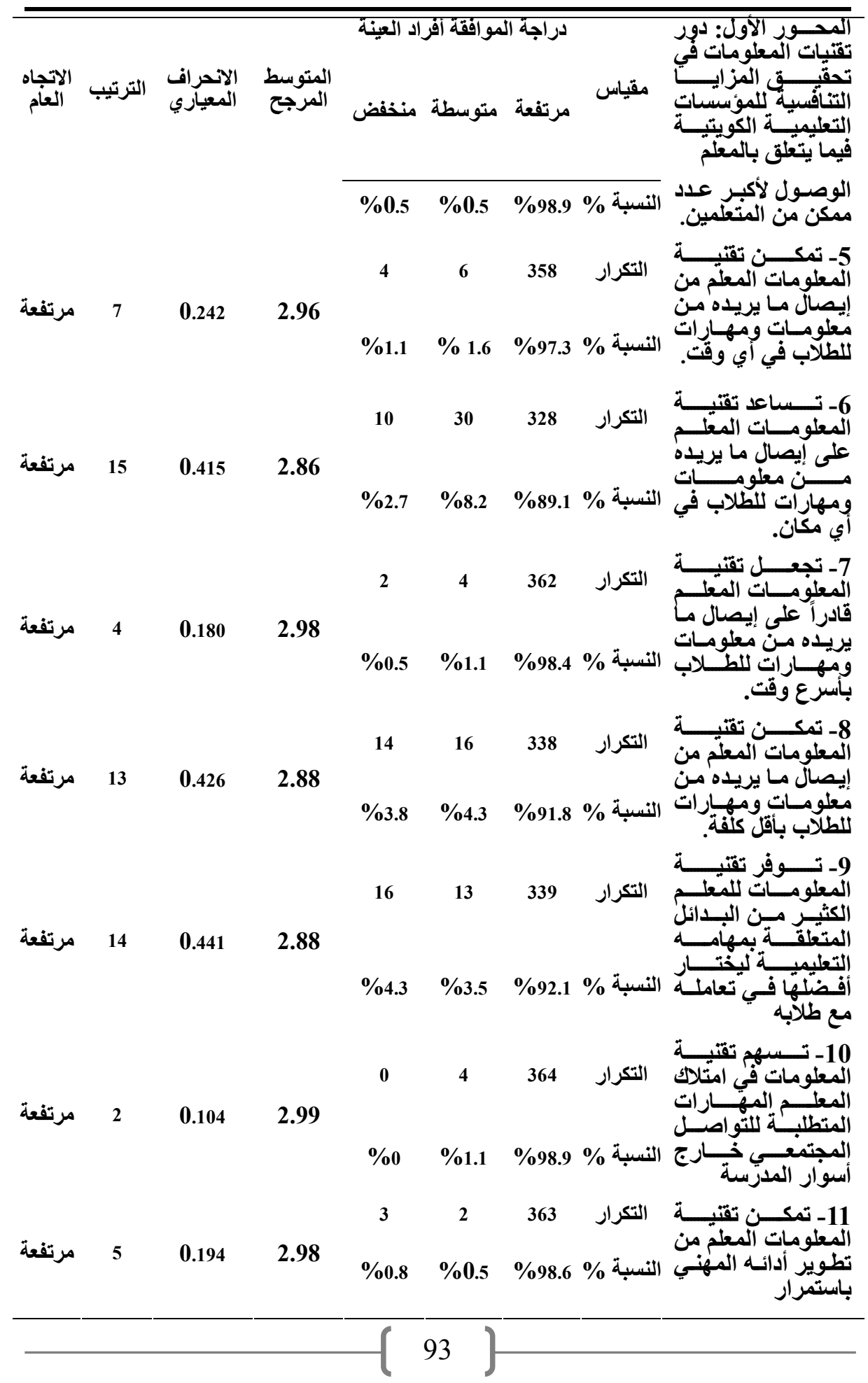




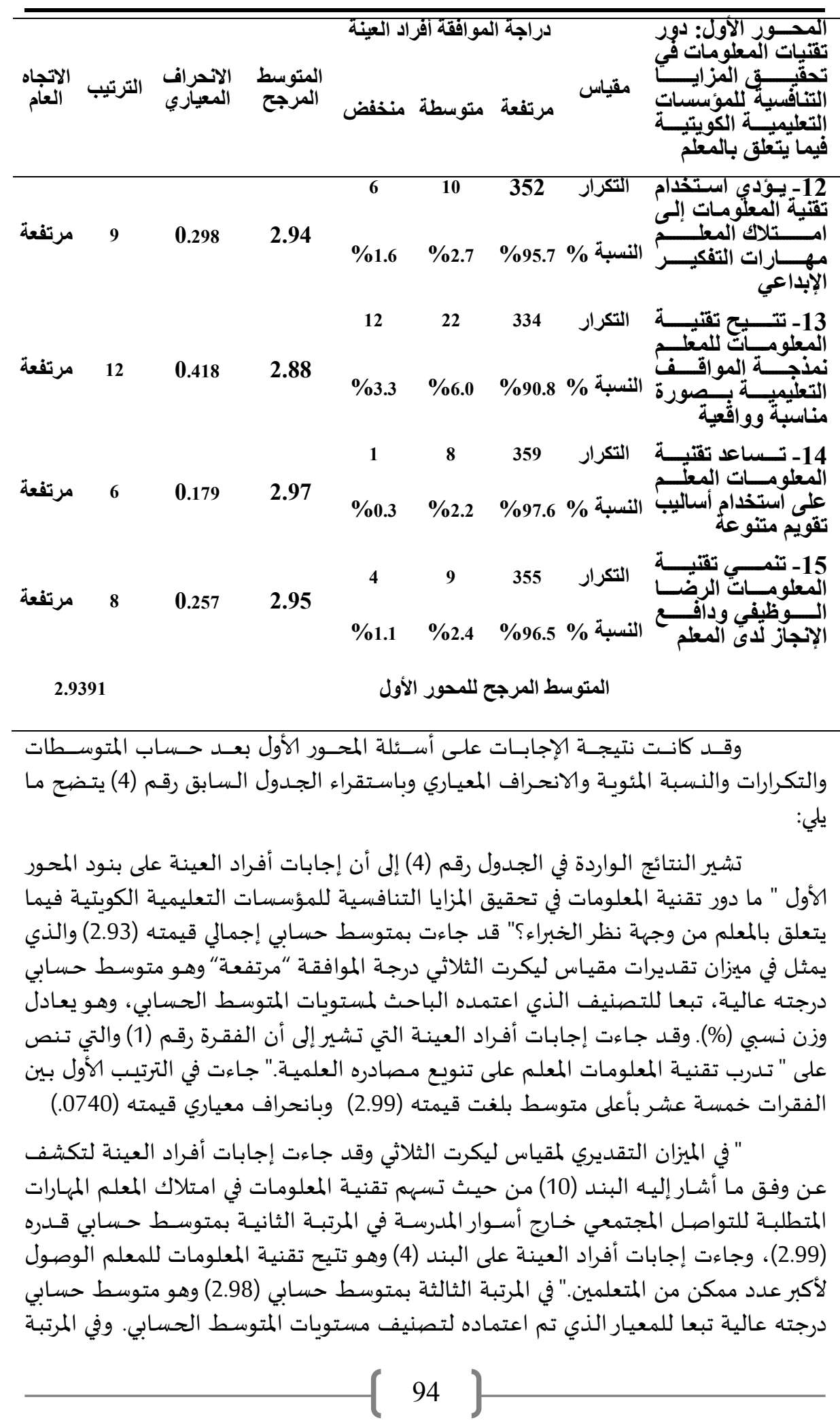




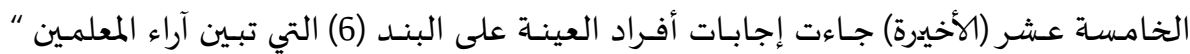

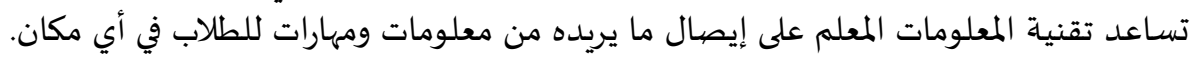

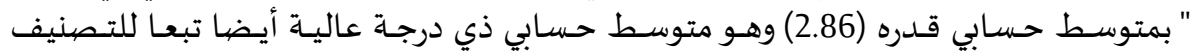

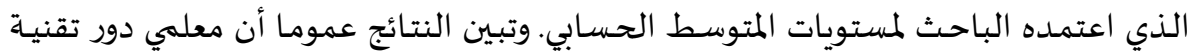

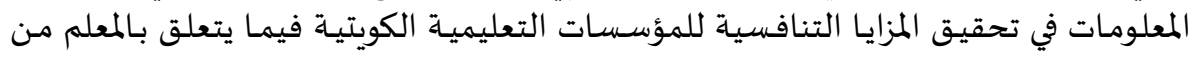

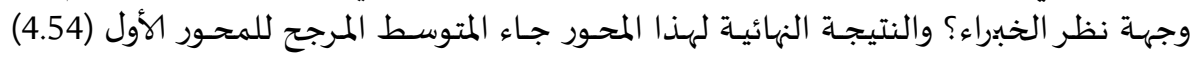

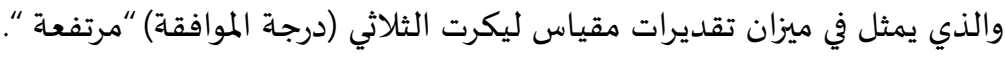

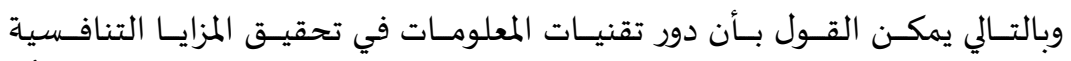

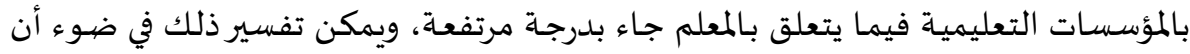

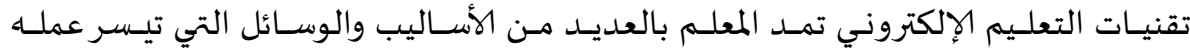

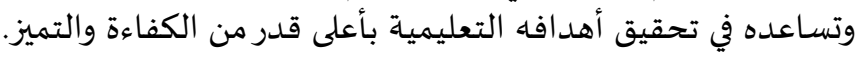

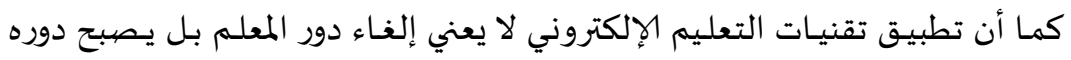

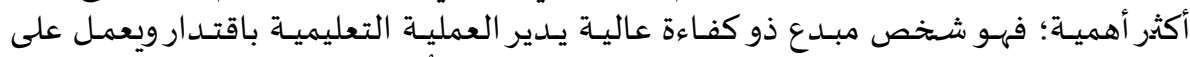

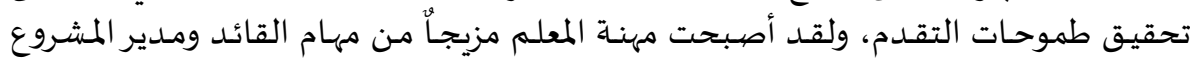

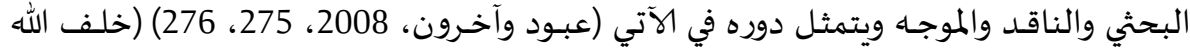

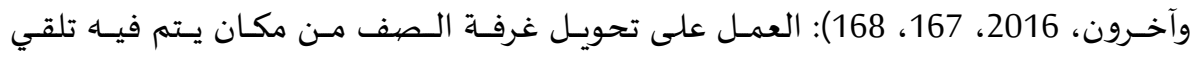

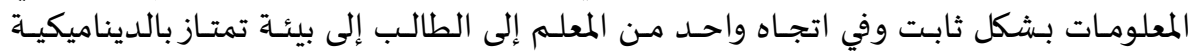

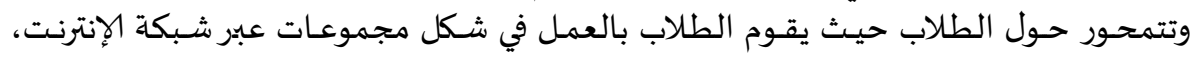

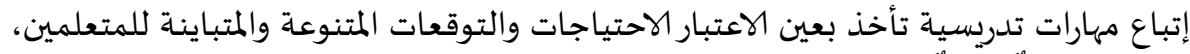

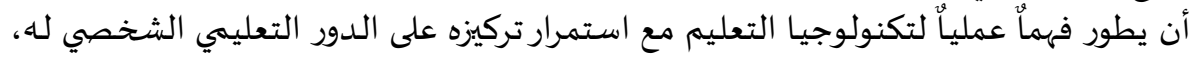

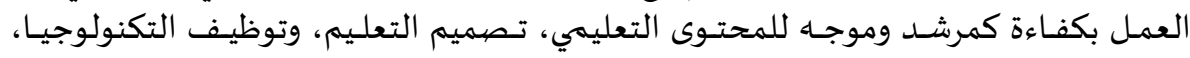

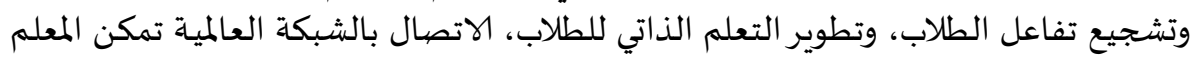

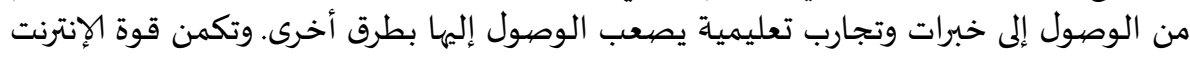

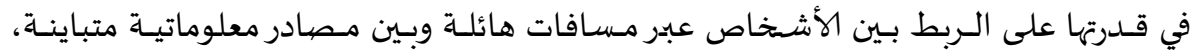

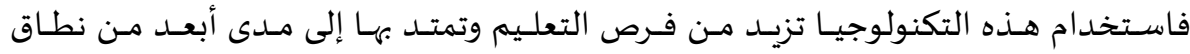

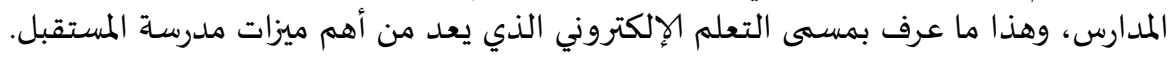

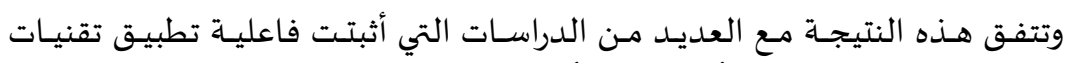

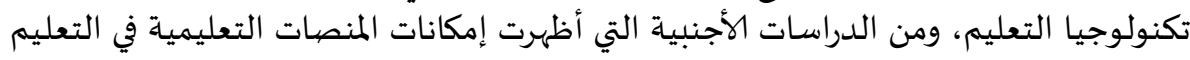
دراسة كل من سايزلوبيز (Saez Lopez, 2014)، ودراسة باتسيلا وآخرين(المين (Batsila, et.al, 2014).

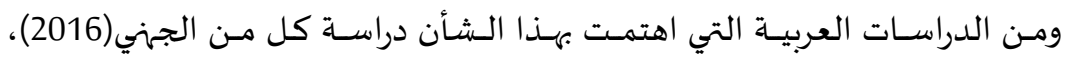

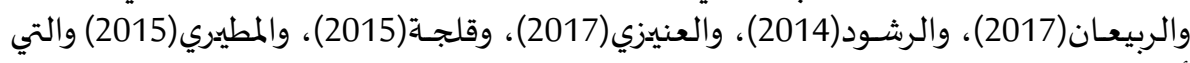

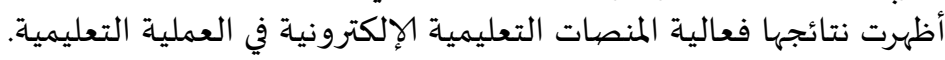




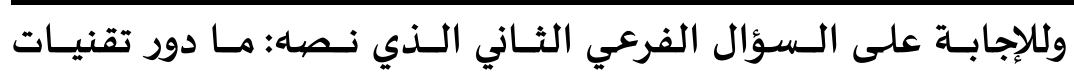

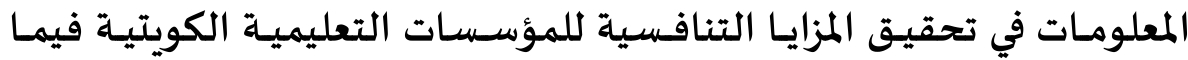

يتعلق بالطالب من وجهة نظر معلمي ومعلمات المرحلة الماتلة الثانوية؟

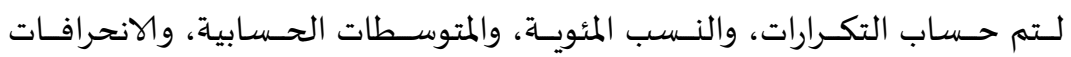

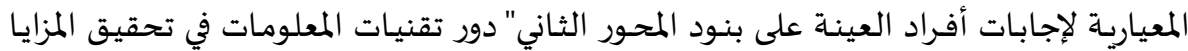

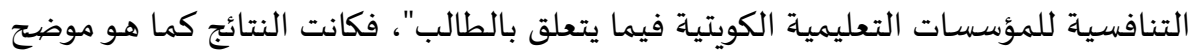
في الجدول (5) الآتي:

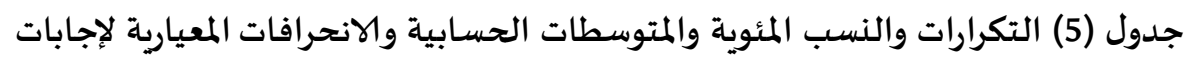

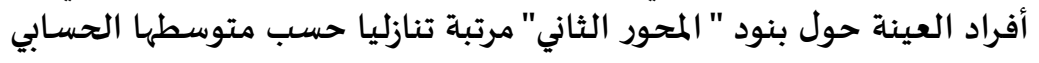

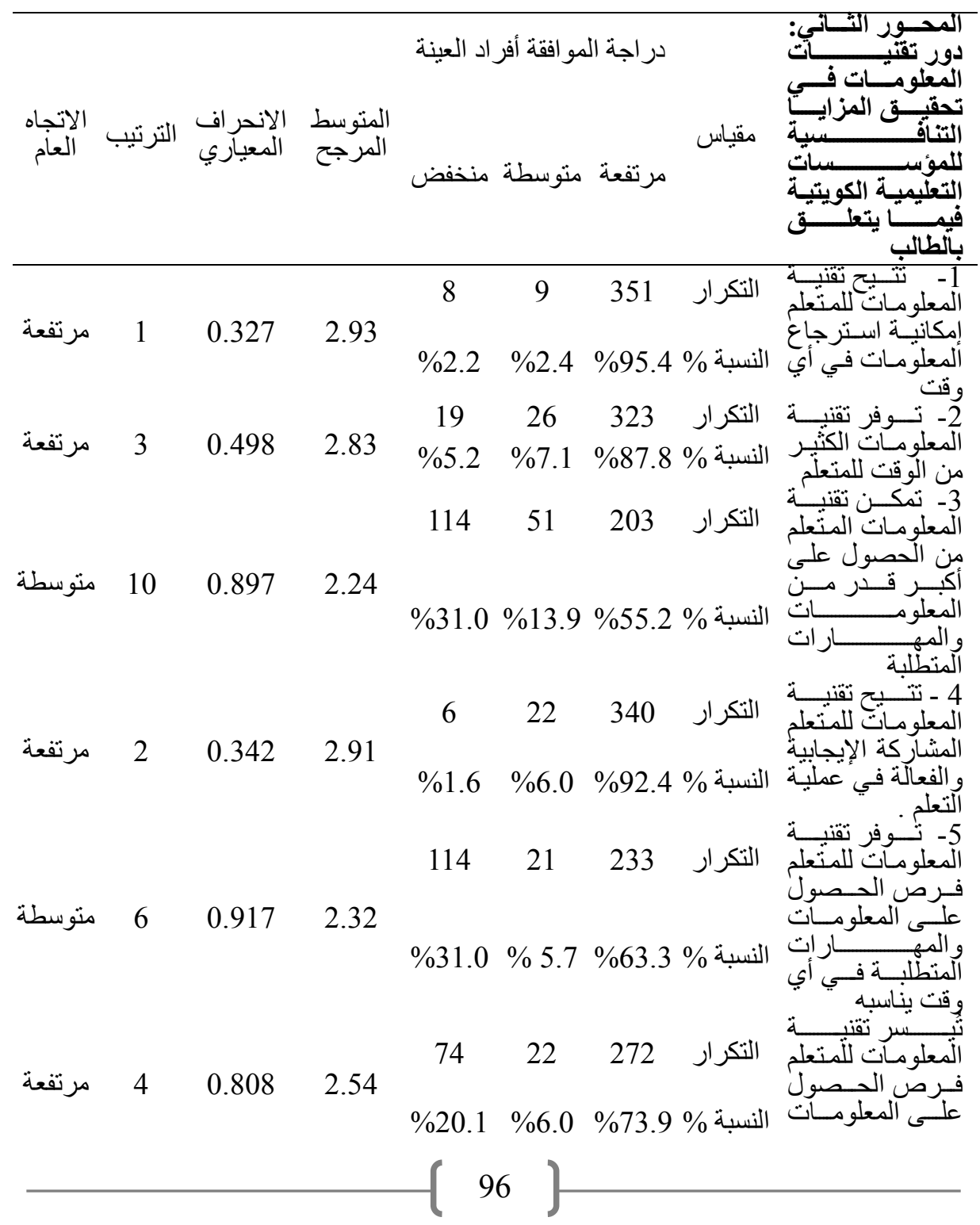




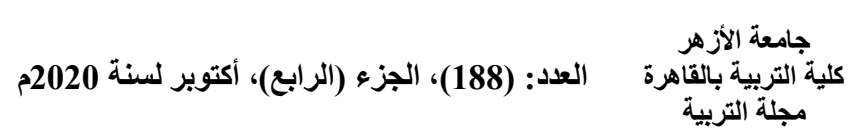

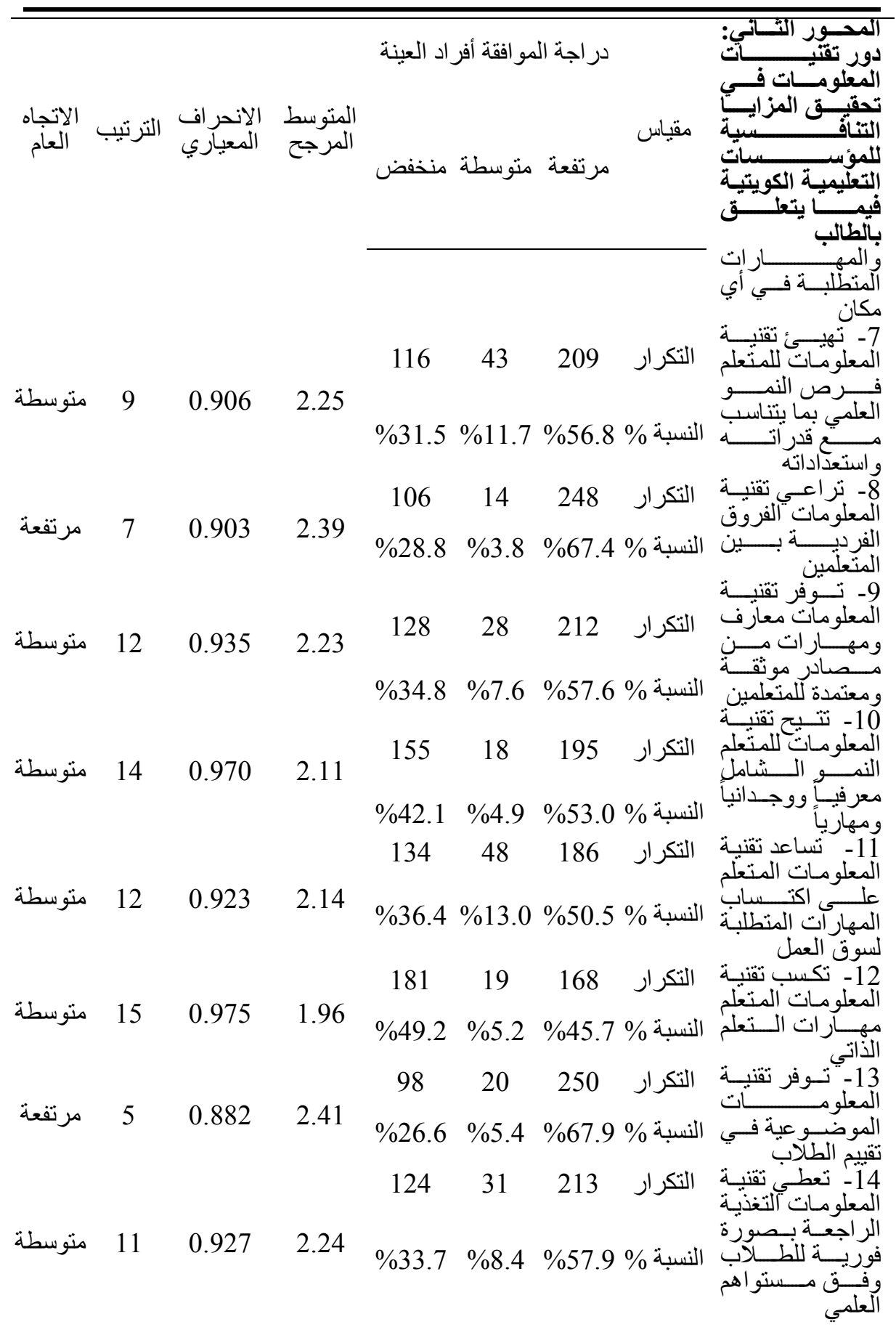




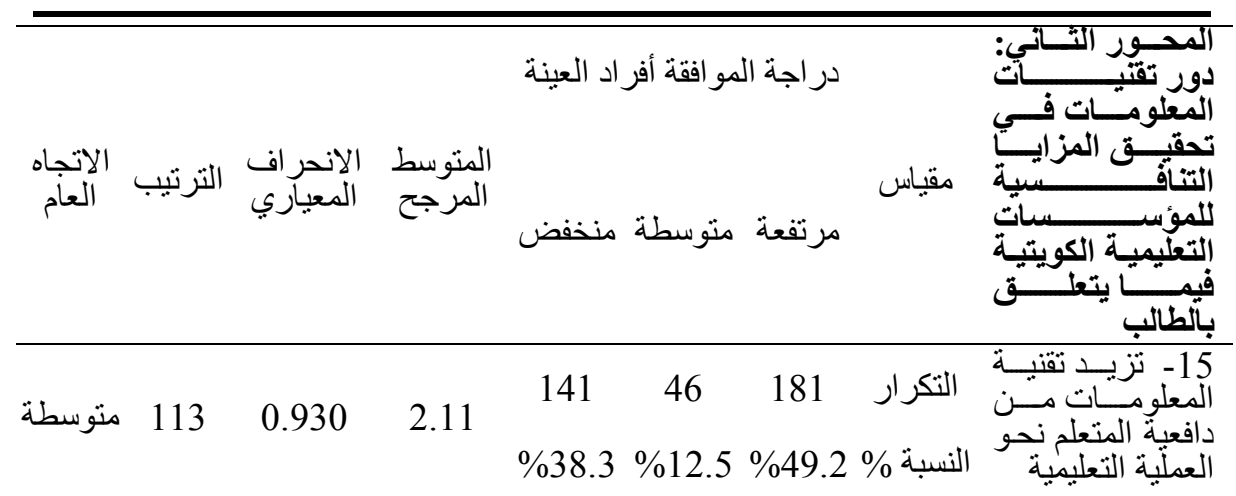

تشير النتائج الواردة في الجدول رقم (5) إلى أن إجابات أفراد العينة على بنود المحتور

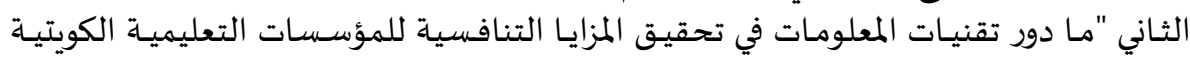

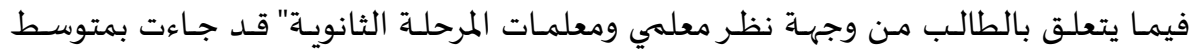

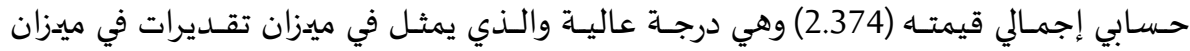

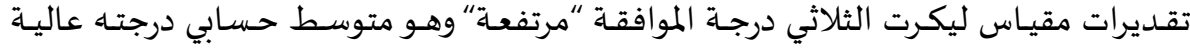

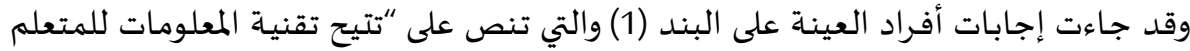

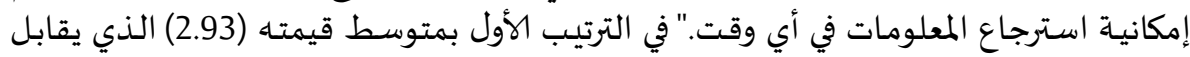

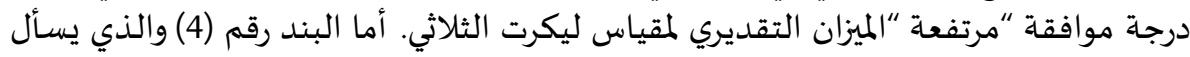

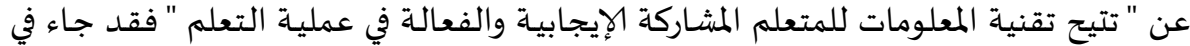

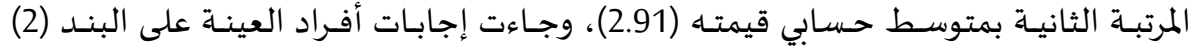

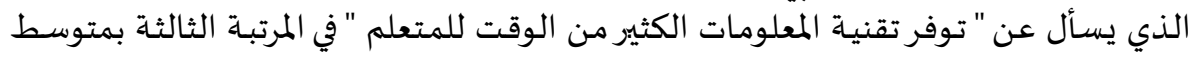

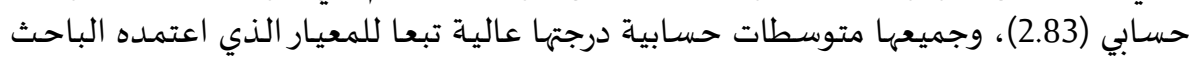

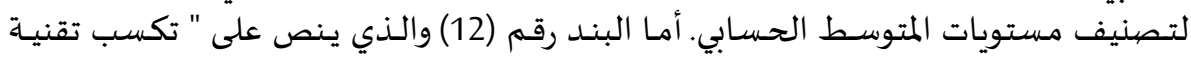

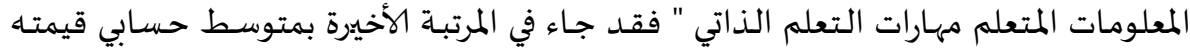

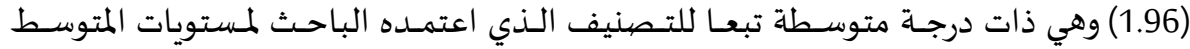

$$
\text { الحسابي. }
$$

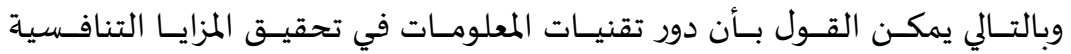

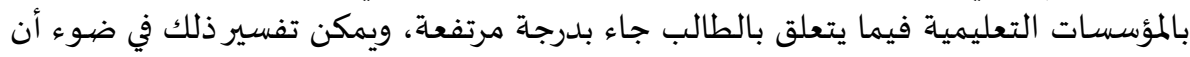
تقنيات التعليم الإلكتروني تجعل المتعلم أكثر إيجابية وفاعلية في العملية التعاية التعليمية.

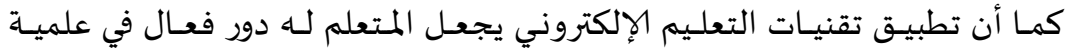

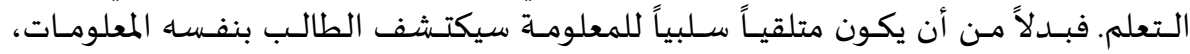

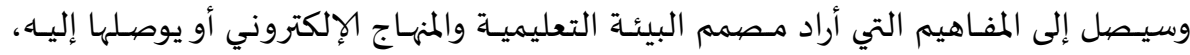

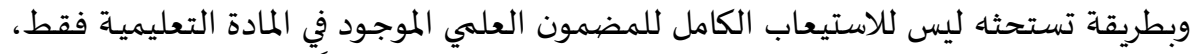

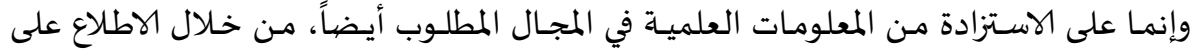
مصادر أخرى، كالإنترانت والإنترنت قواعد المعادمات المعلومات والبيانات أينما توفرت الماليات السلطي، 2004، 


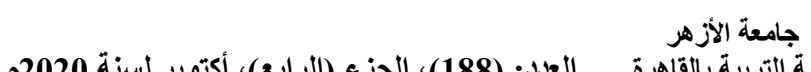

كما أن المتعلم من خلال تطبيق تقنيات التعليم الإلكتروني يقوم بالعديد من الأدوار

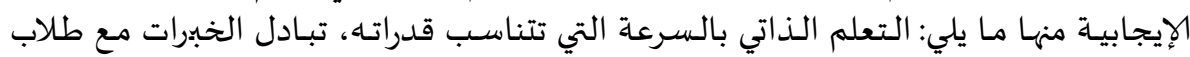

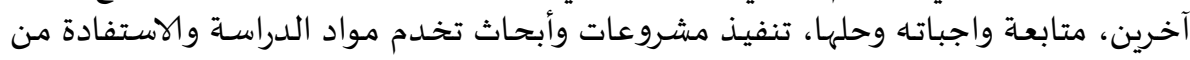

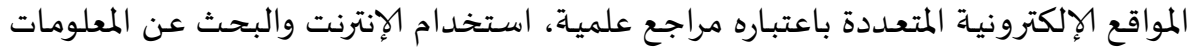

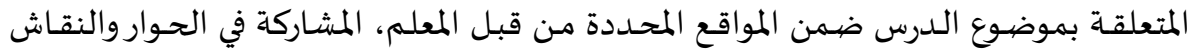

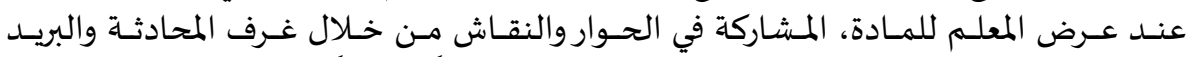

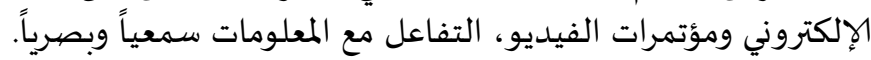

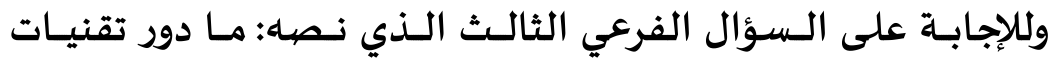

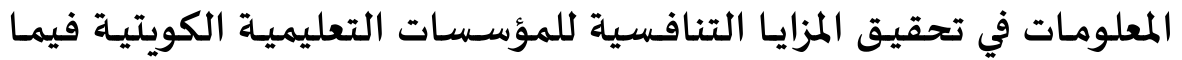

يتعلق بالمناهج الدراسية؟ فئو

تم حساب التكرارات، والنسب المئوية، والمتوسطات الحسابية، والانحرافات المعيارية

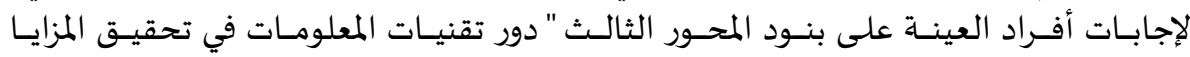

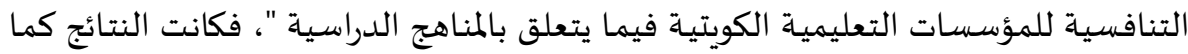
هو موضح في الجدول (6) الآتي:

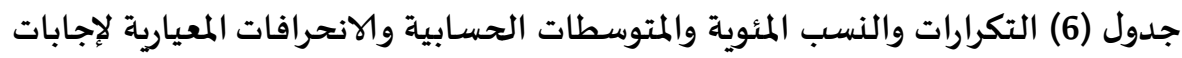

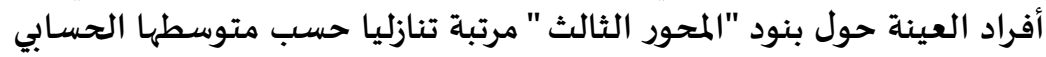

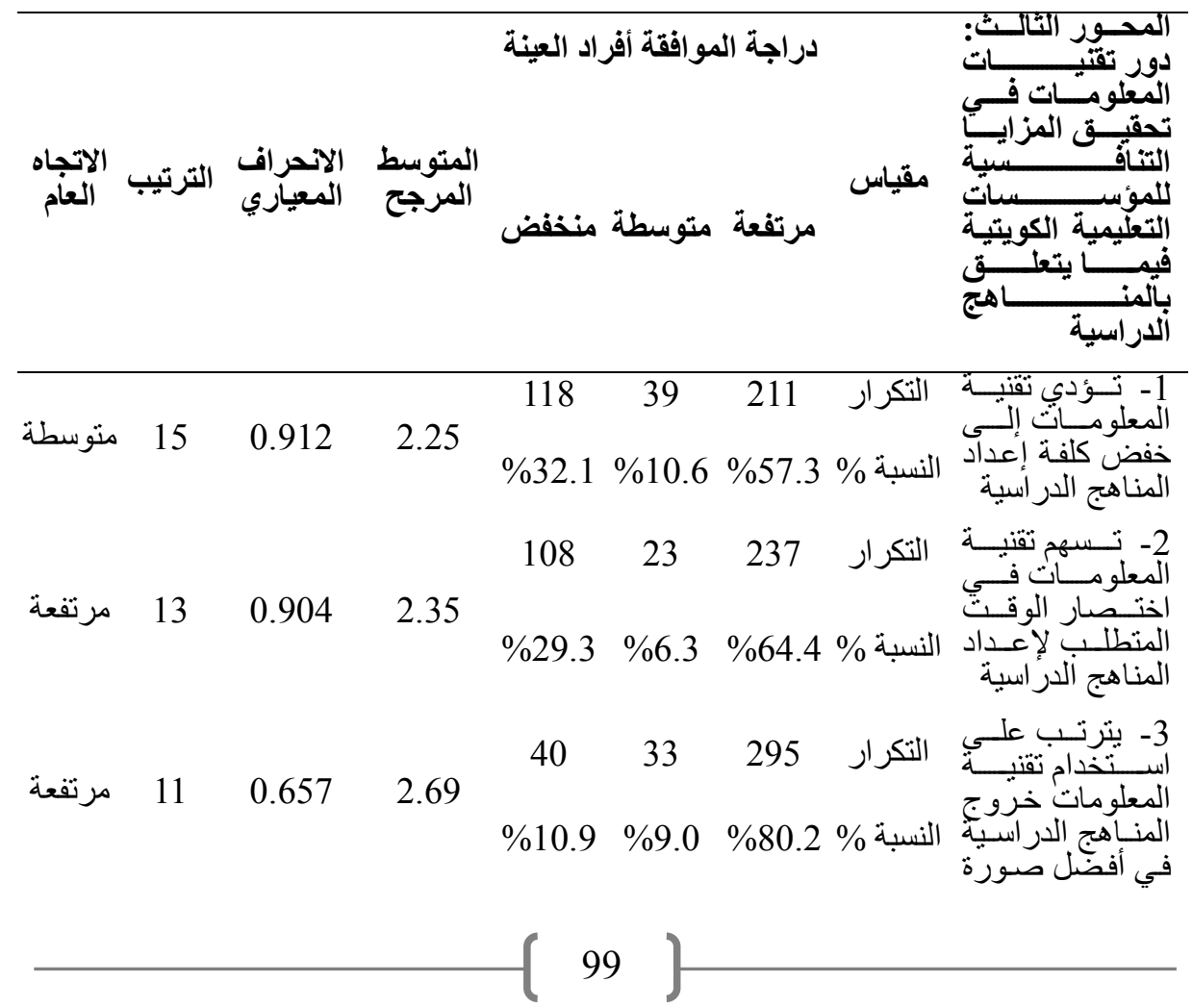




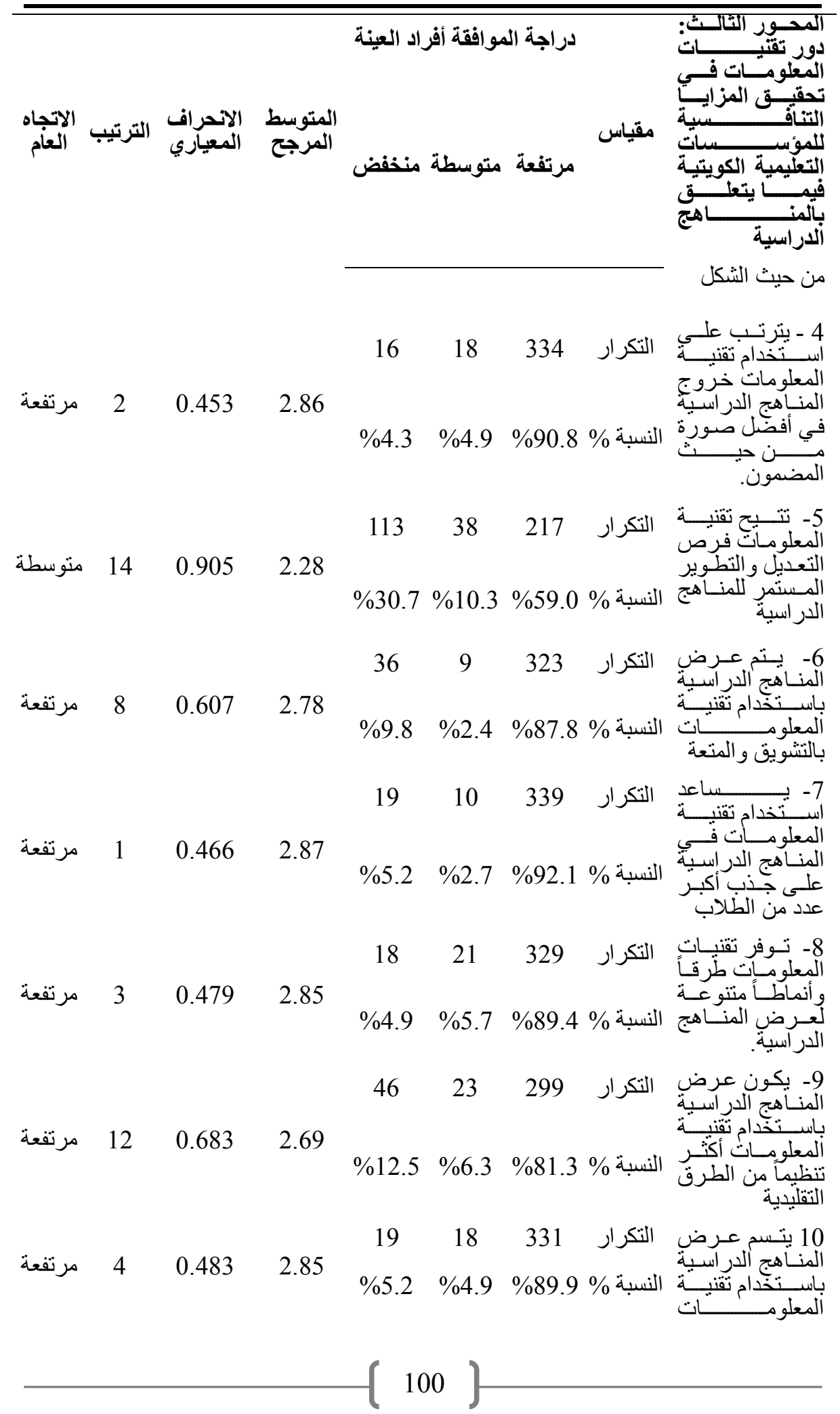




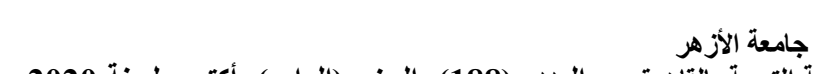

$$
\begin{aligned}
& \text { كلية التربية بالقاهرة العدد: (188)، الجزء (الرابع)، أكتوبر لسنة 2020م } \\
& \text { مجلة التربية }
\end{aligned}
$$

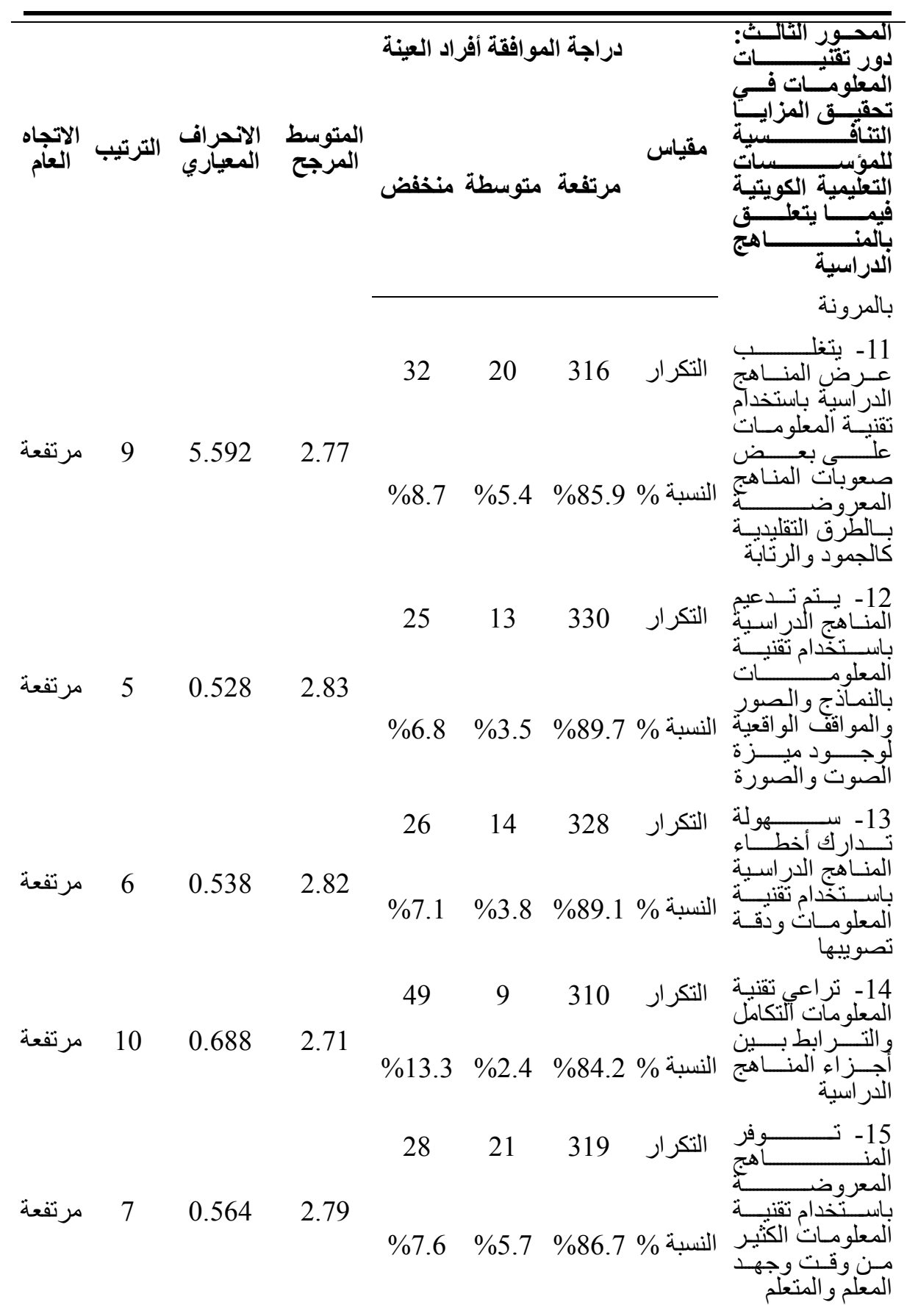


تشير النتائج الواردة في الجدول رقم (6) إلى أن إجابات أفراد العينة على بنود المعاد المحور

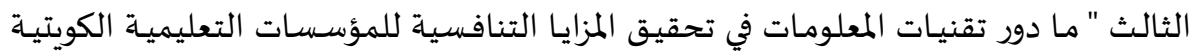

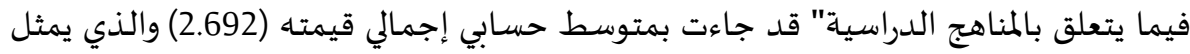

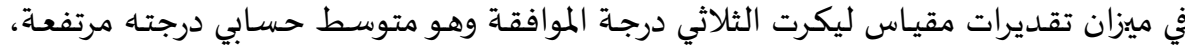

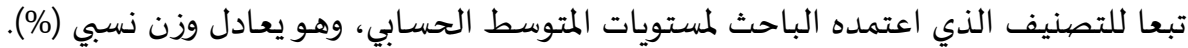

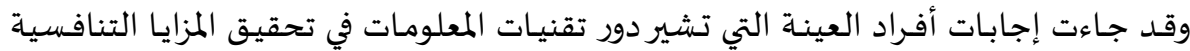

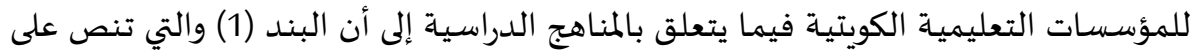

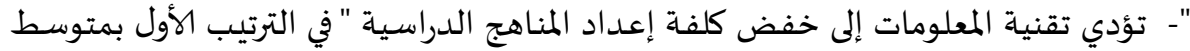

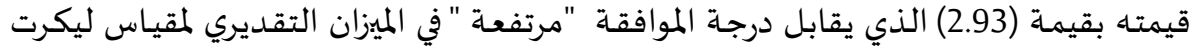

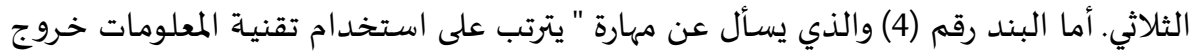

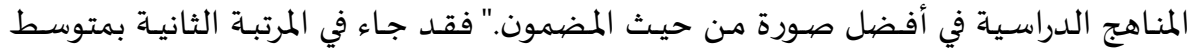

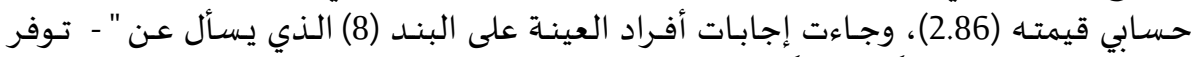

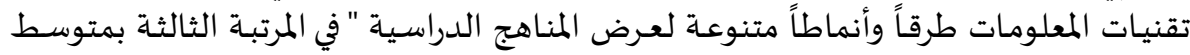

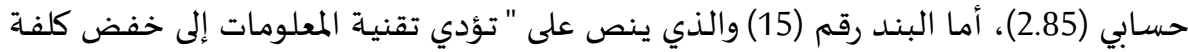

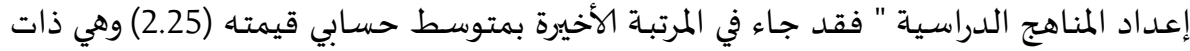

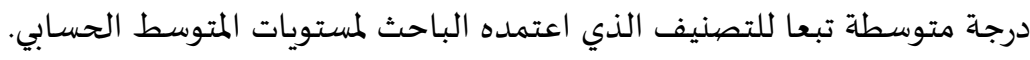

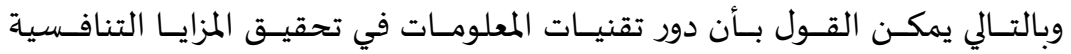

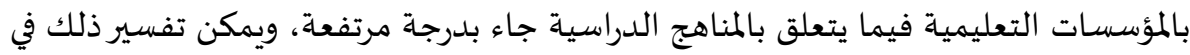

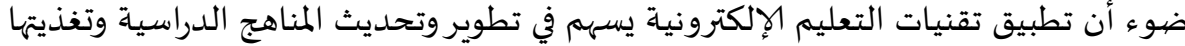
بالمؤثرات التي تجذب انتباه المتعلمين وتزيد من دافعيتهم للتعلم.

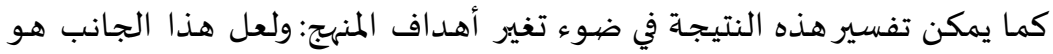

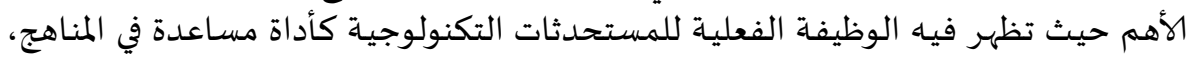

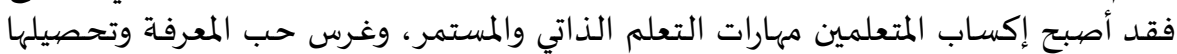
وكيفية توظيفها في عصر الانفجار المعرفي والمعلوماتى من أبرز الأهداف العامة للمناتئ المعاهج الدراسية.

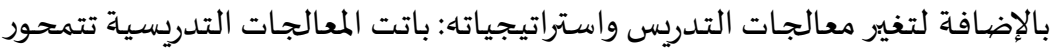

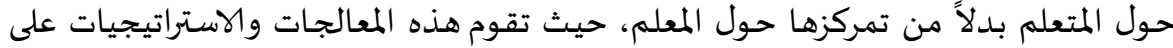

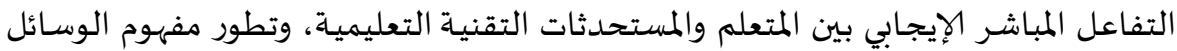

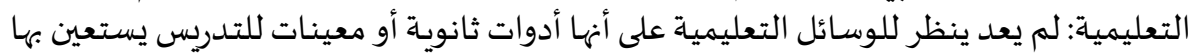

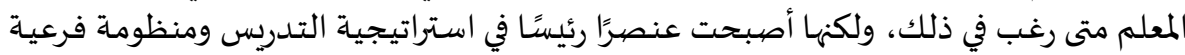

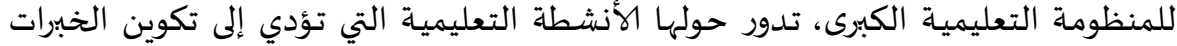




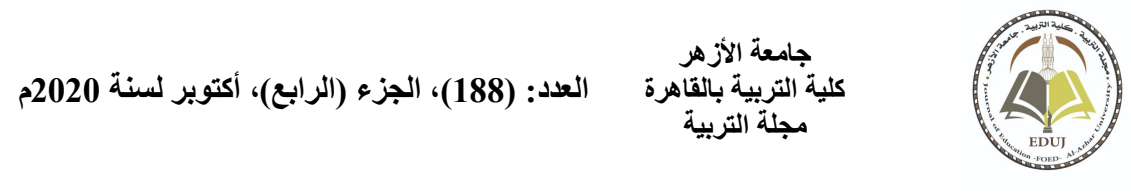

ولإجابة على السؤال الفرعي الرابع الذي نصيه: الآليات المقترحة لتعزيز

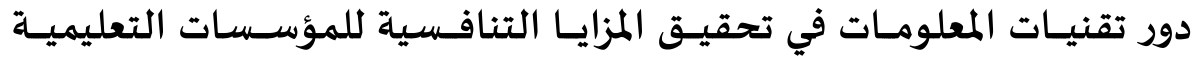

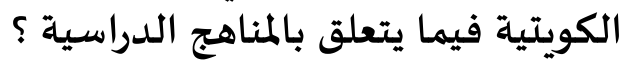

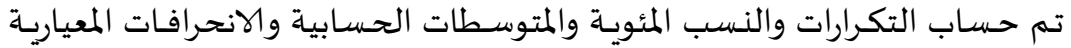

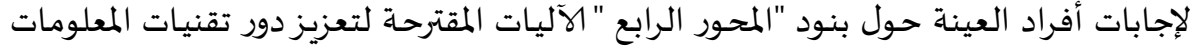

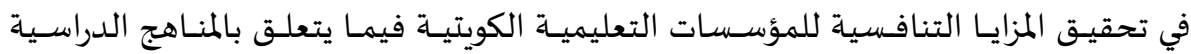
وجاءت كما هو موضح في الجدول المنافية (7) كالآتي:

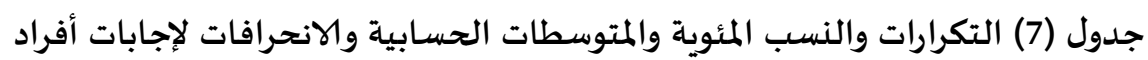

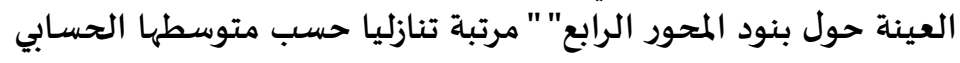

\begin{tabular}{|c|c|c|c|c|c|c|c|c|}
\hline \multirow{4}{*}{ الاتجاه } & \multirow{4}{*}{ الترتيب } & \multirow{2}{*}{\multicolumn{2}{|c|}{ المرجح المعياري الاتحراف }} & \multicolumn{4}{|c|}{ دراجة الموافقة أفراد العينة } & \multirow{2}{*}{ 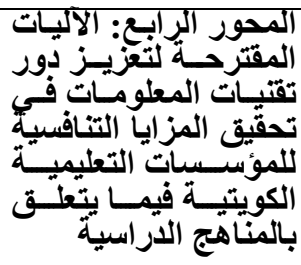 } \\
\hline & & & & \multicolumn{4}{|c|}{ مرتفعة متوسطة منخفض } & \\
\hline & & 0.695 & 2.36 & & & & & 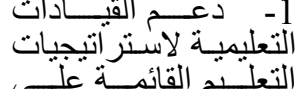 \\
\hline & & & & $\% 12.5$ & $\% 38.6$ & $\% 48.9$ & النسبة \% & تقنيات" أك \\
\hline & & & & 30 & 106 & 232 & الت التكر ار & 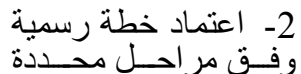 \\
\hline مرتفعة & 3 & 0.642 & 2.55 & $\% 8.2$ & $\% 28.8$ & $\% 63.0$ & النسبة \% & 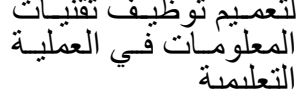 \\
\hline & & & & 26 & 92 & 250 & التكر ار & 3- تــــدريب وتأهيــلـل \\
\hline مرنفعه & 2 & 0.617 & 2.61 & $\% 7.1$ & $\% 25.0$ & $\% 67.9$ & النسبة \% & \\
\hline تق تفة & 10 & 0677 & 247 & 37 & 122 & 209 & التكر ار & 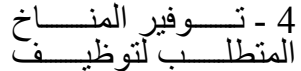 \\
\hline & & 0.012 & 2. & $\% 10.1$ & $\% 33.2$ & $\% 56.8$ & النسبة \% & العنلية التعليمية المعـات في \\
\hline & & & & 34 & 97 & 237 & الت التكر ار & 5- تطوئت البنية التحتية \\
\hline & & & & $\% 9.2$ & $\% 26.4$ & $\% 64.4$ & النسبة \% & 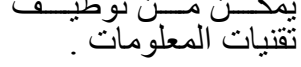 \\
\hline مرتفعة & 12 & 0.609 & 2.43 & 23 & 163 & 182 & التكر ار & 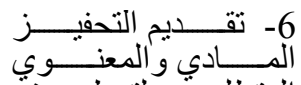 \\
\hline & & & & $\% 6.3$ & $\% 44.3$ & $\% 49.5$ & النسبة \% & 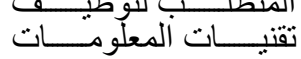 \\
\hline
\end{tabular}




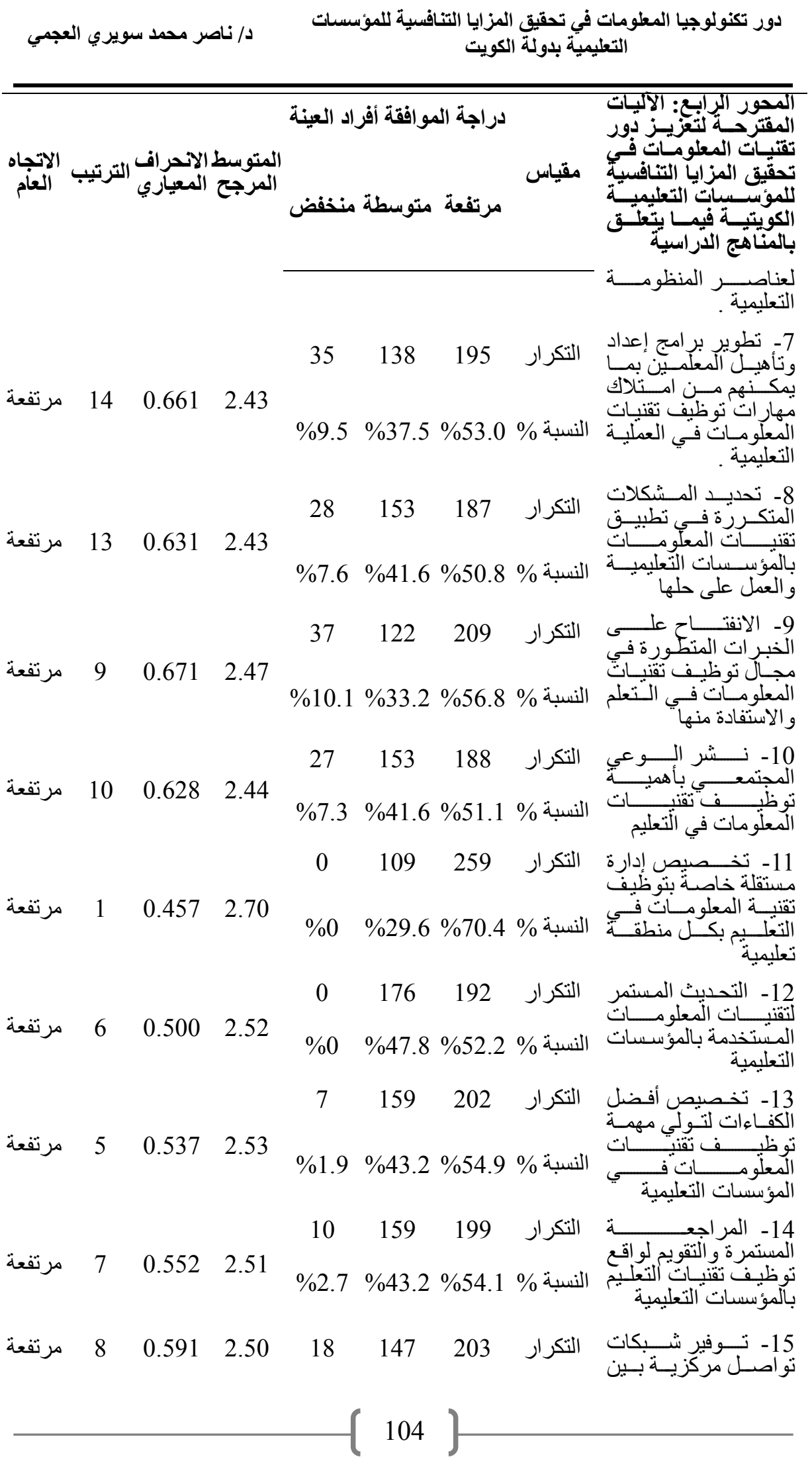




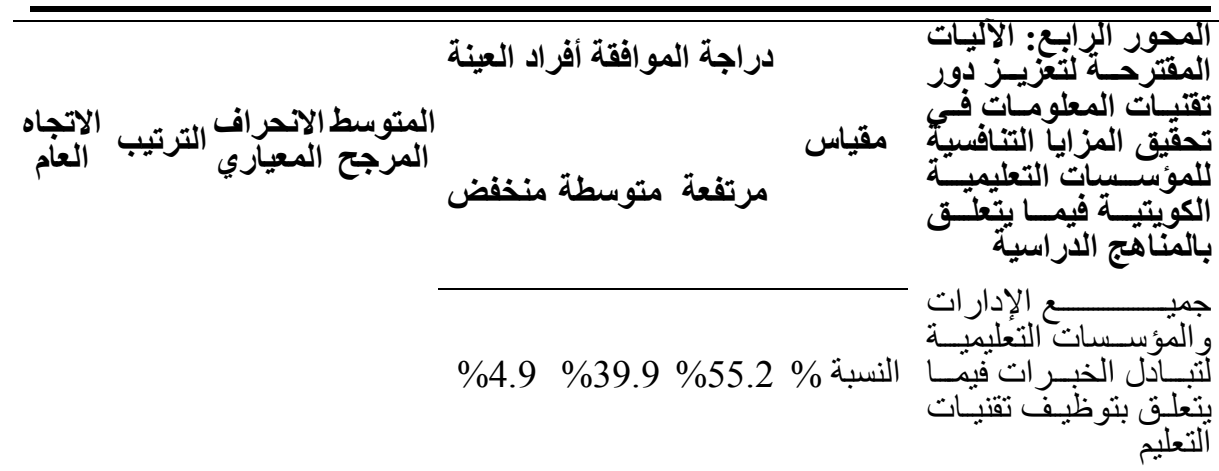

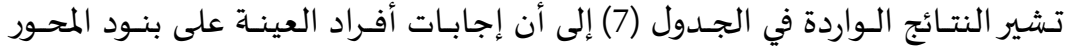

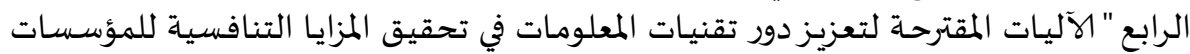

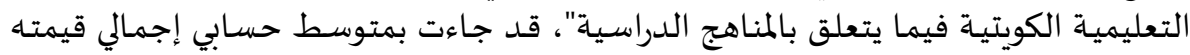

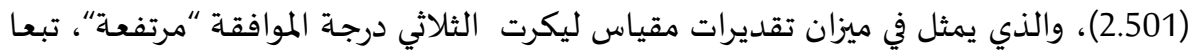

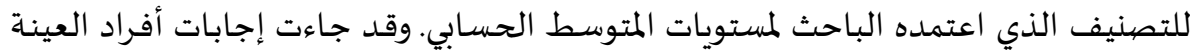

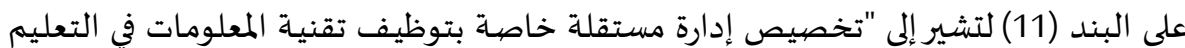

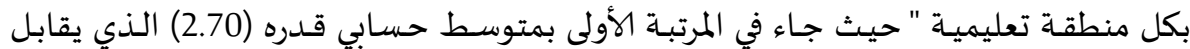

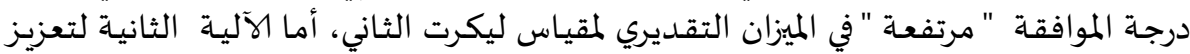

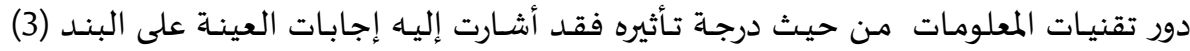

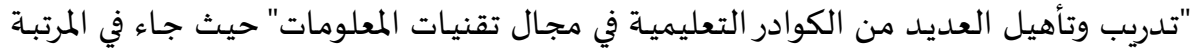

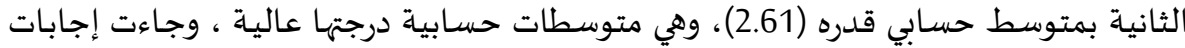

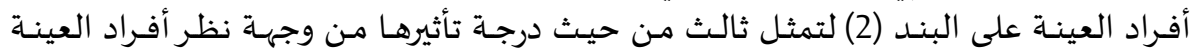

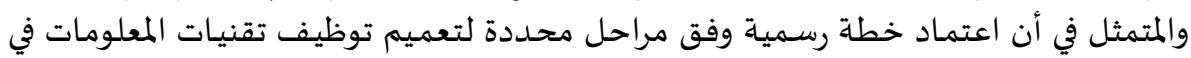

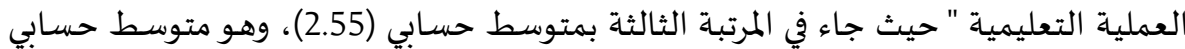
درجته مرتفعة تبعاً للمعيار الذي تم اعتماده لتصنيف المرتبة مستويات المتوسط الحسابي.

وفي المرتبة الرابعة عشر (قبل الأخيرة) جاءت إجابات أفراد العينة على البند (7) التي

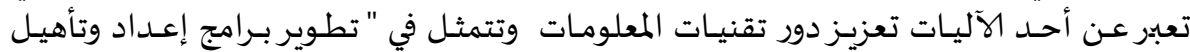

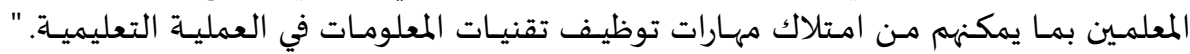

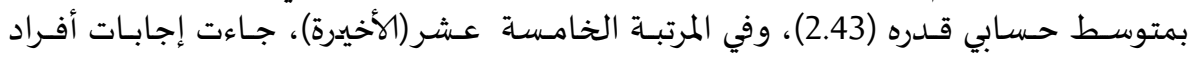

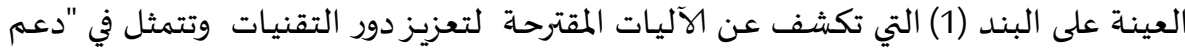

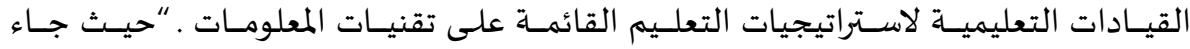

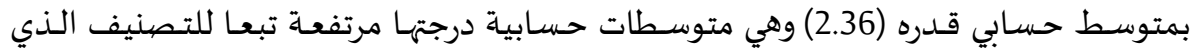
اعتمده الباحث لتصنيف مستويات المتوسط الحسابي. 


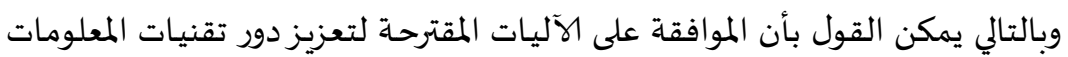

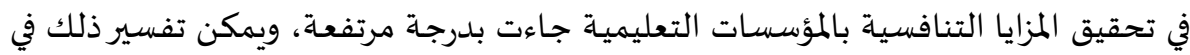

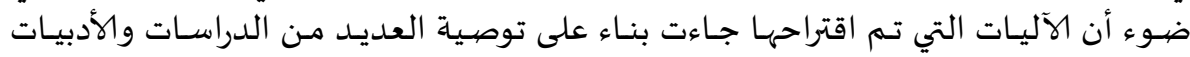

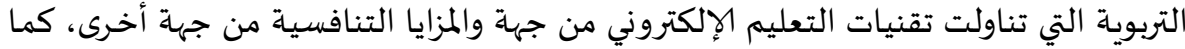

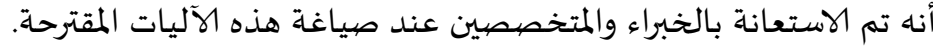

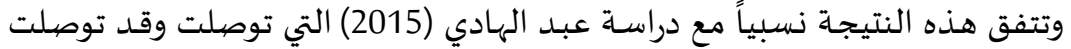

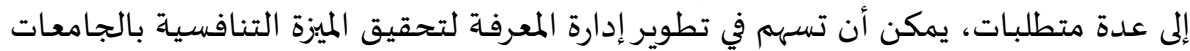

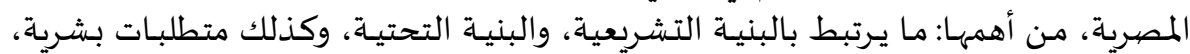
ومتطلبات إدارية تنظيمية، إضافة إلى متطلبات ترتبط بالثقافة المجتمعية.

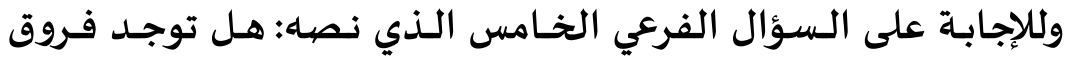
ذات دلالة إحصائية عند مستوى الدلالية

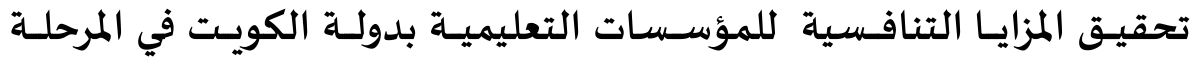

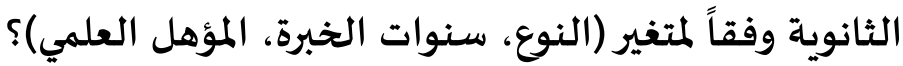

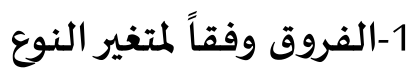

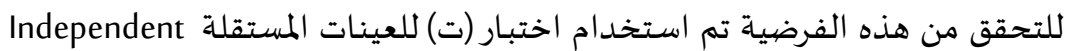
Samples Test

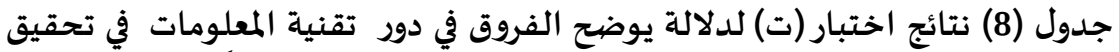

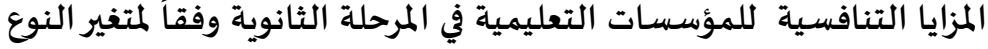

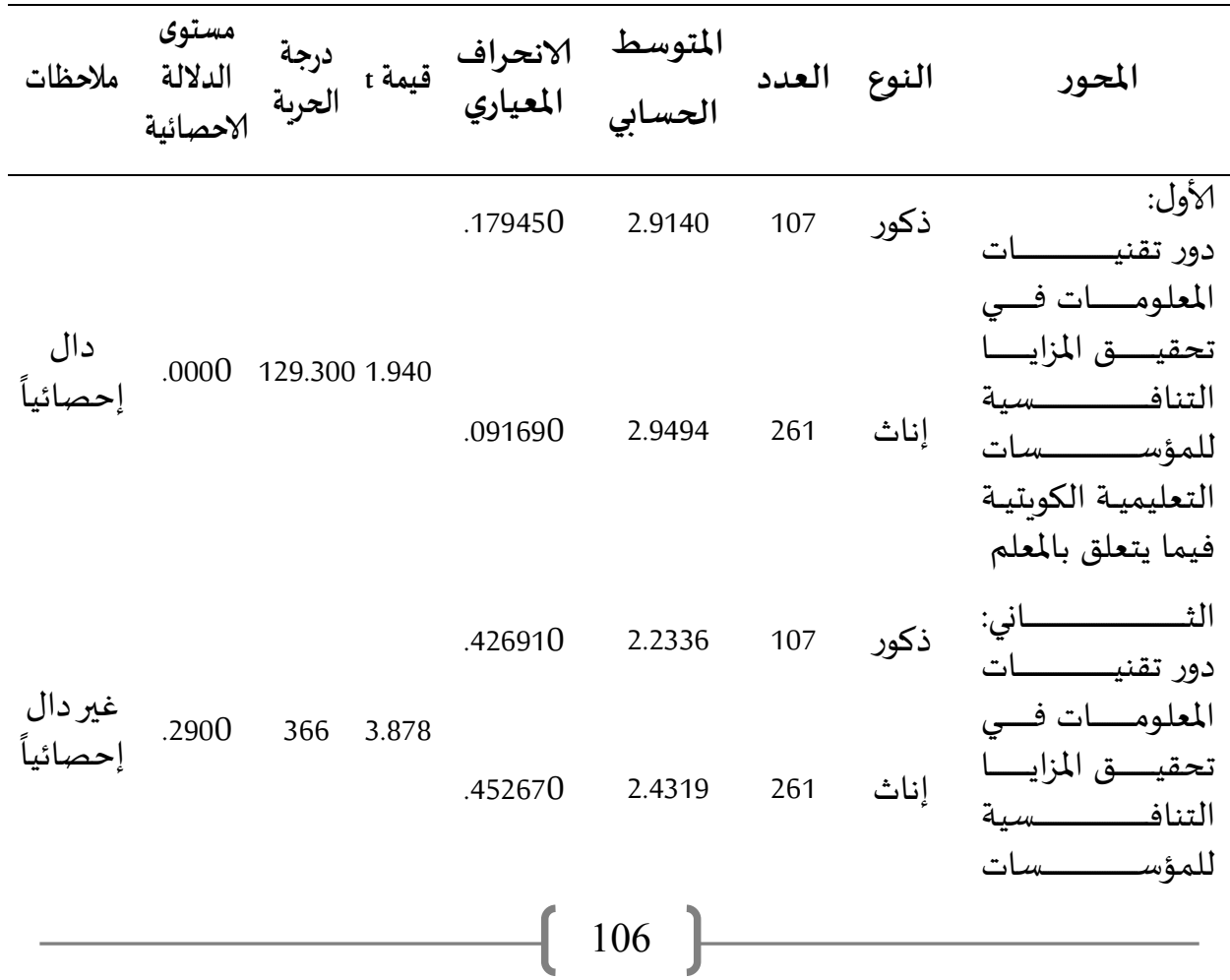




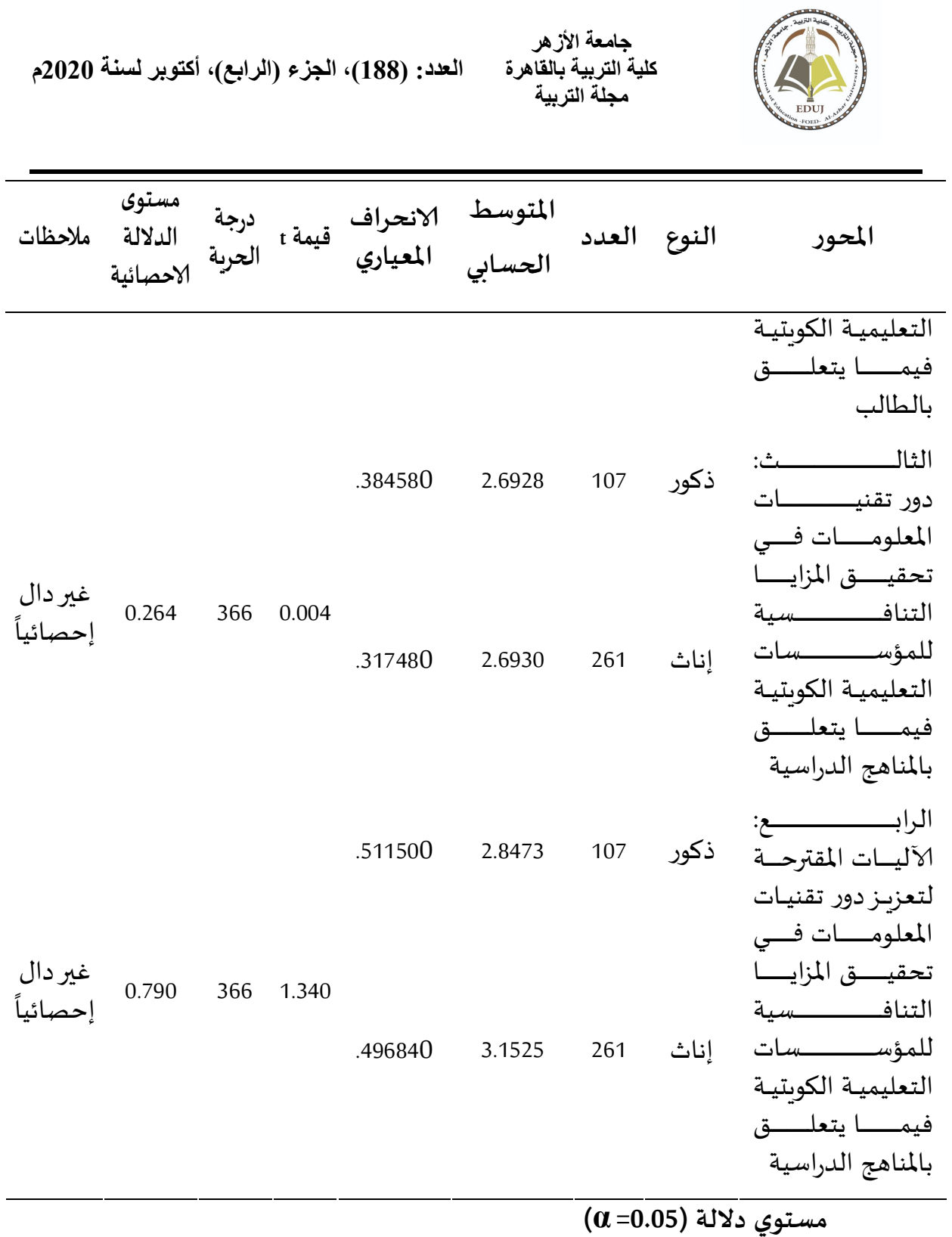

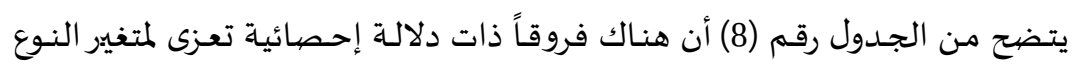

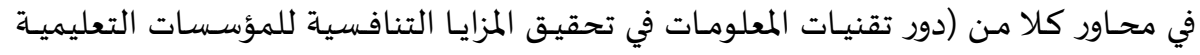

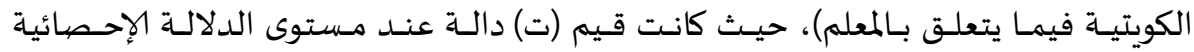

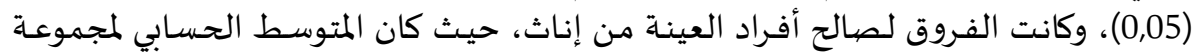

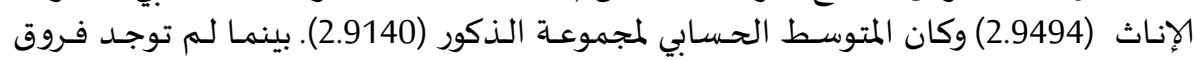

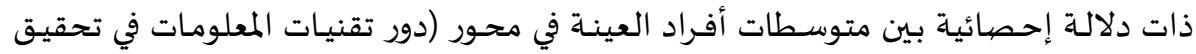

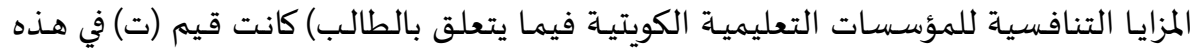

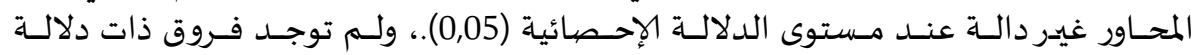


إحصائية بين متوسطات أفراد العينة في محاور في محور (دور تقنيـات المعلومات في تحقيق

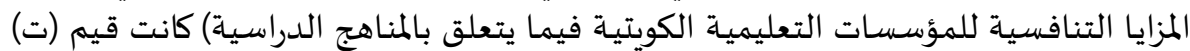

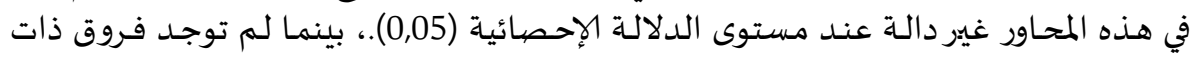

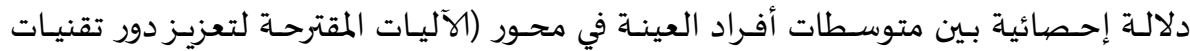

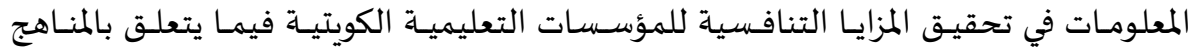

الدراسية) كانت قيم (ت) في هذه المحاور غير دالة عند مستوى الدلالة الإحصيائية (0,05).

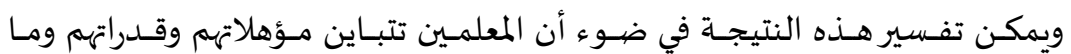

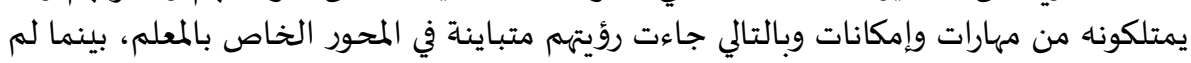
توجد فروق ذات دلالة إحصائية في بقية المحاور.

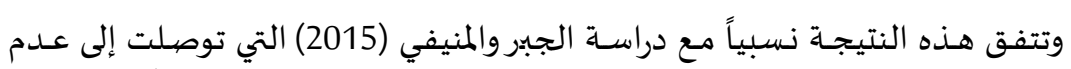

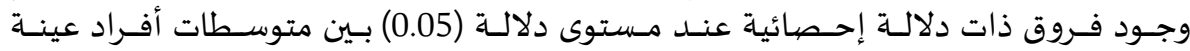

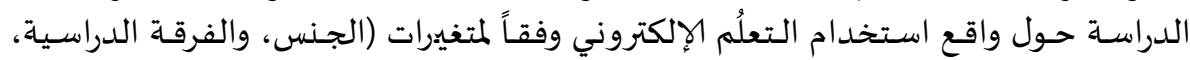

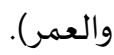

\section{2-الفروق وفقاً لمتغير سنوات الخبرة:}

تم استخدام التحليل التباين الأحادي One - Way Anova يوضح الفروق في آراء

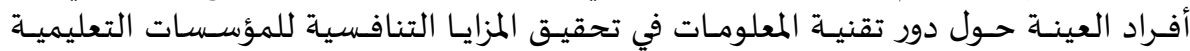

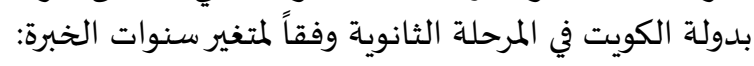

جدول (9) دور تقنية المعلومات في تحقيق المزايا التنافسية للمؤسسات التعليمية وفقاً

لمتغير سنوات الخبرة

\begin{tabular}{|c|c|c|c|c|}
\hline المعياري - المراف & 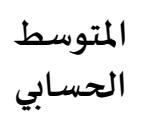 & 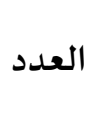 & 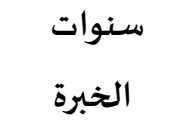 & 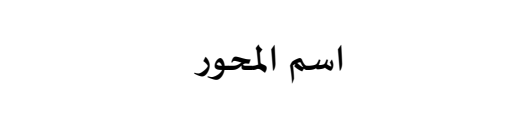 \\
\hline 0.16414 & 2.8862 & 41 & أقل من 5 & \\
\hline 0.17320 & 2.9073 & 64 & 10 - 6سنوات & الأول: \\
\hline 0.10985 & 2.9588 & 110 & 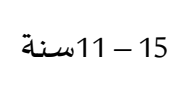 & دالتنافسية للمؤسسات المعلومات التعليمية تحقيق الكوتيةيا \\
\hline 0.09145 & 2.9551 & 95 & 1 & فيما يتعلق بالمعلم \\
\hline 0.08097 & 2.9483 & 58 & 21سنة فأكثر & \\
\hline 0.12456 & 2.9391 & 368 & المجموع & \\
\hline 0.40635 & 2.5154 & 41 & سنوات 5 & 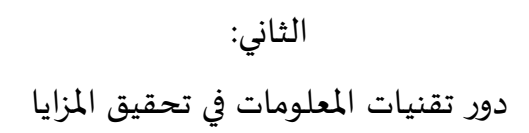 \\
\hline 0.43899 & 2.4042 & 64 & (10-6سنوات & التنافسية للمؤسسات التعليمية الكويتية \\
\hline
\end{tabular}




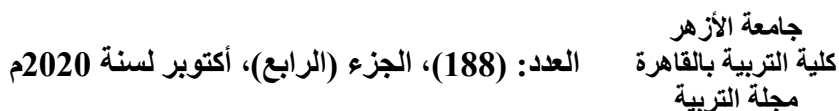

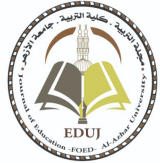

\begin{tabular}{|c|c|c|c|c|}
\hline 0.45622 & 2.3109 & 110 & 15 - 11 11سنة & فيما يتعلق بالطالب \\
\hline 0.45318 & 2.3958 & 95 & 20 - 16 سنـة & \\
\hline 0.48392 & 2.3264 & 58 & 21سنة فأكثر & \\
\hline 0.45380 & 2.3743 & 368 & المجموع & \\
\hline 0.32653 & 2.6602 & 41 & س أقل من 5 & \\
\hline 0.37740 & 2.6656 & 64 & 10 - 6سنوات & 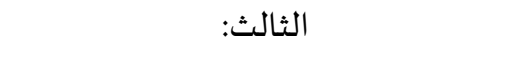 \\
\hline 0.27283 & 2.7661 & 110 & 15 - 11سنة & دور تقنيات المعلومات في تحقيق المزايا \\
\hline 0.34496 & 2.7067 & 95 & 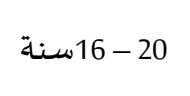 & التنافسية للمؤسسات التعليمية الكويتية \\
\hline 0.37402 & 2.5851 & 58 & 21سنة فأكثر & \\
\hline 0.33782 & 2.6929 & 368 & المجموع & \\
\hline 0.46399 & 2.5268 & 41 & أقل من 5 & \\
\hline 0.46461 & 2.5635 & 64 & 10 - 6سنوات & (t \\
\hline 0.50792 & 2.5327 & 110 & 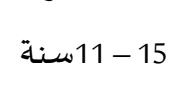 & المعليات المقترحة لتعزيز دور تقنيات \\
\hline 0.51376 & 2.4456 & 95 & 20 - 20 - 16سنة & للمؤسسـات التعليمية الكويتية فيما \\
\hline 0.53572 & 2.4456 & 58 & 21سنة فأكثر & يتعلق بالمناهج الدراسية \\
\hline 0.50167 & 2.5011 & 368 & المجموع & \\
\hline
\end{tabular}


جدول رقم (10) نتائج اختبار (التباين الأحادي- One - Way Anova ) لبيان الفروق في المعادية

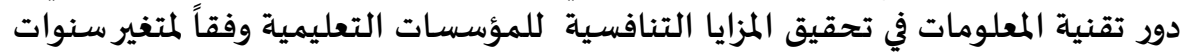
الخبرة

\begin{tabular}{|c|c|c|c|c|c|c|}
\hline الدلالة & فيمه ف & المربعات & دالحرية & المربعات & مصيدر التباين & 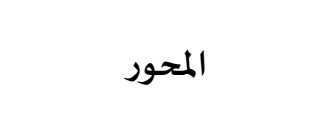 \\
\hline \multirow{4}{*}{ إحصائياً } & \multirow{4}{*}{4.191} & 0.063 & 4 & 0.251 & بين المجموعات & الأول: \\
\hline & & & & & & دور تقنيات المعلومات في \\
\hline & & 0.015 & 363 & 5.443 & خلال المجموعات & تلمقيق المزايا التنافسية التعليمية \\
\hline & & / & 367 & 5.694 & المجموع & الكويتية فيما يتعلق \\
\hline \multirow{3}{*}{ غير دالياً } & \multirow{3}{*}{1.828} & 0.373 & 4 & 1.493 & بين المجموعات & ......... الثاني: \\
\hline & & 0.204 & 363 & 74.086 & خلال المجموعات & دورقيق المزايا التنافسيات المعلومات في \\
\hline & & / & 367 & 75.579 & المجموع & الكويتية فيما يتعلق \\
\hline \multirow{3}{*}{ إحصائياً } & \multirow{3}{*}{3.075} & 0.343 & 4 & 1.373 & بين المجموعات & الثالث: \\
\hline & & 0.112 & 363 & 40.511 & خلال المجموعات & تحوق تقنيقات المزايا التنافسمية فية \\
\hline & & / & 367 & 41.884 & المجموع & بالمويتية فيما يتعلق الدراسية \\
\hline \multirow{3}{*}{ غير داليًاً } & \multirow{3}{*}{0.856} & 0.216 & 4 & 0.863 & بين المجموعات & آآليات المقترحة لتعزبز \\
\hline & & 0.252 & 363 & 91.501 & خلال المجموعات & تدور تقنيقات المعلومات في التنافسية \\
\hline & & / & 367 & 92.364 & المجموع & للمؤسسية الكويتية فيما يتعليقية \\
\hline
\end{tabular}

\section{مستوى دلالة (a=0.05)}

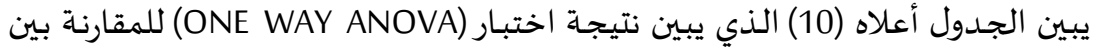

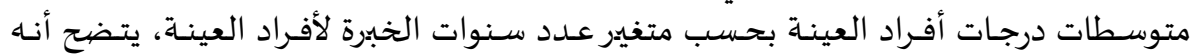

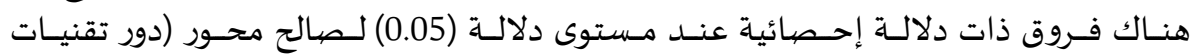

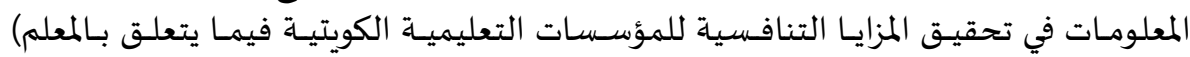




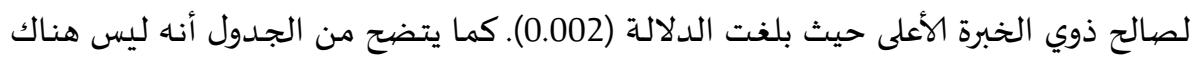

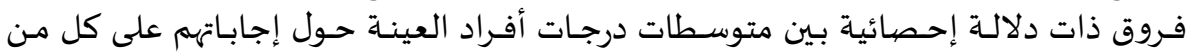

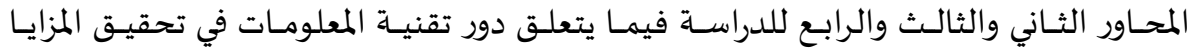

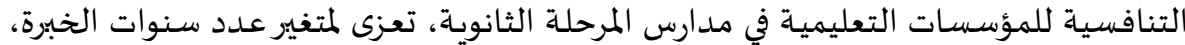

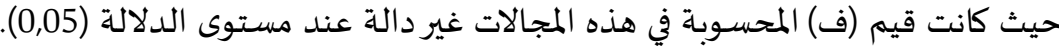
ويمكن تفسير هذه النتيجة في ضيوء أن عامل الخبرة كان له تأثير مباشر فيما يتعلق

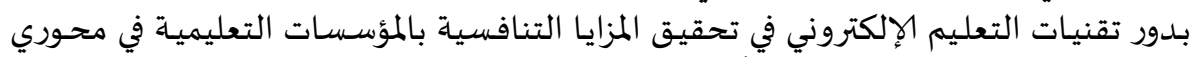

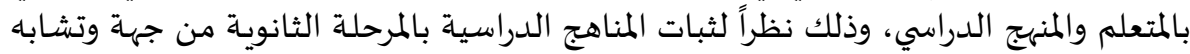

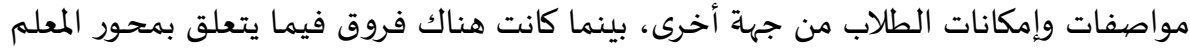

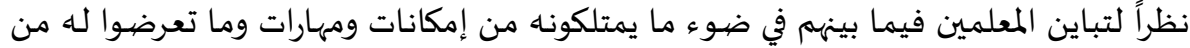
برامج تأهيل وإعداد مسبق.

\section{3-الفروق وفقاً لمتغير المؤهل العلمي:}

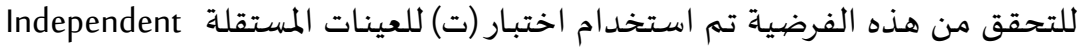
Samples Test جدول (11) بينت النتائج أعلاه في الجدول رقم (11) عدم وجود فروق ذات دلالة إحصيائية عند مستوى دلالة (0.05) وفقا للمؤهل العلمي.

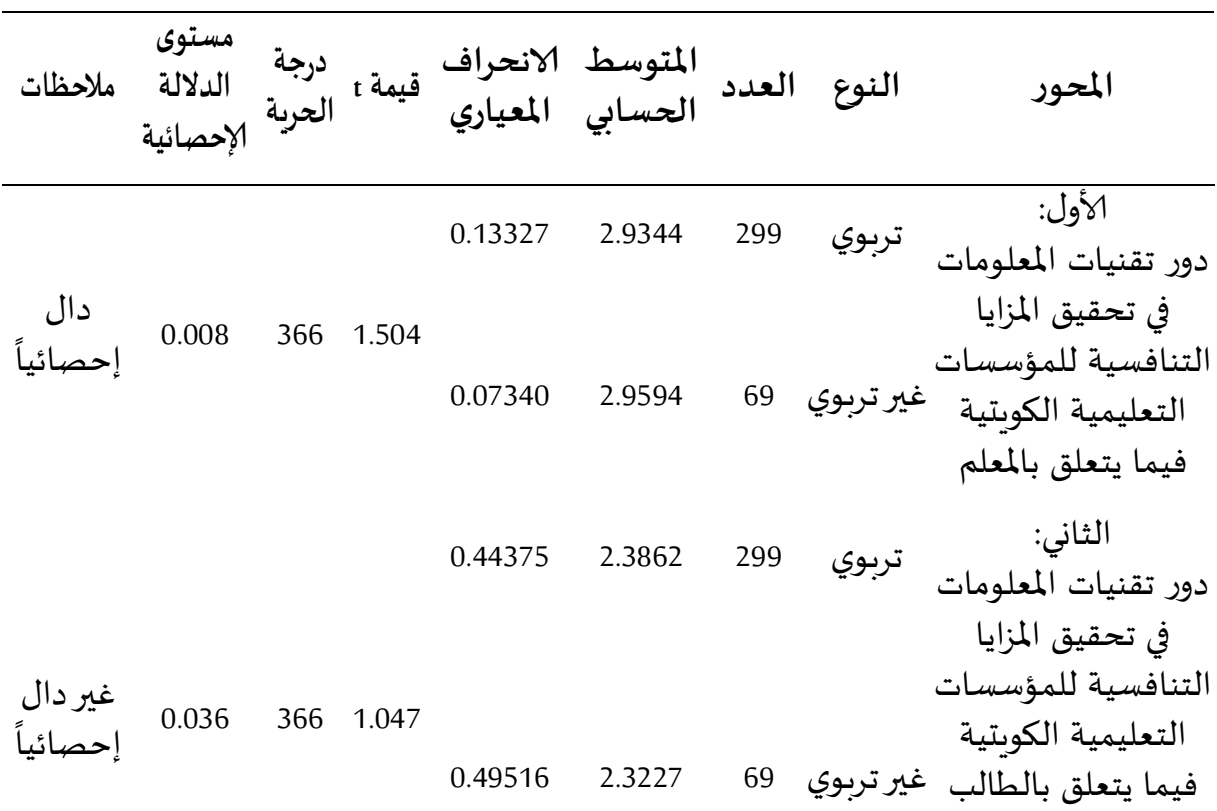




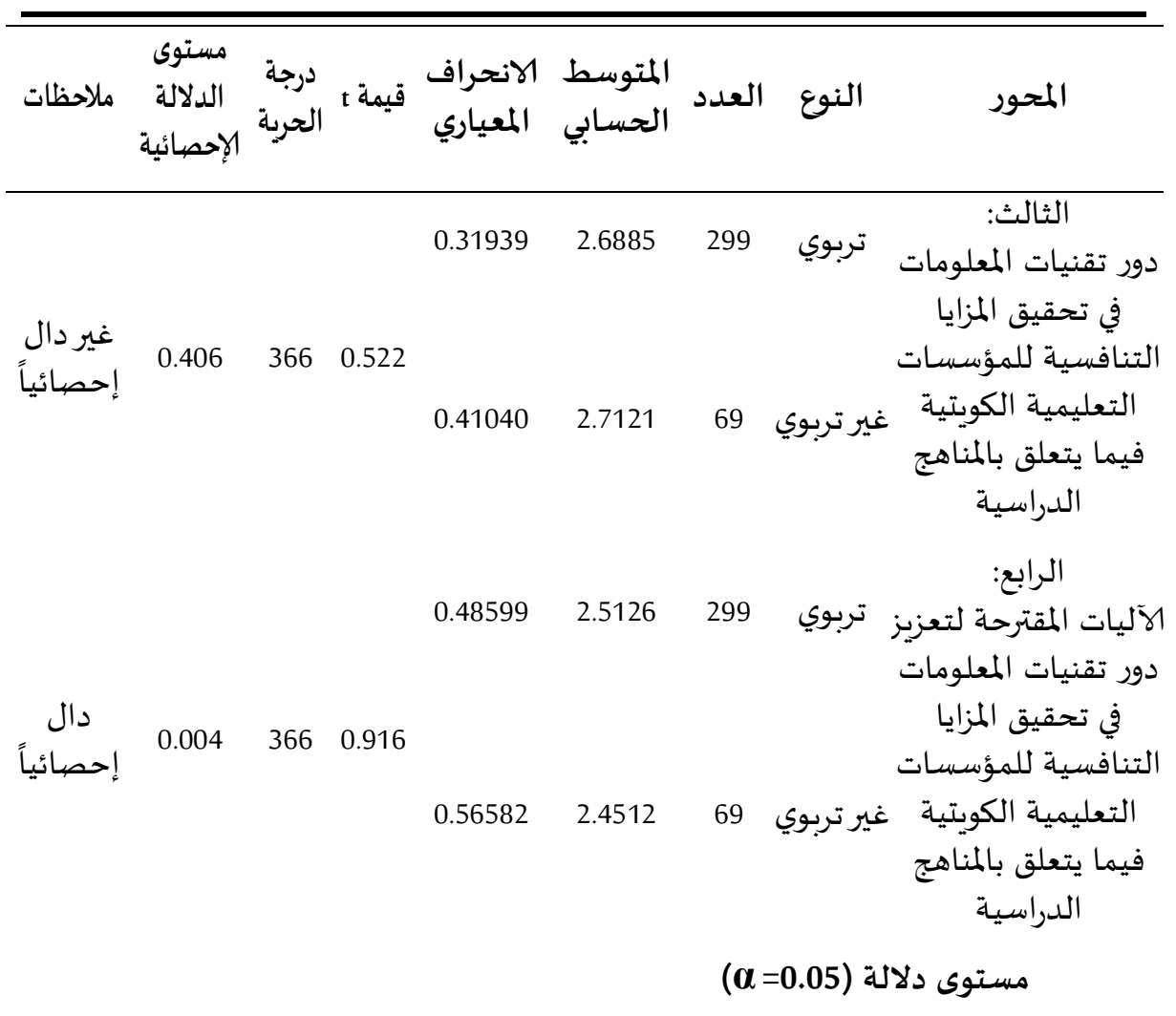

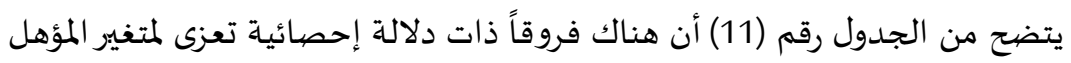

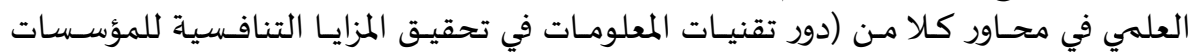

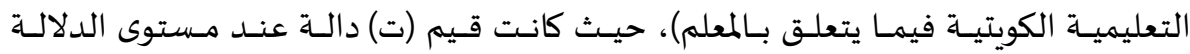

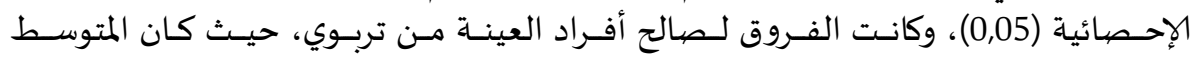

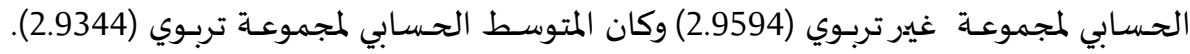

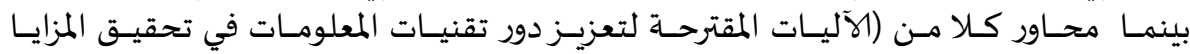

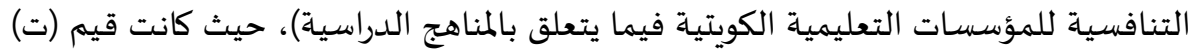

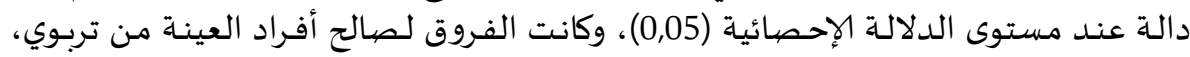

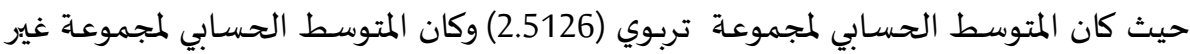

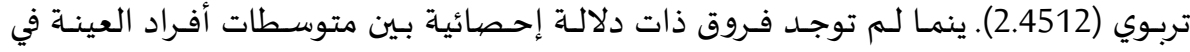

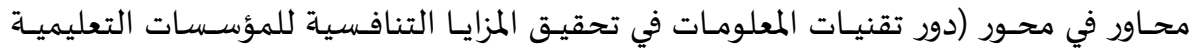

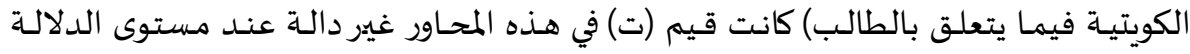

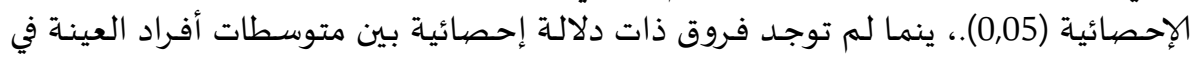

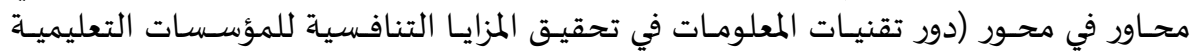

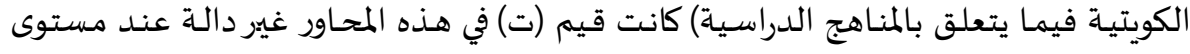

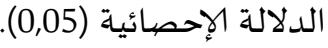

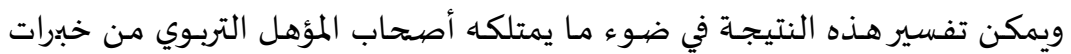

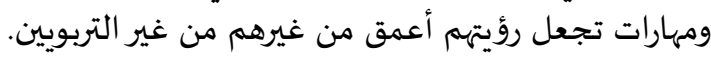




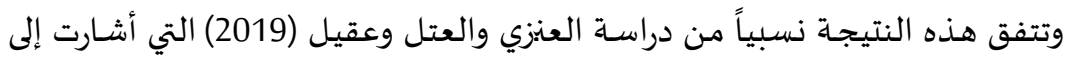

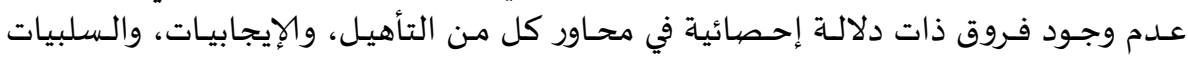

تعزي لمتغيري المؤهل الدراسي والتدريب.

$$
\text { توصيات الدراسـة: }
$$

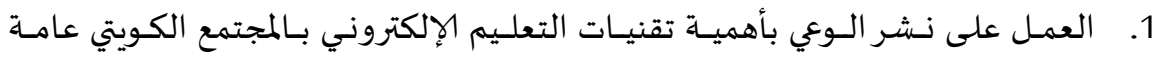

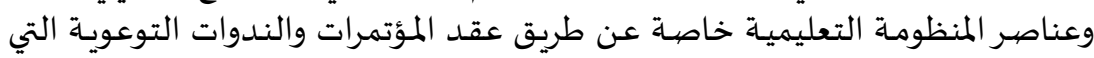

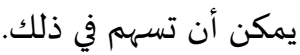

2. تشكيل لجـان متخصصية لبحث متطلبـات توظيف تقنيات التعليم وإجراءات تفعيلها بالمؤسسات التعليمية.

3. تدريب عناصر المنظومة التعليمية بصيورة مستمرة على كيفية توظيف تقنيات التعليم الإلكترونية بالمؤسسات التعليمية.

4. العمل على تقديم الدعم المادي والمعنوي المتطلب لعناصير المنظومة التعليمية المتميزين

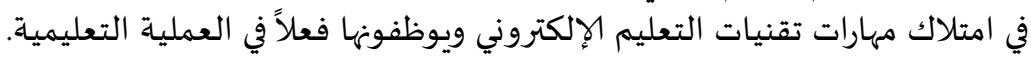

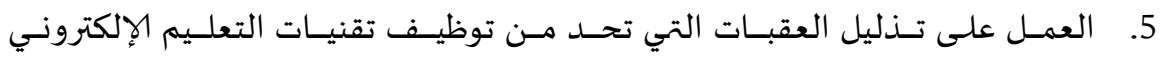
بالمؤسسات التعليمية الكويتية عن طريق تشكيل لجان متخصصية تتولى القيام بذلك.

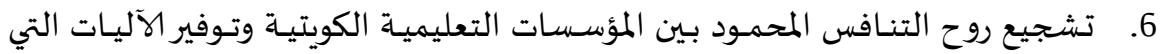
تمكنها من ذلك وبالاستفادة من بعض الخبرد التبرات الخارجية فيما يتعلق بالمزايا التنافسية.

مقترحات الدراسـة: - مقات

1. معوقات استخدام تقنيات التعليم في التعليم الثانوي بالكويت من وجهة نظر المعلمين

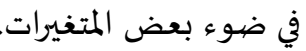

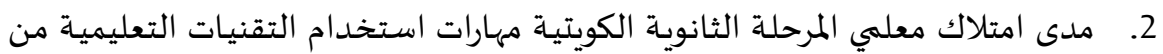
وجهة نظر طلابهم في ضوء بعض المرحلة المتانوبيرات.

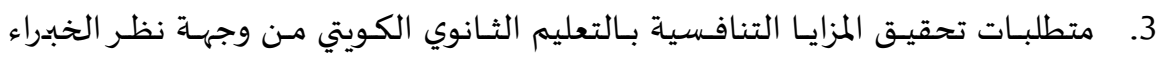
وإجراءات تفعيلها "دراسة ميدانية" المزابات

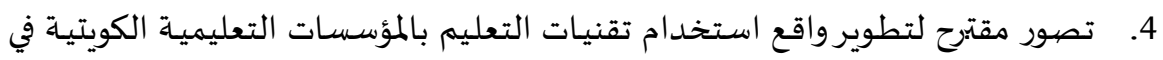

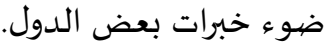
5. مسستوى تـوافر مقومــات المزايـا التنافسية بالمؤسـسـات التعليميـة الكويتيـة والـسبل

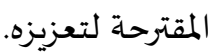


إبراهيم، مجـدي عزيـز. (2006). المنهـج التربوي وتحـديات العصرِ. القـاهرة: عـالم الكتب للنشر والتوزيع والطباعة.

أبـو بكر، مصطفى محمـود. (2006). المـوارد البشرية مـدخل لتحقيق الميززة التنافسية، الــار

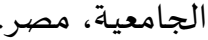

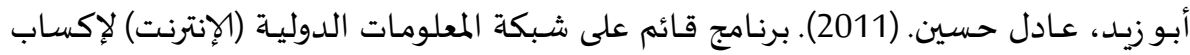

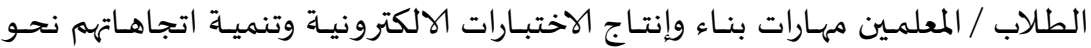
الإنترنت. دراسات في المناهج وطرق التدريس -مصر، ع ع 175، ص ص ص 93 - 138.

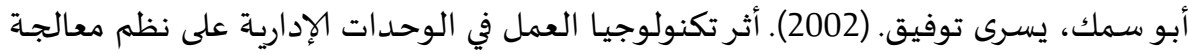

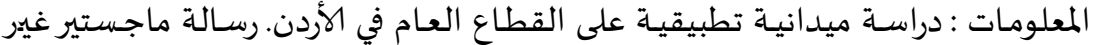

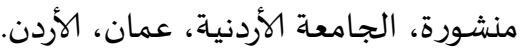

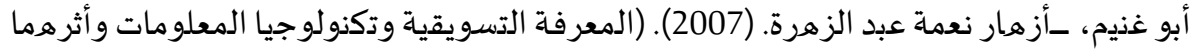

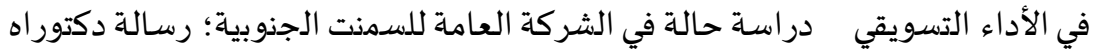
مقدمة الى الجامعة المستذصرية-كلية الإدارة والإقتصاد.

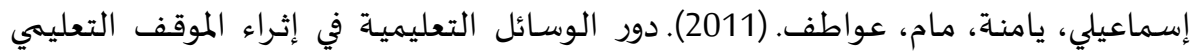

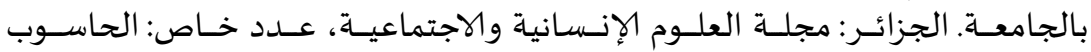

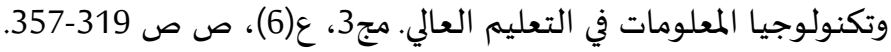

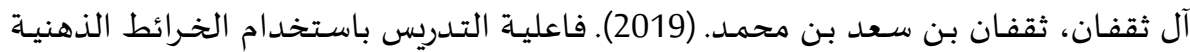

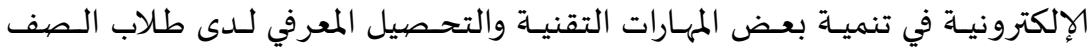

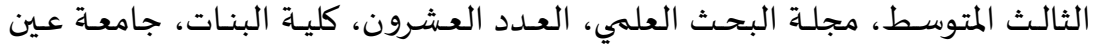
شمس.

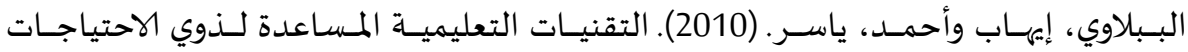
الخاصة، ط1. الرياض: دار الزهراء للنشر والتوزيع.

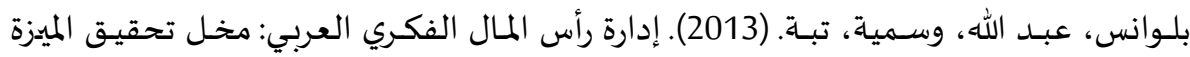

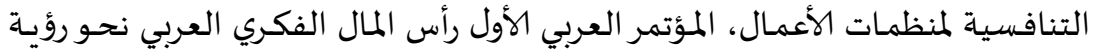

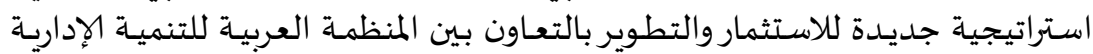

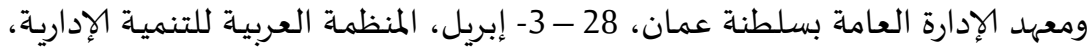

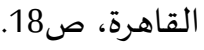

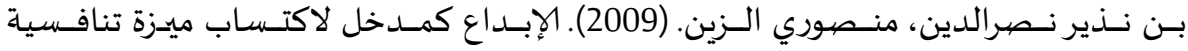

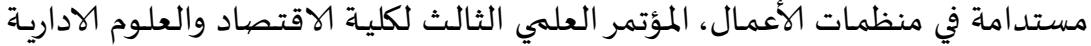
جامعة العلوم التطبيقية الخاصية.

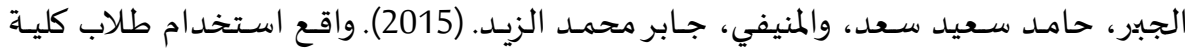

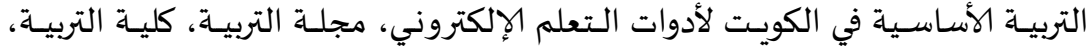
جامعة الأزهر، العدد 166، الجزء الثاني لأدوات التعلي ديسمبر. 


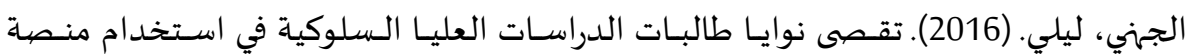

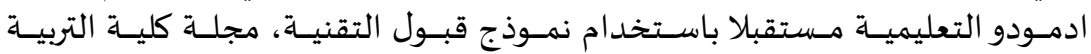

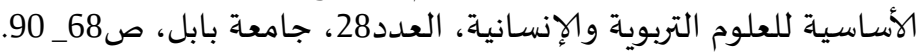

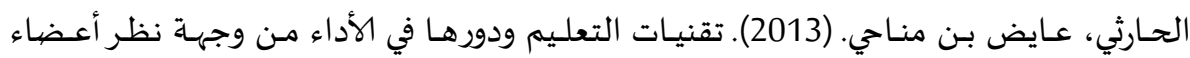

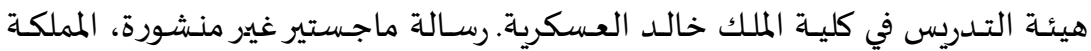
العربية السعودية: جامعة نايف العربية للعلوم الأمنية. الحيلة، محمدد محمود. (2001). التكنولوجيا التعليميـة والمعلوماتيـة. الإمارات العبيـة المتحـدة: دار الكتاب الجامعي.

الحيلة، محمد.(2000). تكنولوجيا التعليم بين النظرية والتطبيق، ط 2، دار المسيرة للنشر، عمان. الحيلة، محممد محمـود. (2008). تكنولوجيا التعليم بين النظريـة والتطبيق. عمـان: دار المسيرة للطباعة والنشر.

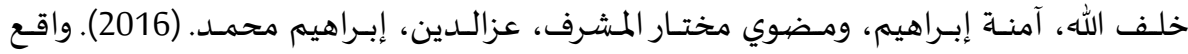

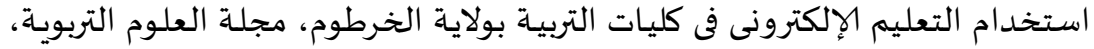

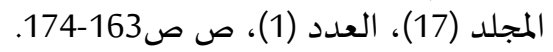

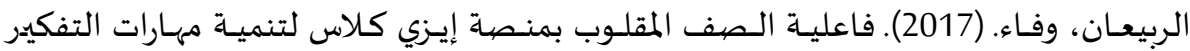

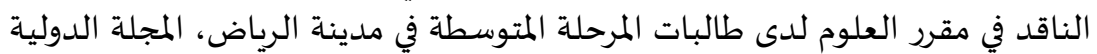

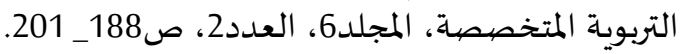

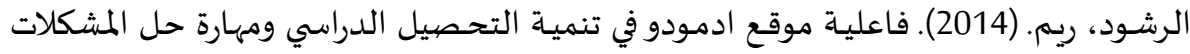

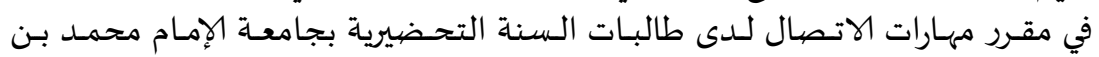

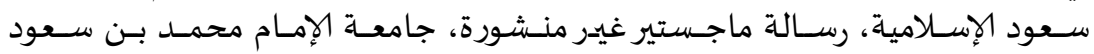
الإسلامية، المملكة العربية السعودية. الزعبي، حسن علي. (2005). "نظم المعلومات الإستراتيجية -مدخل إستراتيجي" ،داروائل للنشر المعرد

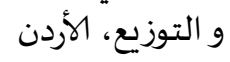

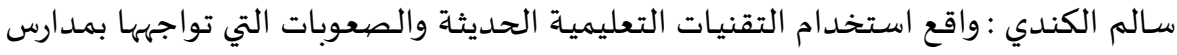

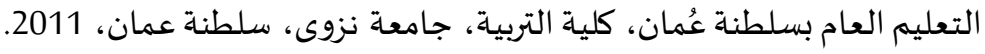

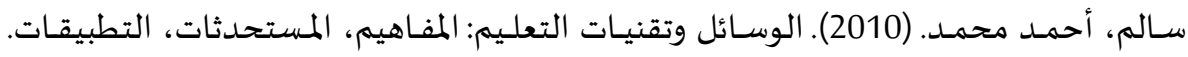

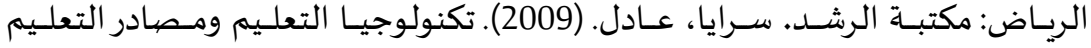
الإلكتروني، مفاهيم نظرية وتطبيقات عملية. الرياض: مكتبة الرشدائ.

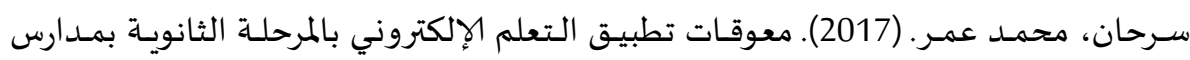
مدينة الرياض، مجلة التربية، كلية التربية، جامعة الأزهر، العدد العرد 174 يوليو.

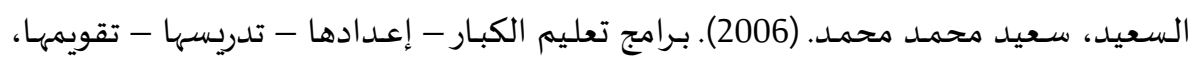

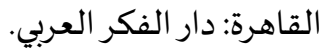


السلطي، مؤنس. (2002). التعلم الإلكتروني على الإنترنت، مجلة العلوم والتقنية، مدينة الملك

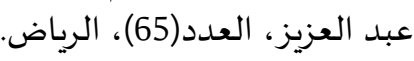

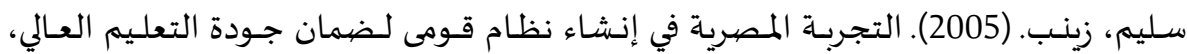

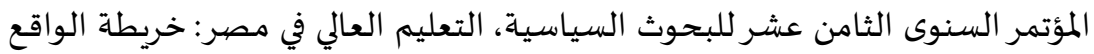

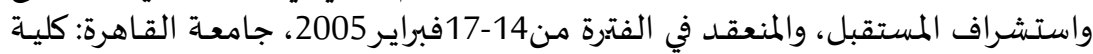

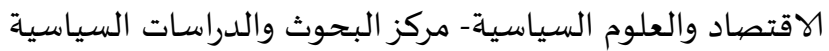

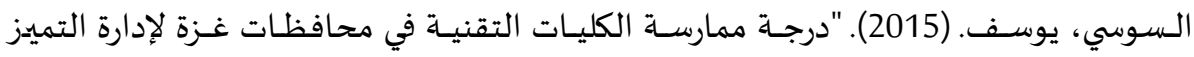
وعلاقتها بالميزة التنافسية". رسالة ماجستير. الجامعة الإسلامية. غزة.

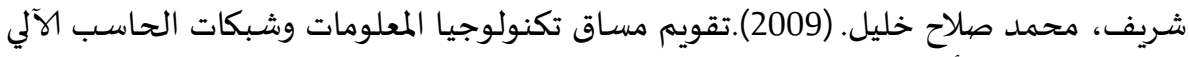

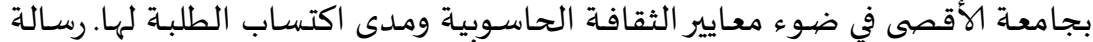
ماجستير. كلية التربية. الجامعة الإسلامية بغزة.

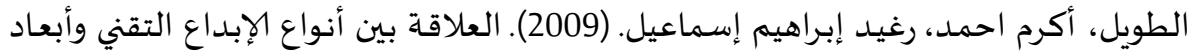

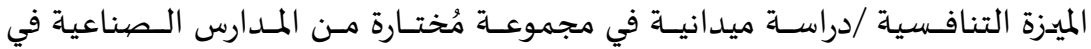

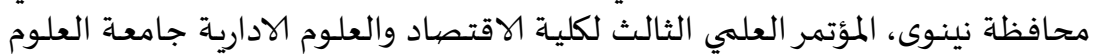

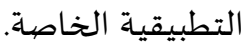

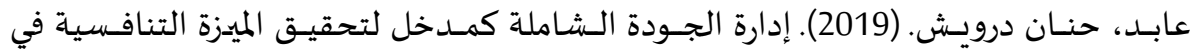

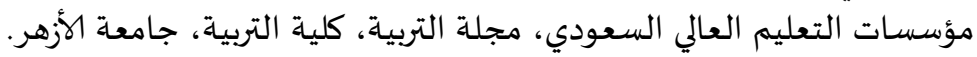

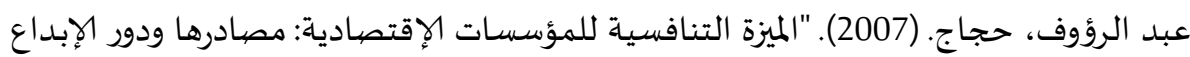

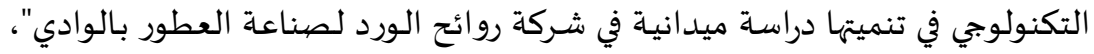

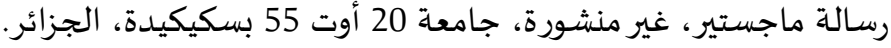

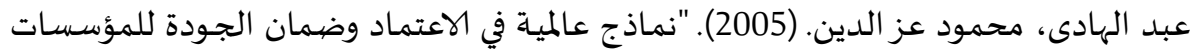

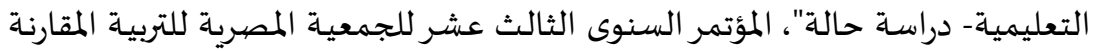

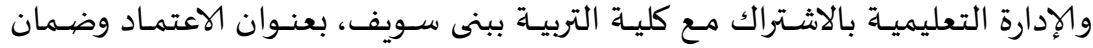

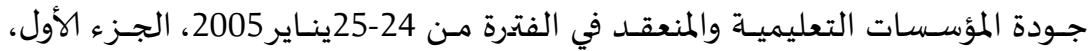

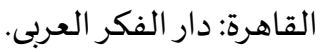

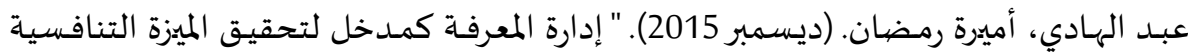

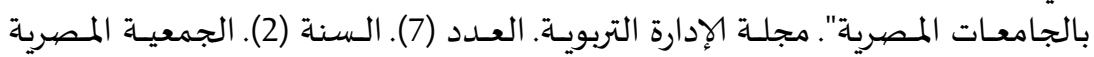
للتربية المقارنة والإدارة التعليمية.

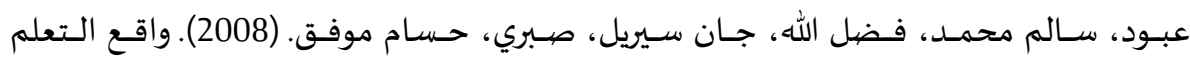

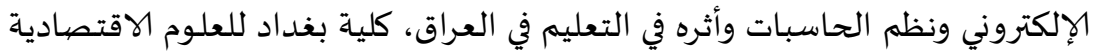

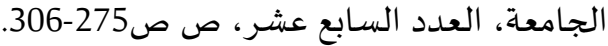

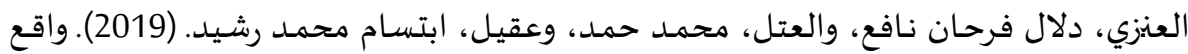

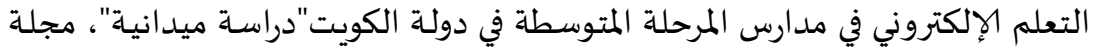
البحث العلمي، العدد العشرون، كلية البنات، جامعة عين شمس. 


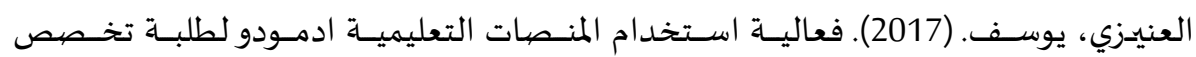

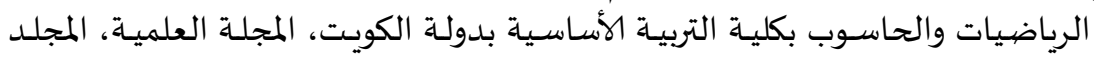

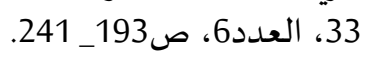

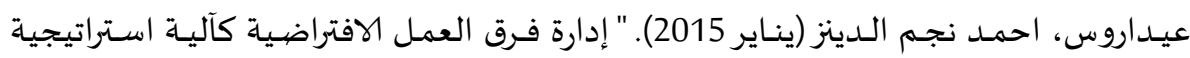

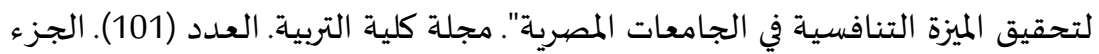
(1). كلية التربية. جامعة بنها.

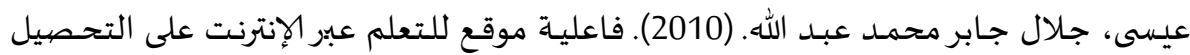

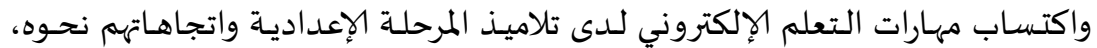

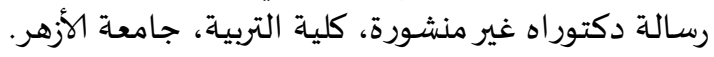

فرحان، طارق حسين. (2012). صعوبات توظيف التعلم الإلكتروني في الجامعات الفلسطينية

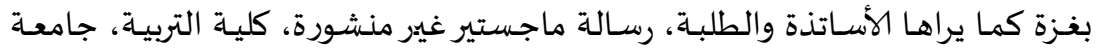

$$
\text { الأزهر - غزة. }
$$

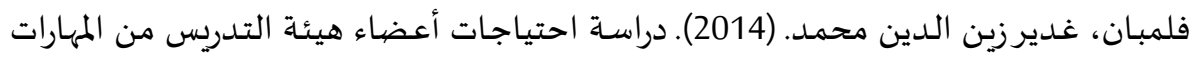

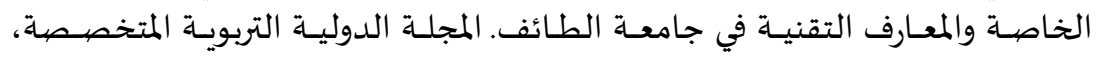

$$
\text { المجلد (3)، العدد (41)، ص صارف المقيبة في جامعة-36. }
$$

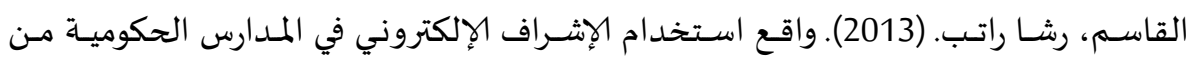

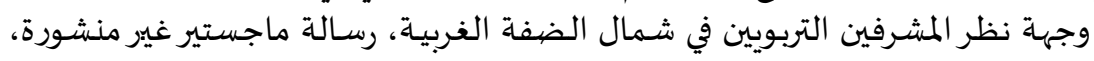
كلية الدراسات العليا، جامعة النجاح الوطنية بنابلس- فلسينين.

قرني، أسامة محمود والعتيقي، إبراهيم مرعي إبراهيم. (نوفمبر2012). " إدارة رأس المال الفكري

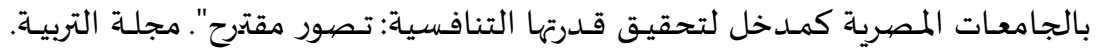

$$
\text { العدد (38). السنة (15). (15). }
$$

قلجـة، مي. (2015). فاعليـة اسـتخدام المنـصـات التعليميـة ادمـودو على تحسين الأداء الكتـابي

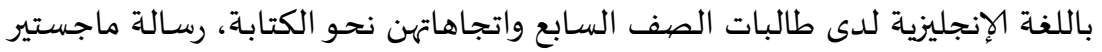
غير منشورة، الجامعة الإسلامياة، غزة.

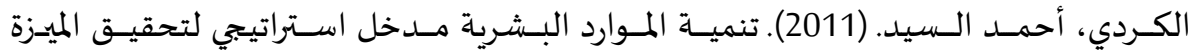
التنافسية في منظمات الاعمال ،جامعة بنها، كلية التجارة.

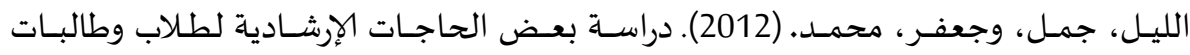

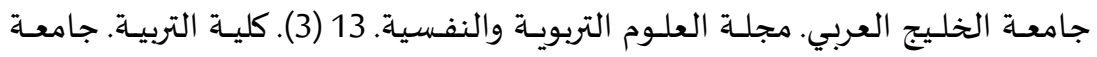
البحرين. ص ص 135 - 164.

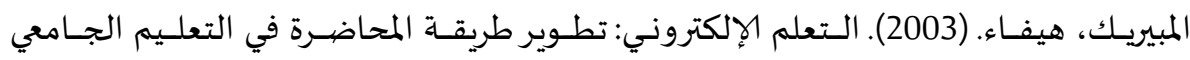

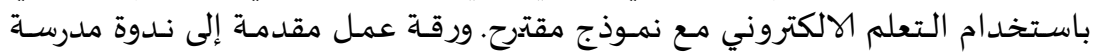

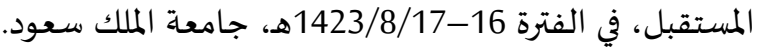




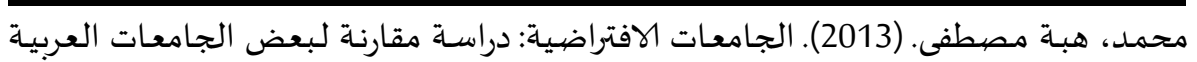

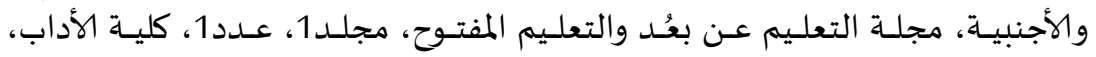
جامعة بني سويف. مجلة التعل

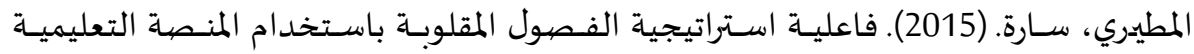

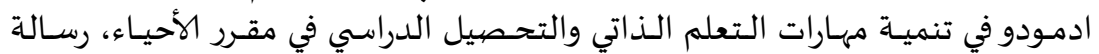

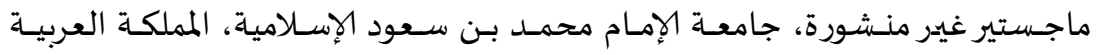

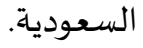

المـؤتمر الــدولي الثـاني للتعلـيم الإلكتروني والتعلـيم عـن بعـد، 18-21 ربيـع الأول (1432هـ). الرياض، المملكة العربية السعودية.

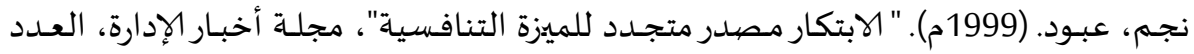

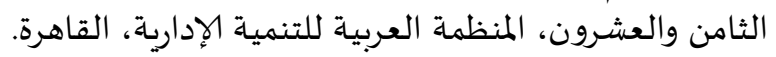

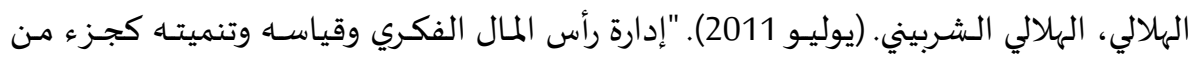

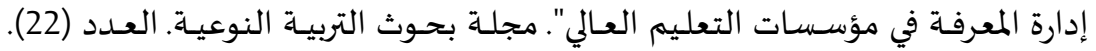

جامعة المنصورة.

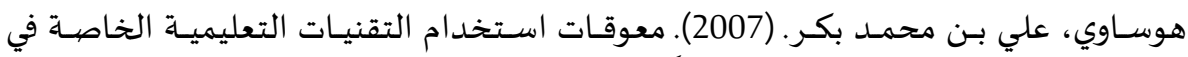

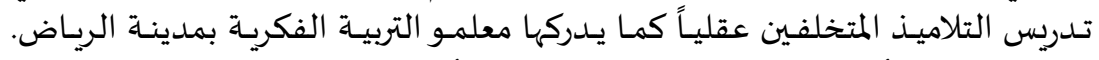

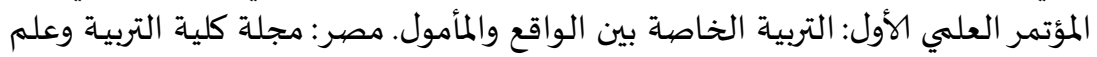

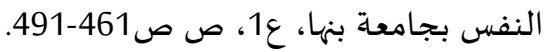

الوادي، محمـود حسين والزعبي، على فلاح. (2011). "مستلزمات إدارة صلمارة الجـودة الشاملة كأداة

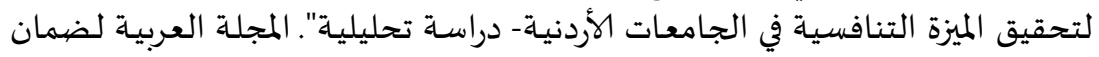

جودة التعليم الجامعي. العدد (8). المأردن.

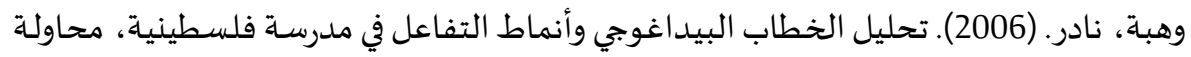

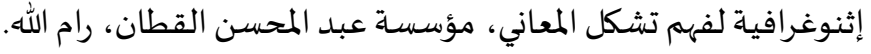

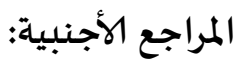

Al-Jaradat et al,(2012),’'Intellectual Capital and its Role in Achieving Competitive Advantage: A Field Study for the Jordanian Income Tax Service", European Journal of Scientific Research, Vol., 69, No., 3, p:.400.

Anstadt, P., Bradley, S., Burnette, A., Medley, L. (2013): Virtual Worlds: Relationship Between Real Life and Experience in Second Life. International Review of Research In Open \& Distance Learning, VOL. (14), NO. (4) ‘pp 26-54.

Arora, A. (2015). Using e-learning technologies to improve educational quality of language teaching. Retrieved 19.12.2017 from website: https://elearningindustry.com/usinge-learning-technologies-improve-educational-qualitylanguage-teaching 
Basilaia, G., \&Kvavadze, D. (2020). Transition to Online Education in Schools during a SARS-CoV-2 Coronavirus (COVID-19) Pandemic in Georgia. Pedagogical Research, 5(4), em0060. https: //doi.org/10.29333/pr/7937 Retrieved, 20/1/2021.

Batsila, M., Tsihouridis, C., \& Vavougios, D. (2014). Entering the Web-2 Edmodo World to Support Learning: Tracing Teachers> Opinion After Using it in their Classes. International Journal Of Emerging Technologies In Learning, 9(1), 53-60. doi:10.3991/ijet.v9i1.3018.

Behera,S.,K. (2013). E-And M-Learning: A Comparative Study, International Journal on New Trends in Education and Their Implications, Vol.4, Issue.3, pp 65-78.

Bisaria, G., (2013): "Achieving Competitive Advantage by Private Management Colleges or Private Universities", International Journal of Social Science and Interdisciplinary Research, Vol. (2), No.(3).

Breznik, L. (2012). Can information technology be a source of competitive advantage?. Economic \& Business Review, 14(3).

Bruque-Cámara, S., Fuentes, J. M., Hernández-Ortiz, M. J., \& VargasSánchez, A. (2003). Information Technology and Competitive Advantage: The Role of the Ownership Structure.

Burden, K., Hopkins, P.(2016): Barriers and Challenges Facing PreService Teachers use of Mobile Technologies for Teaching and Learning. International Journal of Mobile and Blended Learning (IJMBL), Vol (8), Issue (2), pp 1-17.

DanLi, Manuel Portugal Ferreira, Fernando Serra ‘Technology Transfer within MNEs: An Investigation of Inter-Subsidiary Competition and Cooperation * http://dx.doi.org/10.2139/ssrn.1426024

Dinder, D. (2008). Exploring and Undertading The Benefits of Tutoring Software on Urban Students Science Adheivement Paper Presented at the Regional Educational. Research Association Conference, Hilton Head Islanel. Usa.

Flores, S. A. (2012). Online counseling and online counselor preparation: A mixed methods investigation. (Order No. 3523240, Texas A\&M University - Corpus Christi). ProQuest Dissertations and Theses,6 122. Retrieved from http: //search.proquest.com/docview/1069266681?accountid=43793 . (1069266681).

Gould, Marie, (2008), "Sustainable Competitive Advantage", Research Starters Business, www.searchebscochost.com. 
Hodges, C., Moore, S. Lockee, B., Trust, T., Bond, A. (2020). The Difference Between Emergency Remote Teaching and Online Learning

http: //www.meammarketing.com/advantages-and-disadvantages -ofelectronic-communication/

Huang, Hsun (Tony), Binney, Wayne and Hede, Anne-Marie (2010). "Strategic marketing of educational institutions." In ANZMAC 2010 : Doing more with less: Proceedings of the 2010 Australian and New Zealand Marketing Academy Conference, ANZMAC, Christchurch, New Zealand

Krauss, J. (2012): Infographics: More than Words Can Say. Learning \& Leading With Technology, vol. (39), No. (5), pp 10-14.

Low, Swee Foon and Praveen, Balakrishnan Nair, (2010), "Revisiting the Concept of Sustainable Competitive Advantage: Perceptions of Managers in Malaysian MNCs", International Journal of Business and Accountancy, Vol. 1, No. 1, Pp 63-78.

Luppicini, R. (2005). A Systems Definition of Educational Technology in Society. Educational Technology \& Society, Vol. (8), No.(3), pp 103-109.

O'Brien James, (2004), Management Information Systems : Managing Information Technology in the Business Enterprise, 6th ed. McGraw-Hill.

Palladan, A. A., \& Kadir, K. A. (2016). Information Technology Capability for Nigerian Public Tertiary Institutions: A Tool for Gaining Competitive Advantage. Sains Humanika, 8(4-2).

SáEZ LóPEZ, J. M., DOMíNGUEZ GARRIDO, C., RUIZ RUIZ, J. M., \& BELANDO MONTORO, M. (2014). ANáLISIS DEL USO DE LOS SISTEMAS DE GESTIóN DE APRENDIZAJE EN EL DESARROLLO PROFESIONAL DOCENTE DESDE UNA PERSPECTIVA PRáCTICA EN LA ESCUELA COMPLUTENSE. (Spanish). Bordón, 66(3), 133. doi:10.13042/Bordon.2014.66309

Sigalas, C.,\& Economou, V., P.,\& Georgopoulos, N., B., (2013)."Developing a Measure of Competitive Advantage" Journal of Strategy and Management. Vol.(84). No.(4)

Srivastava, M., \& Franklin, A.,\& Martinette, L., (2013). "Building a Sustainable Competitive Advantage". J. Technol. Manag. Innov. ،Vol., (8), Issue (2).

Turban, E.,et al, "Information Technology for management, Making connections for strategic Advantage,2nd ed,John Wiley,\&sons,NewYork, 1999.

Webster's dictionary: Knowledge Economy, Retrieved, (2016). Available at: http// www.websters-online-dictionarv.org.access date: $20 / 1 / 2021$ 